Portland State University

PDXScholar

1980

\title{
A Generalist approach to social work practice : model and synthesis
}

Chuck H. Johnson

Portland State University

Paul S. Knight

Portland State University

Michael W. Krumper

Portland State University

John H. Rademaker

Portland State University

Follow this and additional works at: https://pdxscholar.library.pdx.edu/open_access_etds

Part of the Social Work Commons

Let us know how access to this document benefits you.

\section{Recommended Citation}

Johnson, Chuck H.; Knight, Paul S.; Krumper, Michael W.; and Rademaker, John H., "A Generalist approach to social work practice : model and synthesis" (1980). Dissertations and Theses. Paper 3578.

https://doi.org/10.15760/etd.5462

This Thesis is brought to you for free and open access. It has been accepted for inclusion in Dissertations and Theses by an authorized administrator of PDXScholar. Please contact us if we can make this document more accessible: pdxscholar@pdx.edu. 


\title{
A GENERALIST APPROACH TO SOCIAL WORK PRACTICE: \\ MODEL AND SYNTHESIS
}

\author{
by \\ CHUCK H. JOHNSON \\ PAUL S. KNIGHT \\ MICHAEL W. KRUMPER \\ JOHN H. RADEMAKER
}

A group practicum submitted in partial fulfillment of the requirements for the degree of

MASTER OF SOCIAL WORK

Portland State University 


\section{ACKNOWLEDGMENTS}

The completion of this group practicum project has taken a long time and has been difficult for us. We wish to thank everyone who has helped us. In particular, we wish to thank our wives for their support. Most of all, we wish to acknowledge the invaluable contribution from our research advisor, Lynn Thompson, and thank him for his patience, support and expertise. 
TABLE OF CONTENTS

PAGE

ACKNOWLEDGEMENTS ............................. $i$

LIST OF FIGURES .................... . . . .

CHAPTER

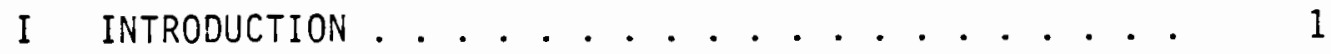

I A HISTORICAL REVIEW OF SOCIAL WORK IN THE UNITED STATES .................. 3

Introduction: Social Work Practice Dilemmas . . 3

The Emergence of the Field of Social Work . . . 7

Progressive Era ............ . 12

Striving for Professional Identity..... . 15

The Emergence of Social Work as a Profession. . 19

Social Work Practice Approaches .. . . . . 22

Fragmentation of the Social Work Profession . . 25

Challenge of the 1960's . . . . . . . 27

II THE GENERALIST APPROACH: REVIEW OF THE LITERATURE . 29 Introduction . . . . . . . . . . . 29

Allen Pincus and Anne Minahan ....... 35

Robert Klenk and Robert Ryan ......... 48

Ruth Middleman and Gale Goldberg ....... . 54

Carol Meyer .............. . . 63

Carel Germaine and Alex Gitterman ..... . 65 
CHAPTER

Joel Fischer............. . . . 67

Conclusion .............. . . . 79

IV PRESENTATION OF THE MODEL . . . . . . . . . . 83

Part One: Models and Model Building

in Social Work.......... . 83

Part Two: Overview of the Model ....... 100

Part Three: Constructs of the Model . . . . 112

$\checkmark$ RESEARCH APPLICATIONS OF THE MODEL ........ 151

The Research Problem . . . . . . . . . 151

Research Hypotheses, Questions, and
Variables ............... 153

Population and Sampling ......... 155

The Research Instrument . . . . . . . . 156

Questionnaire Design.......... 157

Data Analysis ............. 161

VI CONCLUSION .......................... 162

BIBLIOGRAPHY .................... . . . . 165

APPENDICES . . . . . . . . . . . . . . . . . 173 


\section{LIST OF FIGURES}

FIGURE

PAGE

1. The Nature of Problems of Living . . . . . . . . 49

2. A Frame of Reference for Social Work

Practice...................

3. Roles as Related to the Level of

Intervention . . . . . . . . . . . . 78

4. Graphic Representation of the Model . . . . . . 108 


\section{INTRODUCTION}

The strength of the profession of social work 1 ies in its dual focus on people and their environments, on people and their life situations; effective social work practice requires application of knowledge from a variety of behavioral and social science disciplines. In our opinion, the generalist approach exemplifies this strength: it is eclectic, holistic, and snythesizes diverse theoretical approaches in order to meet the "total needs" of clients.

The authors of this research project have all had experience working in various social service settings. Some of these settings limited the effectiveness of staff in meeting the needs of their clientele -- many of the services offered (or sometimes mandated) were inappropriate, inadequate, coercive and stigmatized. Through graduate training we learned that the social work profession has historically been plagued with practice dilemmas similar to those we experienced in our work places.

We believe that the generalist approach to social work transcents, to a large degree, these dilemmas by offering a more integrated, systematic, and holistic approach to social work practice.

The purpose of this research practicum is twofold. First, to present a synthesis of current generalist literature and to formulate a practice model which is both comprehensive and representative of current generalist practice in direct services. To our knowledge there 
is no single reference or source which in and of itself accomplishes this purpose. Therefore, such a model would make an important contribution to the field. Second, to develop a questionnaire which could be used to conduct a descriptive survey of generalist social work practice in Oregon. It would determine the extent to which practitioners in Oregon are practicing as generalists. We are interested in discovering 1) the relationship between generalist practice and the personal characteristics of practitioners, as well as 2) the relationship between generalist practice and the type of agency in which the practitioner works. It appears to us that certain agencies encourage ineffective, inappropriate, and unidimensional practice, while others tend to encourage more effective and holistic practices

This research practicum is organized in the following manner. Chapter II reviews the important historical trends and practice dilemmas which led to the development of the generalist approach. Chapter III offers a review of the generalist 1 iterature from which our model was formulated. Chapter IV deals with the presentation of our model and consists of three parts: (1) a review of the literature on models and model building in social work, (2) an overview of the general characteristics of the model, and (3) a description and analys is of the model's specific concepts and constructs. Chapter $V$ provides a research proposal and design which includes a questionnaire (once pretested) which can measure the occurrence and/or non-occurrence of generalist practice. Finally, in Chapter VI, we discuss some possible research avenues which might be generated by our model and questionnaire and the implications for social work in the future. 
CHAPTER I I

\section{A HISTORICAL REVIEW OF SOCIAL WORK \\ IN THE UNITED STATES}

In order to more fully understand the generalist approach to social work practice, particularly its development in social work, it is necessary to review some of the major trends and issues throughout the history of social work in the United States.

The history of social work may be viewed in terms of the evolution, development, modification and abandonment of various ways of conceptualizing and performing social work practice. ${ }^{1}$ Historically, these approaches to social work practice have differed greatly--and continue to do so today--largely in terms of theoretical orientation, methodology, fields of service, and practice settings. Underlying these developments were even more significant factors.

The history of social work and the development of various models and methods of practice may be more accurately viewed as expressions of the profession's repeated attempts to resolve more fundamental practice issues and dilemmas. Historically, three major practice issues have confronted the profession--the dilemmas of cause/function, social/ psychological, and generic/specific. These dilemmas, which are at the core of both social work theory and practice, have been problems which

${ }^{1}$ Throughout the social work literature these various ways of thinking about and practicing social work are referred to as the models and methods of social work practice. 
have polarized the profession. As Schwartz (1969) notes, these dilemmas have seemingly imposed inoperable, dichotomous, either-or choices for social work. Social workers have been forced to choose between cause or function, social casework or social action, professional or political activity, micro or macro practice, etc. Thus, in order to understand the historical significance of these "choices" and their relevance to the development of generalist thought and practice, we will briefly analyze the substantive issues inherent in these dilemmas. 2

\section{Cause/Function}

The cause/function dilemma has to do with what should be the main purpose of professional social work. The proponents of social work as a cause view it not only as a profession but also as a social movement. Highest priority is given to achieving the ideal purposes or ends to which social work in general should be directed -- that of social reform and advocacy. As Charlotte Towle (1942, p. 389) observed, "Cause is the purpose, the reason, and the motive for providing the means by which social ills may be prevented, abolished, or remedied through social action."

However essential a sense of cause may be, it is not enough -ultimately purpose must be translated into action. Function has to do

2 Throughout the literature these dilemmas have been given their own, separate labels, e.g., cause/function. The practice issues inherent in each of these dilemmas, however, are highly interrelated; as conceptual categories they are not mutually exclusive. For example, specialists, such as psychiatric social workers, have emphasized concerns of function and have favored the psychological perspective. On the other hand, cause-oriented social workers have favored a social action approach and have relied on sociological explanations. 
with operationalizing and institutionalizing social work practice. Highest priority is given to professional concerns, that is, to the means of social work practice; the use of methods and techniques, the effectiveness and efficiency of practice, of the development of policies and procedures to provide social services. As Lieby (1978, p. 279) observes "inevitably... (for the proponents of function) their thought turned to method; what to do, how to do it, how to do it better."

\section{Social/Psychological}

The dilemma of social/psychological deals with 1) the theoretical perspectives used in social work for viewing and understanding human behavior and social problems, and 2) the types (or focus) of the interventive approaches used in social work practice. The social perspective is system centered. The focus is on making external or environmental changes, and priority is placed on changing social and economic conditions, institutions, and policies which adversely affect large groups of people. The psychological perspective is person centered. The emphasis is on the treatment of individuals, families or small groups by helping them to make internally based, intra-psychic changes in personality structure or in interpersonal relationships or behavior patterns.

More so than any other practice issues, the dilemmas of cause/ function and social/psychological have persistently plagued and polarized the profession of social work. ${ }^{3}$ As Minahan (1976) notes, however, cause/function and social/psychological and the controversy surrounding these dilemmas. 
the issue of social workers as generalists or specialists have been hotIy discussed and debated as well.

Generic/Specific

The dilemma of generic/specific has to do with the relative merits of a unitary conception and approach to social work practice as contrasted to the division and fragmentation of practice into specialties. Generic refers to a "common base" (Bartlett, 1970) for social work practice which transcends various approaches by methods, fields of service or practice setting. Specific emphasizes the need for differences in knowledge, skill and function in various aspects of social work, that is, for specialization of practice by method, treatment modality, field of practice, population or social problem, geography or size of target. As Minahan observes, practice by specialization requires "...a skilled technical worker, a competent expert in a (particular) specialty...", whereas generic practice is based on "...a worker who can work in many different types of situations, interact with a variety of people and deal with many kinds of social problems" (1976, pp. 58-59).

To a significant extent the history of professional social work in American has consisted of the repeated attempts to resolve the practice dilemmas of cause/function, social/psychological and generic/ specific. Since social work has lacked a framework capable of integrating these dilemmas, the generalist approach to practice may be viewed as a response to this need. 
THE EMERGENCE OF THE FIELD OF SOCIAL WORK

The history of social work in the United States can be described in terms of several stages, during each of which are seen the divisions characterizing one or more of the dilemmas discussed above.

As Kaufman (1974) points out, following the Civil War there were many social problems which were related to various factors such as poor working conditions, low wages, long hours, mass unemployment, periodic depressions, and urban slums. According to Harriet Bartlett (1970) the two trends which came to typify early social work practice efforts centered around 1) giving of aid or assistance to individuals and families under stress with a focus on individual treatment, as carried out by the volunteer Charity Organization Society (C.0.S.), and 2) the social reform movement, which focused on environmental change for larger groups of people as exemplified in the Settlement House Movement.

The first Charity Organization Society (C.O.S.) was founded in Buffalo, New York, in 1877 . It was an attempt at the scientific provision of charity, i.e., scientific philanthropy, which began in England in 1869 (Kaufman, 1974). Like other charity organizations of the day, the C.O.S. were highly influenced by the Elizabethan Poor Laws of England, and the judgmental tenents of Anglo-Judeo-Christian charity. According to Kaufman (1974) the C.0.S. Movement operated on four basic principles, 1) the need for a detailed investigation of each applicant, 2) a central system of registration to avoid duplication of charity, 3) a high degree of cooperation among member agencies, and 4) the extensive use of volunteers. 
The C.0.S. societies were founded in order to provide assistance and relief to their own members, much like the religious orders and charities which they resembled, and were thus dominated by the belief that the causes of poverty were largely personal, due to the sloth, intemperance, or general sinfulness of the poor (Kaufman, 1974).

The goals of the early C.0.S. were, 1) the rehabilitation of families who were less than self-sufficient, 2) the education of the community in the correct principles of relief, and 3) the elimination of poverty (Kaufman, 1974). The C.O.S. attempted to help individuals and families--in as friendly and planful way as possible--in the hopes of helping them overcome their moral ineptitude. This approach called for the "friendly visitor" 1 to visit the homes of the poor and then to determine, based upon the circumstances of the family, what assistance to give. The "friendly visitor" collected information concerning family income, expenditures, health, relatives, work history, and moral integrity. The major task of this volunteer worker was to decide if the family was worthy to receive assistance. Once accepted, the friendly visitor formulated a plan specific to the needs of the particular "case". For example, if a child was found to be sickly, or if the family had no food or money, then initially every effort was made to obtain money from a relative. If this was not possible, then the child was taken to the doctor, or the family was given a small sum of money or food, much in the spirit of a "friendly loan." It seems that there

${ }^{1}$ The C.0.S. concept of friendly visitor predated the use of the term, caseworker. 
was little regard for client self-determination, and that the primary objective of "social casework" of the friendly visitor was to differentiate the worthy from the unworthy poor (Briar and Miller, 1971).

Mary Richmond was an early and prominent theorist who contributed much to the design and implementation of the work of the C.0.S. ACcording to Kaufman (1974, p. 10) Mary Richmond's practice theory "rested on three foundation blocks: the philosophical views of the Charity Organization Society, the intensive side of friendly case records, and the concept of character or personality." Mary Richmond is credited with bringing the scientific method, as adapted from the medical model, into the process of social work. She integrated the medical model of study, diagnosis, and treatment into casework (Kaufman, 1974).

Mary Richmond believed that the individual's character was central to the understanding of social problems. Although Richmond (1899, pp. 8-9) stated that "personal and social causes of poverty act and react upon each other," she seemed convinced that the family and the individual should be the primary focus of social work intervention (Kaufman, 1974). She believed, as did the C.0.S., that society was not a negative force, and that individuals were responsible for their own problems. Although in the course of her lifetime Richmond came to favor a collaborative, more democratic practice, nevertheless, she and C.O.S. were rather judgmental in their attitudes toward $c l i e n t s$ and saw the purpose of social work as bringing the poor more into conformity with middle class standards (Kaufman, 1974). In Social Diagnosis (1917) Richmond emphasized her belief in the need for the caseworker to conduct a thorough psycho-social assessment, by obtaining information from 
such collateral sources as family, friends, neighbors, schools, police, hospitals, doctors, as well as by direct observation. Her intent was to make diagnosis more complete and scientific and therefore, more effective. As Carel Germain (1970, p. 10) observes, her approach was based on the premise that uncovering the cause would reveal the cure, a premise "that reflected nineteenth-century science and scientism."

In contrast to the C.O.S. focus on individuals, efforts of the Settlement House Movement were community oriented, designed to improve the general welfare of the poor, the handicapped, and the deprived. According to Jane Addams, the focus of the Settlement House Movement was not in the realm of an individual ethic, but in a social ethic (Kaufman, 1974). Adams and her cohorts called attention to larger "public issues" -- to the need for social reform. The goal of their efforts was to prevent and alleviate problems that affected entire communities or neighborhoods, such as unemployment, disease, poor housing, and low wages (Bartlett, 1970).

Jane Addams established Hull House in Chicago in 1889. It was based roughly on the model of Toynbee Hall in England. Jane Addams viewed the Settlement House as an experimental way of providing solutions to the social and economic problems created by modern industralized society (Kaufman, 1974).

Residence, Research and Reform were the three guiding principles of the movement. The settlement's main purpose was to help unite and organize the poor and working middle-class families to advocate on their own behalf. Another important function of settlement houses was to conduct research on social "ills" since they were located in their 
geographical midst and were staffed by workers interested in social reform (Bartlett, 1970).

Jane Addams viewed man and his relationship to society as a reciprocal process. As such, she was interested in the welfare of people at all levels and sought to bring the "best results of civilization" to bear on social problems (Addams, 1910, p. 105). According to Kaufman (1974) this was accomplished by the settlement's twin goals of removing the obstacles to greater social development and by the provision of opportunities. The settlements offered a meeting place for the formation of trade unions and reform movements; they also provided adult education, recreation for the children, day-care, as well as social and civic activities (Kaufman, 1974).

The notion behind having better educated workers living in the same neighborhood was to provide a better example in the hopes of working toward eliminating class distinctions. This concept of "neighborliness" helped support Jane Addams' idea of individual self-determination, as she believed the characteristics of the helper would encourage the neighbor to improve his environment.

Thus, even during the earliest period in the history of social work the cause/function dilemma began to manifest itself. The Settlement Movement focused primarily on el iminating the causes of poverty while the Charity Organization Society emphasized efficient functioning in meeting the needs of the poor. The beginnings of the social/ psychological dichotomy were present as seen in the writings of the two most prominent social work practitioners of the day, Jane Addams, 
who emphasized the need for social reform, and Mary Richmond, with her emphasis on individual character.

It is generally agreed that the current practice of social work is the result of the coming together of these two separate and distinct traditions. Kaufman (1974) asserts that the eventual merging of these two trends left key issues unresolved, e.g. the purpose of practice, the role of the social worker, the functions of agencies, which are reoccuring issues today.

\section{The Progressive Era}

Kaufman (1974) maintains that the victory in the Civil War of the North over the South was not so much an issue of slavery and succession, but was a victory of the forces of the modern industrial, urban society over the rural agricultural life of the South. The victory meant a rapid and assured increase in industrialism and the evenual dominance of major areas of American life by railroads, banks, and large industry during the late nineteenth century.

During the early 1900 's popular and professional thinking came to reject the values inherent in the concept of Social Darwinism, and increasingly the middle class began to revolt against the abuses of the rich and powerful corporate structures. Economic and social change, or reform, was a central and pervasive subject of the day and was embodied in the platform of Teddy Roosevelt (Kaufman, 1974). This was a protest against big business and managerial policies which sought to maximize profit at the expense of social justice. According to Kaufman (1974) the Reform movement sought the 1) expansion of democratic 
participation and 2) the control of economic and social abuses. The emerging profession of social work came to be most involved in these areas, particularly the alleviation of social injustice (Kaufman, 1974).

The concerns of the Progressive or Reform Era centered around controlling economic and social abuses. Increasingly the federal government became involved in anti-trust action, legislation to control child labor, the establishment of workman's compensation, limiting of women's working hours, and wage and hour standards for all workers. In the area of politics we see the "establishment of direct party primaries, the introduction of women's suffrage, and the direct election of senators" (Kaufman, 1974, p. 2).

In terms of social reform Borenzweig (1971), states that women were becoming more active in social action -- many of them became the "reformers" and pioneers who built the profession of social work. "These women were middle and upper-class people who were deprived of using their abilities elsewhere" (Borensweig, 1971, p. 8). Reform efforts attempted to change municipal politics and began to introduce health and safety measures into urban life (Kaufman, 1974). The clamor for social justice, as exemplified by such early workers as Jane Addams and Lillian Wald of the Settlement House Movement, gave legitimacy and impetus for social work to be involved in social action.

By the early 1900 's it was clear to some of these workers that slum conditions and aggregate poverty were not caused by moral ineptitude of the poor, but were a consequence of large-scale social, political and economic problems caused by the rapid growth of industrialism, immigration of largely non-English speaking populations, frequent and 
severe economic depressions, and increasing urbanization. These "social" problems gave credance to the idea that the poor were victims of economic and environmental forces outside their control (Briar and Miller, 1971).

During the Progressive Era it appears that social work stressed cause more than function and social more than psychological in programs and practice. But in the aftermath of World War I, the pendulum swung in the opposite direction. At the same time, as social work sought to become a profession the generic/specific dilemma emerged as the fields of social work proliferated and became increasingly specialized and fragmented.

World War I brought an end to the Reform Era -- the political and social climate became more conservative. Kaufman states that the reform movement came to a halt "and its momentum would not recover until the depths of the depression" (Kaufman, 1974, p. 3). Social reformers and their movements and efforts became increasingly suspect as the "Red Scare" of Bolshevism entered the mainstream of the nation's political consciousness. Borenzweig (1971) states that the Red Scare of the 1920's largely contributed to the demise of the Settlement House Movement. Further, he quotes Jane Addams as she comments on the Palmer raids of settlement house workers: "Any proposed change was suspect, even those efforts that had been considered praiseworthy before the war...social workers carefully avoided any phraseology of social reform" (Clarke A. Chambers, Seedtime of Reform, 1963, p. 117). The war also brought with it new theories about human behavior and new directions for the profession to explore. 
Striving for Professional Identity

World War I had one immediate effect upon the potential clientele of social work agencies in that it separated families as husbands went into the service, leaving younger children and wives at home. The Home Service Bureau was an example of the new services and agencies established to deal with the problems and contingencies caused by the war. Social workers soon experienced growing caseloads made up of a more varied clientele; some clients were from higher socio-economic backgrounds, many were receiving casework services for the first time, usually for family, social, medical or emotional problems rather than for economic relief (Briar and Miller, 1971). These changes presented a challenge to social workers and provided a stimulus to seek new ways to define and carry out their practice. As a result social work began to look to other disciplines, notably medicine and the emerging specialty of psychiatry.

The war also contributed a growing body of knowledge to the field of psychology. For instance, the causes of "shell-shock" were explored and subsequently published in the literature. Social workers attached to recovery hospitals learned first hand about these new theoretical developments and brought the ideas and treatment techniques into their practice of casework (Briar and Miller, 1971).

In 1915 Abraham Flexner gave a speech at the National Conference of Charities and Corrections in which he discussed the question, "Is social work a profession?" He concluded that social work was not a profession because it lacked a communicable theory base, and he questioned the possibility of building a profession on volunteer or under- 
paid service (Encyclopedia of Social Work, Vo1. 1, p. 485). Flexner's contentions plunged the field of social work into what was to become a professional "identity crisis."

The ever increasing search for an identifiable theory and knowledge base, i.e., the quest for professional status, the avoidance of social reform in the aftermath of World War I, and the publication of Mary Richmond's influential book, Social Diagnosis in 1917, provided a climate for the acceptance of psychoanalytic theory as a theoretical base for casework (Borenzweig, 1971).

Carol Germain notes that just prior to this time the commitment to a scientific outlook began to intensify rapidly with the result that charity organization societies became bureaucratized, i.e., functionoriented, and shifted away from the use of volunteer workers to utilizing more scientifically trained and paid staff, who began to strive increasingly for professionalization (Germain, 1970). Casework, drawing from the medical model with its emphasis on the diagnosis and treatment of individuals, became the primary method of social work practice. Increasingly, social workers focused on the personal deficiencies and personality defects of their clients.

The focus of the National Conference of Social Welfare in 1919 was on psychological theories which dealt primarily with intrapsychic conflicts. Mary Jarrett spoke on behalf of the conference when she said that there was "a psychological thread running through all of social casework." The conference members debated enthusiastically whether to create a separate specialty of psychiatric social work or to 
try to incorporate the ideas and concepts into the framework of social casework (Briar and Miller, 1971).

Because psychoanalytic theory was thought to be consistent with the thrust for scientific progress, and because it helped to explain the irrational behavior social workers encountered in their practice, it was enthusiastically incorporated into the mainstream thought and practice of psychiatric casework (Borenzweig, 1971). It was believed that Freudian psychology provided casework with the theory base which it had previously lacked.

The increased emphasis placed on the significance of early childhood experience in the family resulted in the child guidance movement of the 1920's. Clinics were set up around the country to assist families and individuals through the provision of psychiatric services for children. These clinics relied heavily upon both the medical model and the theoretical and interventive methods of psychoanalytic theory (Briar and Miller, 1971).

The adoption of psychoanalytic theory and practice set in motion several fundamental changes regarding the notion of the client, the nature of the helping relationship, and the nature of client problems. For example, there was a change in the way information was solicited from the client. Use of collateral sources for data gathering was de-emphasized in favor of obtaining an extensive psychological developmental history of the client. Answers to client problems could now be stated in intra-psychic terms, based solely on what the client supplied for information and the caseworker's interpretation of this data. This had its positive aspects in casework because client problems could be 
approached from other than economic or moral terms. However, as casework increasingly identified itself with psychiatry and patterned its treatment approach on the so-called 50-minute hour, the emphasis on social reform diminished (Briar and Miller, 1971). Mary Richmond warned that the profession was leaning too heavily on individual psychology and stated that both a "retail" and "wholesale" approach were required to meet the needs of the profession in providing services to the society (Borenzweig, 1971). According to Bertha Reynolds, it was easier for social workers "to seek the answers to problems by specialization and individual study rather than by examining or looking for the causes of sickness in the society" (Briar and Miller, 1971).

At the time of the Milford Conference in 1929 the primary developments in the field of social work were the expansion of practice into various fields of service and a growing trend toward fragmentation of service and specialization of methods. There was a concurrent rise of interest in professional organizations of social work as well. These developments were based on the need for the profession to gain identity and sanction for itself but was met with the counter trend which set the stage for the Milford Conference.

At this conference, of which Porter Lee was president, the problems of cause and function, the diagnostic-functional controversy, the issue of the status of the social work profession, and the search for a common or "generic" basis for all social work practice were explored and debated.

Porter Lee (1929) identified what he saw as the transformation of social work from cause to function -. its ever increasing preoccupation 
with techniques, method, and efficiency (Germain, 1970). Porter Lee reminded the profession that at one time the primary concern of social work had been the well-being of mankind and social justice; these were the causes which had brought workers together to form the charity and settlement house movements. To quote him,

The achievement of a cause...depends on methodical function to implement it. But social work, al though it must develop and administer its service as an efficient, science-based activity, must also retain its capacity to insure enthusiasm for a cause (Lee, 1929, p. 27).

Increasingly, Porter Lee observed, social work had become institutionalized and tended to neglect social reform as it sought greater efficiency and emphasis on techniques in its efforts to serve the functions of society; in short, social work was losing sight of its original purpose.

The Milford Conference of 1929, coming on the eve of the Great Depression, may be viewed as the profession's attempt to reconcile its differences, define its essential, generic nature, and work toward establishing its professional identity and status.

The Emergence of Social Work As a Profession

In 1929 many factors, working both singly and in combination, helped bring about large scale economic and social changes that greatly influenced the delivery of social welfare services. The failure of the banking system, the stock market "crash," a severe production slow down in basic industries, a wide spread attitude of speculation and of money making, and an apparent absence of social or economic responsi- 
bility helped bring about a severe depression. The depression affected not only the poor (a traditional occurrence), but was so severe as to seriously affect the middle class as well.

The clientele of social work expanded as the social and economic conditions worsened. It became increasingly evident that $c l$ ients' problems were more a consequence of large scale socio-economic disorder than the fault of individual clients. In order to cope with the increased caseloads, the need for a short term means of providing material services became clear. New skills, new knowledge, and new resources were necessary. No longer were the techniques of long term psychoanalysis appropriate for casework to meet this new demand for services.

In order to cope with the sheer size of the problems caused by the depression, the U.S. government passed legislation implementing the programs of the "New Deal." This brought a rapid expansion of public agencies into an area which previously had been the territory of private and volunteer relief giving agencies. Public agencies such as the Civilian Conservation Corps, Work Progress Administration, and Public Works Administration provided both work opportunities and relief services. As a result of having to staff these new agencies, many caseworkers left the private sector to go to work in the public sector. Many of them were individuals who had become disillusioned with the unclear results and inappropriateness of psychoanalytic casework and sought to perform in roles which were part of the "New Deal."

Many of the more psychoanalytically-oriented social workers moved into positions vacated in the private agencies. There they felt freer 
to give therapeutic services without the drawbacks and complications of also having to provide material relief. However, the services of the private agencies more frequently became oriented toward treatment of clients who were above the poverty line.

During this period, the traditional social work practice dilemmas of cause/function and social/psychological were manifested in terms of the divergence in practice and theory between practitioners in the private and public agencies. Social workers in private agencies for the most part focused on technique (function) and the psychological aspects of client adjustment, while those working the the public sector were more concerned with reform (cause) and economic and material provision.

By the end of the 1930 's social work was separated into five different fields of practice: family and child welfare, medical, psychiatric, corrections, and school social work. In a functional sense public agencies provided services directed at the clients' physical needs, while private agencies provided services directed at the clients' social, ego, and self-fulfillment needs. Thus fields of practise in social work became increasingly specialized and consequently practice became increasingly fragmented by the agency setting in which it occurred. The organizational setting actually determined the nature of social work practice by limiting it to the parameters and policies of the agency. The trend was toward a specific agency or method orientation rather than generic base. 
Social Work Practice Approaches

Social workers have implemented their professional purposes and values largely within organizational limits, in part by specializing in casework, group work, or community organization.

Diagnostic casework, as illustrated in the works of Florence Hollis and Gorden Hamilton, employs two main treatment strategies: the development of psychological insight and (2) psychological support. The theory base of this school of thought consists primarily of psychoanalytic theory and ego psychology which stress the importance of early childhood experinces as the cause of client problems.

The caseworker directs his efforts primarily to the individual client and, if necessary, the client's environment. The intention of the caseworker is primarily to change the client's behavior, in order to help the client adjust to social "realities." At the same time the caseworker tries to maximize the client's potential for self-fulfillment within those realities.

The functional school of casework as illustrated by the works of Ruth Smalley and Jesse Taft placed an added stress on the importance of client self-determination. This emphasis is a direct result of the assumptions found in the theory of human development and psychotherapy propounded by a student of Freud's, Otto Rank. In the words of Yelaja (1974, p. 155)

Turning its back decisively on the diagnostic preoccuation with the past, functionalism placed new and creative emphas is on the present experience and its power to release growth potential. The concept of treatment was replaced by the concept of service, of a helping process in which the use of relationship, the dynamic interaction of the social worker as helper and the client as determinant of the process, was paramount. 
The functional caseworker directs his efforts primarily to the individual client, with the worker deliberately limiting the scope of his efforts to those problems which are primarily related to the services and resources that can be furnished by the agency. Worker and client deal only with issues related to the client's personal growth and problems directiy related to the function of the agency. The caseworker uses "therapy" as a means to promote individual growth and realization of human potential as opposed to a means of helping the client adjust to his surroundings.

Problem solving casework as illustrated in the work of Helen Harris Perlman is basically supportive and educational. The caseworker helps clients learn how to analyze their problems and educates clients, in a consultive fashion, in the art of effective problem solving.

The caseworker directs his efforts toward working with the client to mutually assess the client's strengths and weaknesses for dealing with his problems. Problems are often prioritized in terms of importance. Methods of solution are analyzed in terms of the degree to which they would satisfactorily solve the problem at hand. Solutions to problems are formulated in terms of long range goals, short range goals, objectives to be achieved, and tasks to be assigned to the worker and client respectively for achieving these objectives. The client and worker enter into a contract in which the goals, objectives, tasks, and expected outcomes are time limited and delineated with a high degree of specificity and clarity.

Group work and community organization approaches to social work practice borrowed theories from other fields and professions, particu- 
larly from sociology, social psychology, and anthropology. As approaches to social work practice, group work and community organization relied on more of a social/environmental perspective. Social workers utilizing these approaches viewed their clients differently than did caseworkers who still seemed preoccupied with their clients' intrapsychic functioning.

Since the mid-1930s group work has increasingly come to be recognized as a primary method of social work practice. The American Association of Group Workers defines group work as follows: "The group worker enables various groups to function in such a way that both group interaction and program activities contribute to the growth of the individual and the achievement of desirable social goals." Group work was thought to be a useful approach to social work practice that could be used in conjunction with casework techniques to better serve the total needs of clients. Group work builds on casework in that the group worker uses casework skills in relating to individual group members. Group work goes beyond casework in that the groups' activity generates social resources much greater than those developed in the caseworker/client relationship.

Community organization was not formally recognized in the profession until 1946 when the Association for the Study of Community Organization was formed. Community organization is defined by Murray Ross (1955, p. 39) as "a process by which a community identifies its needs or objectives, orders these needs, develops the confidence and will to work at these needs, finds the resources to deal with these 
needs, and takes action in respect to them, and in so doing extends and develops cooperative and collaborative attitudes and practices in the community."

Federico (1956) delineated the practice activities that are essential steps to all community organization approaches. First, the community to be worked with is identified. Second, the resources available to the community are identified. Third, the worker sets about identifying problems that exist within the community for which there is a realistic chance of solution using community organization principles. Community organization came to be viewed as a powerful tool. It is important for the practitioner to make sure that the beneficiaries of his efforts are actually the ones who were intended to benefit. The practitioner needs information and particularly involvement, not only from the people who provide the resources, but also from the people who are to benefit from the effort as well. Community organizers can mobilize community resources to solve social problems which act as barriers to the adequate functioning of social work clients. Community organization is capable of and functions as a tool for facilitating social reform, social improvement, and social problem prevention.

Fragmentation of the Social Work Profession

The field of social work became increasingly divided into specialties based on method (casework, group work, or community organization) or setting (hospital, school, or government program). This fragmentation increased the difficulty for social workers to adequately meet the needs of their clients. As a result of their specialization, case- 
workers developed skills in helping clients deal with their psychological problems but often did not realize the importance, or lacked the skills, for helping clients obtain necessary resources from their social environment. Casework was based largely on the medical model of study, diagnosis and treatment of individual dysfunction and on psychoanalytic personality theory. Group workers, on the other hand, developed skills for aiding their clients to interact more satisfactorily with other people, whether in the family or other small groups. However, they often placed too little emphasis on working specifically with the individual client and did not relate client problems to the need for additional resources which could be obtained for other social agencies or organizations. Similarly community organizers placed too little emphasis on the importance of working with individuals and groups of clients. In this way fragmentation of the field contributed to problems of resource provision and service delivery, and to an ever increasing concern that social work was not fulfilling its mission as a profession.

These criticisms were of great concern to some social workers who were looking for a more holistic or comprehensive base for practice. In 1956 the formation of the National Association of Social Workers brought together the five major professional associations and in 1958 established a commission which had the task of formulating a new "working definition" for social work practice. The goal of this effort was to develop a unitary view of social work practice. Commission members identified what they considered to be the generic, or common base for professional practice: purpose, values, knowledge, sanction, 
and method. This definition renewed the search for elaborating the generic in all of social work and seeking a theoretical base which could accommodate the whole of practice.

\section{Challenge of the 1960 's}

In the 1960's the profession of social work was increasingly challenged and criticized for not effectively helping its clientele, primarily because its major practice approaches, e.g., psychosocial casework, were holdovers from the past. These traditional "method and skill" models (Bartlett, 1970) gave primary importance to the role of direct services in helping individuals, families, and small groups, usually within the service limits imposed by specific practice settings, such as hospitals, mental health clinics, and family service agencies. Furthermore, they were based largely on the medical model of study, diagnosis and treatment of individual dysfunction.

The civil unrest and social upheavals of the 1960's, as evidenced by the civil rights, ecology, self-help, anti-poverty and anti-war movements-and the ever increasing public recognition of the ineffectiveness of social work intervention--threw social workers once again into a full-scale professional crisis. These factors, coupled with the vast funding and expansion of Great Society programs, provided the necessary impetus which stimulated social workers to develop new practice approaches which would provide more effective and relevant services to a broader range of clients, particularly the poor and disadvantaged.

Such social and economic changes necessitated not only new forms and modes of practice, but also new ways of thinking about social work 
services and how they could be made more effective for these new kinds of clients and problems. In the introduction of their book on generalist practice, Klenk and Ryan (1974) make this point well,

Given the basic aim of social work -- to enhance social functioning -- these developments made it clear that a new kind of worker was needed, one with the requisite knowledge and skills to work with a variety of situations. The generalist approach to social work practice is a response to that need ( $\mathrm{Klenk}$ and Ryan, 1974 , p. 2). 


\section{CHAPTER III}

THE GENERALIST APPROACH TO SOCIAL WORK PRACTICE:

\section{A LITERATURE REVIEW}

The purpose of this chapter is to set the stage for the presentation of our model for generalist social work practice. First will be a review of some of the limitations of traditional social work approaches, and a brief description of two schools of social work thought which recognize the validity of these criticisms and attempted to strengthen the field of social work by providing a more integrated approach to practice. These schools, precursors of the current generalist approach in social work, were known as: (1) the generic school of social work, exemplified in the writings of Harriet Bartlett and William Gordon, and (2) the general systems theory approach, which was spearheaded by Gordon Hearn. Second, the literature on generalist social work practice will be reviewed, paying attention to common threads of agreement and areas of difference among the most prominent authors.

As noted in Chapter II, throughout the history of the theory and practice of social work, serious questions have been raised as to the effectiveness of social workers in helping their clients. In spite of the best efforts of many talented and dedicated people in the field, many studies indicate that social workers have been ineffective in aiding their clients (Eyesenck, 1965 and Fischer, 1973). Two factors have contributed to this failure: (1) Social work practice 
has often resulted in blaming the victim; that is, social workers have told clients, either directly or indirectly, that their psychological states were the principal cause of their problems when other causes, e.g., lack of available resources in the environment and/or inadequate linkage to resource systems were equally, if not more, important.

Thus the social worker, in focusing on the client's personal deficiencies, often failed to have an effective impact on the client's immediate environment to promote a more humane social service system which would provide the necessary resources for people in need. Instead, social workers have been preoccupied with helping clients to make the psychological changes required for better adjustment to the "realities" of their situation. The practice of social casework, therefore, has tended to encourage and enforce client adjustment which served the needs of dominant social institutions rather than the needs of the clients themselves. Instead of empowering clients by helping them learn how to change their environment in order to gain better access to resources, social workers have contributed to the maintenance of the status quo.

(2) The field of social work continues to be fragmented into specialities based on method (such as casework, group work, and community organization) or setting (hospital social work, family agency social work, etc.). This fragmentation makes it difficult for social workers to realize that in order to adequately meet the needs of clients they must be able to work effectively at three levels -- the individual, the group, and the organization. For instance, as a result of specialization, caseworkers develop skills in helping clients deal 
with their psychological problems but often do not realize the importance of, and lack of skills for, helping clients obtain necessary resources from the community, or their informal social network. Conversely, community organizers have neglected the importance of working with individuals or groups of clients. In this way, fragmentation has contributed to the inadequate resource provision and service delivery systems which characterize the social service field. These criticisms were of great concern to some social workers who looked for more comprehensive and effective approaches to social work practice.

In his article, "General Systems Theory in Social Work," Gordon Hearn (1974) describes how he became progressively disenchanted with the tendency toward fragmented specialization in social work. Hearn wanted to find some way to conceive of individuals, groups, organizations, and communities as interacting, interdependent entities. He therefore sought a theoretical framework which would allow social work to develop a theory interrelating all these "systems." Through such a theory, workers would be effective in meeting the total needs of their clients and in this way would practice a "holistic" social work.

In 1955 Hearn read an article by James Miller (1955) on the subject of general systems theory and became enthusiastic about the possibility of applying concepts from the general systems approach to social work practice. Hearn's expressed purpose for applying general systems theory to social work was to generate a unified theory of social work practice.

Hearn's theoretical formulations of social work practice, expecially as espoused in his book Theory Building in Social Work (1958), 
predated many of the important concepts and precepts of the generalist approach. For instance, Hearn stressed: (1) the importance of viewing people and their environments in terms of a systems perspective,

a systematic approach where clients and target systems could be regarded either as individuals, groups organizations, or communities; (3) the importance of helping clients obtain and utilize necessary resources through a collaborative process; (4) the importance of realizing that even social organizations and social institutions may be amenable to influence and can be changed by appropriate social work practices, (5) the importance of viewing social work practice as a means of promoting human growth, human development, and social change. Hearn stressed these things as alternatives to client adjustment to fixed environmental conditions.

Although these concepts were derived less from general systems theory than from Hearn's insightful nature, nonetheless, Hearn's work has greatly influenced most current formulations of generalist practice, particularly in terms of their utilization of a systems framework.

Another group of social workers sought to transend the practice dilemmas and fragmentation which limited the effectiveness of the profession. The generic school of social work originated in the attempts of social workers to: (1) develop an optimum curriculum for enhancing social work practice; (2) understand what is unique about social work as a basis for laying the ground work for the establishment of a profession; and (3) include under the rubric of social worker not only caseworker, but also group worker and community organizer. 
One of the major contributors to this school of thought was Harriet Bartlett, whose book, The Common Base of Social Work Practice (1970), provides the essential components of a common overall purpose, mission, underlying set of values, and philosophy espoused by social workers in all three "methods." In addition, Bartlett makes a good case for the applicability of certain casework techniques and the usefulness of a large part of casework theory for the practice of both community organization and group work. Bartlett, perhaps more than anyone, has strongly influenced social workers to look for "common bases," not only of general mission and underlying values, but of practice, knowledge, and skills as well. William Gordon and others have carried on this task and have been especially effective in enhancing and clarifying both a commonly agreed upon mission for social work as well as a clear conceptualization of its underlying values and philosophy.

The generic school of social work has made a valuable and lasting contribution to the profession of social work: Its proponents emphasized that any social work practice model needed to include a "common base" of: (1) mission or overall purpose, (2) underlying values and value premises, (3) knowledge base, (4) practice skills. It pointed out the importance of not restricting social work to work with individuals (casework), but including work with groups (group wor), and organizations (community organization) as well. In this way the generic school helped to give caseworkers, group workers, and community organizers a common professional identity -- that of social worker. 
The generic school had its greatest influence on social work in the 1950's. More recently, however, social workers have come to see that although they may share common goals and values, as well as some basic knowledge and skills, each method area has its own unique knowledge base, skills, and interventive strategies.

Literature Review: Who Are the Generalists?

Although generalist social workers appear to differ from one another in their use of terminology and in their emphasis on different aspects of generalist practice, nevertheless, in certain fundamental respects they share a similar understanding of the mission of social work and of its underlying value premises.

Generalists differ from other social workers in several important respects: (1) their conception of clients, (2) the nature of problems to be addressed, (3) the practice process, and (4) practice approaches and activities.

(1) According to most generalists (Pincus and Minahan, 1973, Klenk and Ryan, 1974) clients may be individuals, groups, or even organizations or communities. Clients are those people or organizations that might be expected to benefit from the social worker's intervention.

(2) Clients (people) are thought to experience a wide range of problems-of-living and to be effective, social workers must be able to distinguish personal troubles from public issues (Schwartz, 1969).

(3) Whenever possible, the generalist worker engages clients in a collaborative effort-respectful of the person(s) dignity and right 
to self determination--in order to examine the problems-of-1iving they may be experiencing and to work toward problem resolution by means of a systematic, planned change process. The worker negotiates with the client to arrive at a mutually agreed set of goals which are shaped by the client's knowledge and experience of their problems-of-living as well as by the worker's professional expertise.

(4) Generalist practice activities are logically derived from the joint assessment and mutually defined goals set by worker and client. Generalists emphasize the need to perform a variety of practice roles and functions, that is, engage in a variety of practice activities, as the client's situation warrants.

This review of the literature will describe and analyze the works of the most prominent generalist authors and their practice models with respect to the following considerations: The generalist practice perspective, practice process, and practice activity.

\section{Allen Pincus and Anne Minahan}

Pincus and Minahan (1973, 1977) and Minahan and Pincus (1977) have developed a systematic and comprehensive formulation of the generalist approach to social work practice. Their model offers and alternative to the limitations of traditional practice approaches. Deficiencies that they found in traditional practice approaches are:

(1) Traditional models unduly limited the scope of social work practice--these practice approaches were based on specialization by method: casework, group work, or community organization. 
(2) Traditional models conceptualized social work practice in dichotomous terms; such as psychological or environmental change, clinical practice or social action.

(3) Traditional models were heavily dependent on a single theoretical perspective of human behavior. Practice activity was dictated more by the theory base than the needs of individual clients.

Pincus and Minahan define the purpose of social work as follows:

Social Work is concerned with the interactions between people and their social environment which affect the ability of people to accomplish their life tasks, alleviate distress, and realize their aspirations and values. The purpose of social work therefore is to (1) enhance the problemsolving and coping capacities of people, (2) link people with systems that provide them with resources, services, and opportunities, (3) promote the effective and humane operation of these systems, and (4) contribute to the development and improvement of social policy. (1973, p. 9)

Pincus and Minahan base their practice model on the values commonly espoused by most social workers. They give credit to William Gordon for his useful distinction between primary and instrumental values, and they cite two primary values which shape the practice to social work.

1. Society has an obligation to ensure that people have access to the resources, services, and opportunities they need to meet various life tasks, alleviate distress, and realize their aspirations and values.

2. In providing societal resources, the dignity and individuality of people should be respected (1973, p. 39).

In addition to these primary values, they discuss the importance to social work practice of such instrumental values as client selfdetermination, confidentiality, acceptance of the client, empathy on the part of the worker, and democratic decision-making. 
Pincus and Minahan emphasize that to be effective, social workers must possess a broad range of knowledge and skills sufficient to: (1) intervene successfully with a variety of social systems in a holistic fashion, (2) organize action systems to carry out planned interventions, and (3) carry out a planned change process. Clearly, the worker must possess a broad base of knowledge covering the fields of social planning, sociology, psychology, anthropology, political science, economics, and his range of skills must be equally broad.

The authors make this point eloquently, while describing the skills and knowledge of a particular social worker who works in an instution for mentally retarded adults:

What makes her competent to perform these activities? What knowledge and skill does she bring to her work? I suggest she has the base or constellation of knowledge, attitudes and skills required by all social workers. She knows about the tasks that confront all people in living their daily life from birth to death and the special tasks that confront people who are connected to a social problem such as mental retardation. She knows the type of resources people need. She knows how societal resource systems function. She knows about the factors that have an impact on relationships and linkages between people within a system, such as a family or between people within a system, such as a family or an organization. She knows what will effect the realtionships between one system and another. She knows how public social policy is developed. She has a framework or models or "mind holds" that helps her to see a social situation whole and skills in communication, in forming and maintaining a variety of purposeful, professional relationships, in conducting interviews, providing support, conducting group meetings, providing feedback and in gathering and analyzing data. And sha has the knowledge and skill related to the planned change process-how to do a situational assessment, make initial contact, negotiate a contract, form an action system, exercise influence, and terminate with someone. She knows about forces such as motivations and resistances that operate to impede or bring about change. She knows how to clarify her purpose and relationships with all the people she will be working with (Minahan, 1976, p. 63-4). 
Pincus and Minahan strongly advocate that social workers use the methods of scientific research to evaluate and improve their practice. They believe that the goals and objectives of a planned change effort should be specifically spelled out so as to enable social workers and other researchers to measure the effectiveness of intervention. They believe it is important for social workers as well as for others to conduct research for the purpose of testing the effectiveness of their intervention and for developing a body of theory which will aid in improving practice. Thus, Pincus and Minahan stress the need for evaluation of practice and the need for empirical research to develop a theoretical basis for practice.

Pincus and Minahan provide the following definition for the client or client system:

People who sanction or ask for the change agents aid, who are the expected beneficiaries of service, and who have a working agreement or contract with the change agent. (Pincus and Minahan, 1973, p. 63)

Clients or client systems as they are referred to include not only people seeking aid on an individual basis, but also groups of people who are experiencing difficulties and are asking for aid, organizations seeking to improve their functioning, and communities facing social problems and requesting aid from social workers.

The people composing client systems are not a priori viewed as deficient or in need of change. In fact, unless there is clear evidence to the contrary, clients are presumed to be capable of participating in assessment of the problem, formulation of goals and objectives, negotiation of a contract and joint implementation of interventive strategies. 
The concept of a client "system" helps broaden the focus of the individual social worker's practice. Instead of being confined to the limited interventions that characterize the traditional practice approaches, the social worker is able to utilize as needed a variety of interventions which span the range of practice activities usually associated with casework, group work, and community organization.

According to Pincus and Minahan (1973), to function adequately people need to accomplish certain essential life tasks, e.g. providing for material, emotional, and health needs. In order to accomplish these life tasks certain resources are needed. These resources are obtained through people's transactions with other people and systems in their environment (systems such as family, work place, or community organizations).

Central to Pincus and Minahan's practice is the concept of resource system which they define as follows:

People are dependent on systems for help in obtaining the material, emotional, or spiritual resources and the services and opportunities they need to realize their aspirations and to help them cope with their life tasks. (Pincus and Minahan, 1973 , p. 3)

Thus, in Pincus and Minahan's framework any obstacle which interferes with obtaining or properly utilizing necessary resources and which prevents people from achieving their life tasks constitutes an actual or potential problem. Thus, the nature and scope of problems appropriate for social work intervention are as diverse as the variety of potential obstacles which prevent people from obtaining those resources necessary to accomplish their essential life tasks. 
Pincus and Minahan (1973) elaborate on the nature of problems by specifying seven ways by which resource flow and utilization can be obstructed: (1) Client inability to fully utilize resources. (2) A lack of knowledge about resource systems. (3) A needed resource system may not exist or may not provide appropriate help to people who need it. (4) People may not know a resource system exists or may be hesitant to turn to it for help. (5) The policies of the resource system may hinder resource utilization or access. (6) Several resource systems may be working at cross purposes. (7) One or more resource systems may not be functioning properly because of internal problems that hamper its effectiveness. Any assessment of a problem is incomplete unless it takes all of these potential obstacles into consideration (Pincus and Minahan, 1973). Thus by focusing on the transactions between $\mathrm{clients}$ and the resource systems in their environments, the worker is able to assess the nature of problems clients experience in their lives. In order to remove these obstacles and resolve problems in living the worker has the flexibility to intervene at a variety of levels -- with an individual client, the resource system, or other aspects of the social environment.

In addition to the client system, Pincus and Minahan identify and define three other primary systems involved in the course of generalist practice: the target system, the action system, and the change agent system.

Target systems. The target systems are determined by the clientworker agreed-upon goals and goal-directed interventive strategies. 
Wherever there is a serious obstacle to effective interaction, there is a potential target system. If the client and worker agree to work on changing certain personality characteristics or behaviors of the client, then the client system may become a target system. If a welfare agency's policy is preventing the client from obtaining resources to which the $\mathrm{client}$ is entitled, then that agency may become the target of the client and worker's efforts. Finally, if the worker's own agency (his change agent system) is obstructing client access to resources unnecessarily, it, too, may become a target system.

Action Systems. Intervention on behalf of $c$ lients often requires working with many other people in a concerted effort to influence given target systems. The action system is the change agent and the people he works with, and through, to accomplish his goals and influence the target system. The effectiveness or lack of effectiveness of a workers intervention often depends on how well the worker selects, organizes, and maintains the action system.

Change Agent Systems. Because the social worker usually functions in the context of some sanctioning agency or other organization, the change agent system is an important consideration when planning with clients. The change agent system is made-up of the change agent (often the worker) and the people who are part of his agency or employing organization. The regulations, policies, and sanctions of the change agent system need to be taken into consideration when planning interventive strategies. 
Pincus and Minahan (1973) identify three kinds of relationships that a social worker may utilize in the course of practice: collaboration, (2) bargaining, and (3) conflict.

Although the authors do not explicitly define what they mean by a collaborative relationship, it appears to be one in which the worker and another person are working together as a team. More specifically, in the case of work with clients, the worker encourages open sharing of information on both sides, while receiving the client's feelings and ideas with an attitude of acceptance. Both worker and client explore the possibility of reaching mutually agreed upon outcome goals, and associated interventive tasks.

Collaborative relationships with clients are facilitated by social work values that stress self-determination and democratic decision making. In addition the authors note that people are more willing to follow through on a change effort if they have had input in the process of determining the goals and objectives to be achieved.

The worker attempts to establish collaborative relationships not only with clients but with all parties involved in the change process, including his change agent system, action systems, and/or target systems. He explores the possibility of developing a collaborative relationship so long as it does not subvert his own integrity and/or the client-worker goals that he is working toward. When he and members of a target system are in disagreement over goals or find themselves in positions of conflicting interests, collaboration may no longer be possible, and the worker finds himself in either a bargaining or a conflict relationship with these parties. As Pincus and Minahan state: 
"True collaborative relationships are possible only when there is agreement on the goals between the worker and his target system" (Pincus and Minahan, 1977, p. 85). The authors believe that many social workers are co-opted by the pressures and needs of their agency settings -- even though the needs of their clients may not be compatible with the demands of their agency setting. It is important to know when to be collaborative, when to bargain, and when to engage in a conflict situation on behalf of the client system.

During their initial contacts with clients, social workers are involved in bargaining or negotiating relationships. During this period each party tests out the other to see if they can reach an agreement in their assessment of the problems and agree on client-worker goals and objectives. If agreement is possible, the initial bargaining phase is followed by a collaborating relationship in which both parties stipulate and agree to a (working) contract.

According to Pincus and Minahan (1977, p. 85), the social worker becomes involved in barbaining relationships when the following conditions are present:

(1) There is a perceived difference between on one hand, the shared goals of the change agent (social worker) and client systems, and on the other, those of the target system.

(2) The target system perceives the change goals as not entirely in its self-interest.

(3) The target system believes moderate demands for change will be placed on it.

(4) Conditions are present which force the parties into a bargaining situation where there is at least a possibility for agreement or accommodation. 
Whereas in the case of collaborative relationships the worker's behavior is characterized by honesty, openness, information sharing and acceptance, when bargaining on behalf of his client, he can be expected to use tactics of "persuasion, negotiation, and even confrontation-and, occasionally guile--to enhance his bargaining position" (Pincus and Minahan, 1973, p. 78).

When bargaining breaks down or the conditions of bargaining are no longer present, the social worker finds himself in a conflictual relationship with a target system, which is usually characterized by a struggle for power between worker and target, with both parties making a number of power plays to achieve their ends. As the authors state:

A social worker involved in conflictual relationships on behalf of his client system may not always operate with the expected social work values of openness, mutual trust, and honesty vis a vis the target system. He may use such tactics as protest demonstration, open confrontation, threats and court orders in his efforts to influence the target systems, be it individual, group, community organization, or institution. (Pincus and Minahan, 1977, p. 86)

There are certain important ethical limitations, however. Social workers are prevented from engaging in violence by "constraints that stem from the professional base of social work, from social work values, from the organization that employs the social worker, and from society" (Pincus and Minahan, 1977, p. 86). In other words, social workers are not given sanction by any of these sources for engaging in or supporting violent activity.

At the same time, however, the generalist worker may offer alternative perspectives for viewing the problems the client is experiencing, as well as for the goals and appropriate interventive strategies and activities. In this way the generalist may attempt to influence (bar- 
gain with) the client to adopt a more ethical and/or realistic outlook. Thus, the generalist worker in certain instances may need to confront people with the "reality" of their situations (Pincus and Minahan, 1973).

Utilizing a systems framework, the generalist planned change process is similar to the problem-solving approach to social casework as presented by Helen Harris Periman (1957). Both social worker and client discuss the problem/situation freely and openly. The client is treated non-judgmentally as a person of equal dignity. The nature of the helping process is collaborative, democratic, and problem-solving. Generalist social workers do not prescribe to their clients what to do, rather they share their expertise in terms of their understanding of human behavior and of societal functioning in the form of consultation with their clients. It is up to clients to make their own decisions--client self determination is given extremely high value.

At the same time, however, the generalist worker may offer alternative perspectives for viewing the problems the client is experiencing. He may suggest alternative goals and interventive strategies for the client's consideration. In this way the worker and client engage in a mutually acceptable process of bargaining, negotiating, and attempts to influence one another, in such a way that both are able to agree upon a common set of goals, objectives, and tasks.

Intervention, that is, generalist practice activity follows from assessment and goal formulation. After both $\mathrm{client}$ and worker have assessed the situation, after they have reached agreement as to the goals of the planned change effort and considered the feasibility of various interventions, then they formulate a contract for intervention. 
The contract specifies both the outcome and method goals, including the task assignments agreed to by the worker, client, and others involved in the action system. Generalist interventive plans as developed by client and worker are thus, individualized, situation specific, and often involve a multiple number of interventions on different levels -generalist workers are willing and able to engage in a variety of social work practice activities.

The use of a systems perspective in generalist practice broadens the concept of intervention. The generalist conceptualization of the nature of problems and notion of clients further expand the range of generalist practice activity. Pincus and Minahan (1973) have identified seven potential obstacles which prevent clients from obtaining and/ or utilizing necessary resources -- it follows that, in order to be effective in responding to the total needs of clients, the generalist worker must be able to fulfill the following social work functions: (1) Help people (clients) develop and enhance their own problem solving and coping capacities (abilities to obtain and utilize available resources). (2) Link people to resource systems through information sharing and referral. (3) Facilitate interaction between people (clients and potential clients) and resource systems, e.g., improve the quality of service provided to $\mathrm{clients}$ by a resource system. (4) Facilitate interaction (modifying and building relationships) between people within resource systems. (5) Contribute to the development and modification of social policy, thereby contributing to the creation of new needed resource systems and the availability and enhancement of existing ones. (6) Dispense available resources to clients. 
Pincus and Minahan (1973, 1977) describe the interventive tasks of the generalist social worker in terms of social work functions, practice, tasks, activities, as well as the types of relationships developed while implementing the planned change effort. They do not attempt to provide a systematic presentation of social work roles in their practice model, as do, for instance, Klenk and Ryan (1974) and Fischer (1978). However, in the course of describing the social worker's functions and relationships, and in some of their examples of practice tasks and activities, the authors indirectly describe a number of roles that social workers perform. These roles include the following: therapist, counselor, broker, mediator, advocate, consultant, educator, social planner, organizer, facilitator, and researcher (1973).

Perhaps the most important contribution of the authors to the generalist discussion about social worker roles is found in their examination of the relationship between generalists and specialists. Some generalists such as Klenk and Ryan (1974) suggest that generalists perform only case manager roles which coordinate the activities of a number of specialists to provide the client with a holistic (total) treatment or interventive program. Pincus and Minahan, on the other hand, believe that it is possible for social workers to incorporate the generalist approach into their practice. "Social workers who specialize in a field of practice, or problem area, with population groups, or within a geographic area, or with ethnic or cultural groupings can bring the generalist social work orientation (emphasis added) to these 
areas and add to it specialized knowledge and skill that will help them achieve the aims of practice in those specific situations" (Minahan, 1976, p. 65).

\section{Robert Klenk and Robert Ryan}

Klenk and Ryan in The Practice of Social Work (1974) provide a generalist social work practice model which is similar to that provided by Minahan and Pincus. However, it differs from their model in two ways: 1) Klenk and Ryan provide a somewhat more elaborate and systematic approach to the nature of problems and 2) the authors provide a more detailed cataloging of the many possible objectives of generalist social work interventive activities.

The authors provide a framework for describing human problems (e.g. a client's or potential client's problems) as a three dimensional cube, in which the nature of the problem can be described in terms of the client's position on each of the following dimensions: 1) domains of living, 2.) status of functioning, and 3) obstacles to functioning. (See Figure 1.)

The authors define the first dimension as follows:

Domains of living are the areas of man's basic human needs, which can be infinite in number or contracted to be as few as six; for example, health, education, financial resources, employment, and family and community integrity. (1974, p. 8)

The reader will note the similarity between these "domains of living" and the "life tasks" concept used by Minahan and Pincus.

The second dimension is defined as follows:

Status of functioning is a continuum on which any given individual may be functioning at a different level for each domain of living, ranging from well being at one end through stress, problems, and crises to disability on the other. (1974, p.8) 


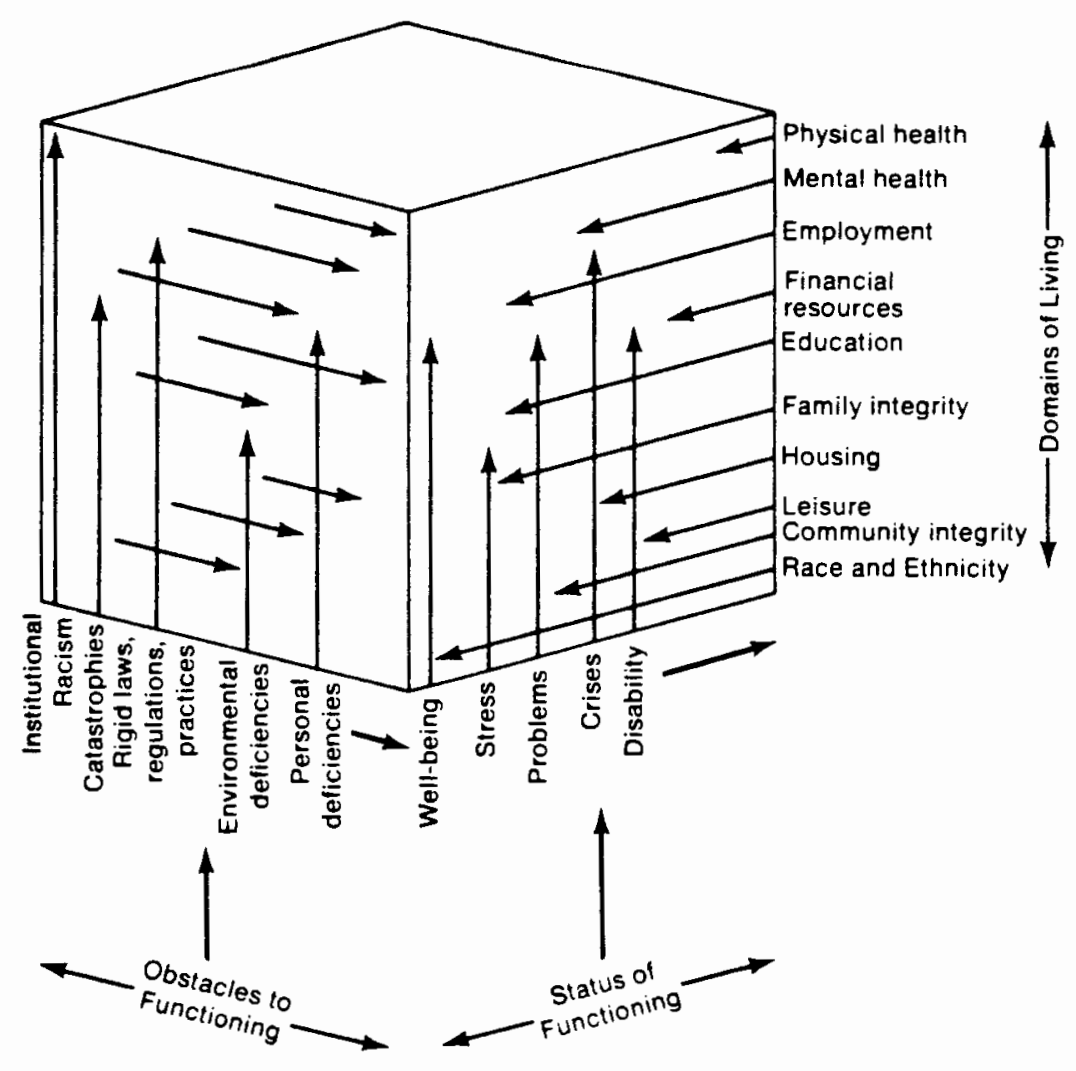

Figure 1. The nature of problems of living.

According to Klenk and Ryan an individual's level of functioning may be different for each domain of living (e.g., his family may be functioning wel1, but he may be out of work).

The concept obstacles to functioning appears to be synonomous with the concept of obstacles used by Minahan and Pincus in their discussion of the nature of the problem. However, in the basic framework of human problem service areas provided by Klenk and Ryan (see Figure 1), obstacles are graded according to the degree of their pervasiveness along a continuum ranging from obstacles due to a single person's disabilities through obstacles which are due to local environmental 
deficiencies, such as family, place of employment, or community, to obstacles which affect great numbers of people and which are environmentally located such as institutional racism. The authors describe this continuum of obstacles as follows:

Obstacles to functioning categorizes these factors in the environment or in the individual that may be impinging upon his or her ability to achieve maximum potential. This continuum extends from individual deficiency at one extreme to natural catastrophe at the other, with such factors as institutional racism, ghettos, poor schools and inadequate housing implied in the terms 'rigid laws and regulations' and 'environmental deficiency.' (1974, p. 8)

The authors claim that their three dimensional framework is useful in at least three ways. First, it facilitates the preventive aspects of the social worker's role by focusing on the different states of client functioning, rather than describing $\mathrm{client}$ behaviors in terms that allude to 1) personal pathology (e.g., mentally ill, schizophrenic, neurotic) or 2) environmental deficiency, (e.g., culturally disadvantaged). It helps focus the worker on the importance of helping ma intain and/or restore client well being in each domain of living. The authors define well being as "a condition in which, by both his own and society's standards, the individual is functioning satisfactorily."

It is the responsibility of social workers "to work to maintain that particular state, i.e., well being... and (to) work to change those social systems that, directly or indirectly, respond to or act upon individuals to produce dysfunctioning" (Klenk and Ryan, 1974, p. 9).

Second, their framework demonstrates that "someone who is dysfunctional in one or more domains of living is not necessarily dysfunction- 
ctional in all domains of living. Part of the social worker's rehabilitative task is to build upon the client's strengths and assets for leverage against the dysfunctional aspects" (KIenk and Ryan, 1974, p. 9).

Third, by providing a more complete description of the different possible states of functioning, i.e., well being, stress, problems, crises, and disability, the authors provide an additional guide for planning interventive activities. For instance, during an initial period of divorce, if a client is experiencing a crisis and is seriously disabled by suicidal thinking, the generalist may need to refer the client to a specialist in the field of psychotherapy.

In sum, the three dimensional framework serves as a basic guide for problem assessment, prioritization of problems, and the development of goal-directed intervention. By knowing the domains to be intervened in and the obstacles to be removed as well as the client strengths, the practitioner has a better idea of the type of action system he needs to develop and the types of specialists he will need to assist in the intervention effort.

Klenk and Ryan agree with Minahan and Pincus that social work practice will be most effective if it is planned and described in terms of its relationship to outcome and method goals. The authors use the term "objectives" in place of the term "method goals" used by Pincus and Minahan. They list twelve different objectives that in their opinion "illustrate the breadth of expectations for the generalist social worker" (p. 10). These are: 1) Detection, 2) Linkage, 3) 
Advocacy, 4) Evaluation, 5) Mobilization, 6) Instruction, 7) Behavior Change, 8) Consultation, 9) Community Planning, 10) Information Processing, 11) Administration, and 12) Continuing Care.

While Klenk and Ryan appear to agree with Pincus and Minahan over the nature of the generalist practice (i.e., the notion of the client, the nature of the problem, the practice process, and interventive activities), they, nevertheless, disagree with Pincus and Minahan in their answers to the following questions: Should all social workers be practicing generalists? Can a social worker practice as a generalist and at the same time specialize in a specific field of social work? In what fields can social workers productively specialize?

In answering these questions Pincus and Minahan (1973 and 1977) assert that the generalist social work practice model should be used as the basis for all social work. At the same time, a social worker can specialize in any given problem area or field of interest (e.g., health, mental health, work with different ethnic groups, etc.). However, the field of specialization must be limited by size of target, e.g., family therapy, or by method, e.g., casework, or by technique, e.g., gestalt therapy.

$\mathrm{Klenk}$ and Ryan differ in their answers to the above questions in several crucial respects. First, in their opinion, not all social workers can or should be generalists. The generalist social worker is himself performing in a specialized role -- a role which is designed to serve the total client (help the client meet his total needs). As such, the generalist worker is much like the doctor who specializes in treating the whole person, i.e., the family doctor or general practitioner. 
The generalist provides case management functions, taking responsibility for insuring that the goals of the planned change effort are met. In doing so, the generalist enlists the aid of various specialists who are selected in terms of the expertise required to successfully attain client-worker goals and objectives. He organizes these specialists into effective treatment or intervention teams, and he coordinates, monitors, and evaluates the work of the action systems.

From this perspective, so long as there is a generalist social worker to represent the total interests of the client, there is no need for all social workers to be generalists. In fact, if the client's needs are to be best served, many social workers must specialize in various fields, which include specialization, not only by problem area, but also by size and type of target system. Skilled caseworkers, group workers, community organizers, and social planners, are all needed who can be called in by generalists to be part of an interventive team working in behalf of clients.

According to Klenk and Ryan, the generalist social worker by virtue of his specialization as a generalist is precluded from specializing in any of the other fields of practice, e.g., he could not specialize in family therapy or community organization. Although the generalist possesses the basic knowledge and skills to be effective in working with individuals, groups, and organizations, he nonetheless, does not possess the expertise of social workers specializing in specific method areas. However, the generalist is skilled in identifying which specialists to entist and in organizing them in a planned effort focused on meeting the total needs of his client. 
Ruth R. Middleman and Gale Goldberg

In their book, Social Service Delivery, A Structural Approach to

Social Work Practice, Middleman and Goldberg (1974) express criticisms of traditional social work practice which are similar to those of the authors discussed above. In particular, they criticize the current forms of practice for their "tendency to define social problems in psychological terms, ... (making) some social workers unwitting parties to the mounting conspiracy against the poor" (1974, p. 25). Operating from this definition, workers have tended to view their clients as being inadequate. Their goals, therefore, have been directed more toward helping their clients adjust to their life circumstances rather than helping them alter their environment in order to accomplish their life tasks and meet their needs.

In order to rectify some of the weaknesses described above, the authors provide "a new microlevel practice model consistent with the emerging social welfare through social change philosophy" (1974, p. 6). This model is designed primarily for the direct service practitioner.

The purpose of the model is to bring about change in the environment so that $\mathrm{clients}$ are better able to meet their needs. As the authors state:

In contrast to other orientations to practice that may aim to help individuals adjust to their situations, to understand their motivations, to gain insight, or to change their ways of thinking and acting, the structureal approach aims to adjust the environment to the needs of individuals (emphas is added) (1974, p. 9).

Although relationships between people and their environment can be improved by 1 ) helping the individual change, 2) helping to change 
(systems in) the environment, or 3 ) by intervening with individuals, people, and systems to change their interactions, i.e., by intervening to change the relationship itself, the authors stress that their model is designed to offset the past neglect of the need for social environmental change. They credit traditional social work with providing adequate knowledge and skills for people-changing and relationshipchanging.

Every instance of social work involves an intervention into the relationship between people and their social environment in order to improve the quality of that relationship. The ultimate target of change may be the people, the social environment, or the relationship itself. The accumulated body of recorded experience in social work includes a variety of conceptual models to guide people-changing and relationship-changing. In the structural model described here, the social environment is the primary target of change. (1974, p. 32)

The authors do not provide an explicit definition of the term client. However, it appears that clients are viewed as being individuals who are experiencing problems in living. Unlike Pincus and Minahan (1973) and Klenk and Ryan (1974), they do not consider groups or organizations as clients.

The perspective adopted by the authors assumes that clients are for the most part capable people and that most problems faced by individuals are not due to their personal inadequacies but to deficiencies in their social environments. The focus is on practice activities which are designed to change social structures.

The practice model suggested here presupposes that large segments of the population - the poor, the aged, the minority groups - are neither the cause nor the appropriate locus for, change efforts aimed at lessening the problems they are facing. (1974, pp. 26-27) 
The social worker intervenes to improve the quality of the relationship between people and the social environment by bringing to bear, changing, or creating social structure. (1974, p. 32).

The author's model consists of the following components: 1) a four quadrant conceptualization of interventive social work activities, 2) four basic principles of social work practice, 3) four basic practice roles, and 4) six basic skills areas and 27 types of behavior useful to the performance of these roles and activities.

The authors begin the presentation of their model by describing all possible social work activities within a four quadrant two by two table, which is built around two dimensions: 1) locus of concern and 2) persons engaged. By locus of concern the authors mean the persons or systems of persons to be helped. By persons engaged they refer to those whom the worker involves in the change process.

Locus of concern constitutes the rationale for social work intervention. The poles on this dimension are: 1) the plight of John G., a specific person suffering in relation to particular facets of various problems (for example, a man cannot get a job because he is a Chicano, and cannot get decent housing because he is poor); and 2) the plight of all John G.'s, a general category of persons identified as sufferers by definition of a social problem (the poor, minority groups).

Persons engaged refers to those people with whom the social worker works at various times in accord with his rationale for intervention. The poles on this dimension are 1) John G. and 2) others. On the one hand, the social worker may engage individuals and/or families and/or community groups in helping themselves and each other to change the particular situations that limit their functioning and exacerbate their suffering. Or the social worker may engage others (neighbors, congressmen, local merchants, other professions such as teachers, lawyers, and/or nurses) in helping as individual, family, or group of clients. (1974, pp. 18, 19)

From these two dimensions the authors construct a two by two table which shows the four possible types of social work practice activities in which one can engage. (See Figure 2.) 
John G.

A

(work with John G. in

his own behalf)

D

(work with others, i.e., nonsufferers in behalf of John G.)

Plight

John $G$.
B

(work with John G. in behalf of himself and others like him)
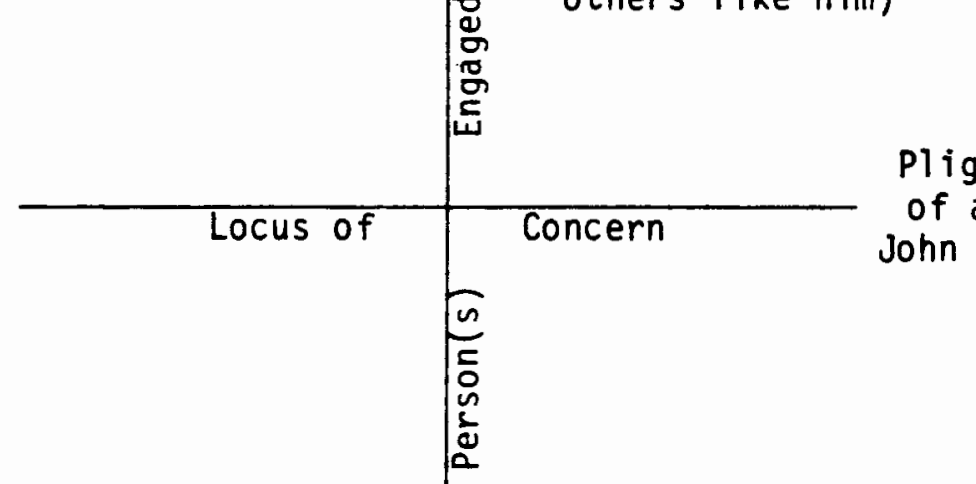

Plight

of all John G.'s

C

(work with others, i.e., nonsufferers in behalf of all John G.'s)

Others

Figure 2. A frame of reference for social work practice. 
1) Quadrant A consists of those activities in which the worker directly engages a specific client, John G., in order to help him meet his needs. That is:

Quadrant $A$ designates all activity in which the social worker directly engages John $G$. out of concern with his particular plight.

A-type activity also includes work with families on problems various members are having with each other, and work with individuals who are having problems with themselves. (1974, pp. 20-21)

2) Quadrant B consists of those activities in which the worker engages

clients in order to aid all similarly affected clients.

Quadrant B designates all activity in which the social worker directly engages John $G$. (a specific sufferer) out of concern with the plight of all John G.'s (a category of sufferers). Typical activities include working with some tenants (specific sufferers) to press for home improvements for all tenents (a category of sufferers), and working with a committee of senior citizens to plan programs for a larger senior citizen population. In other words, the typical Quadrant B activity involves direct engagement of one or a few specific people for the benefit of themselves and others like them. (1974, p. 21)

3) Quadrant $C$ includes all activity in which the worker engages people other than his clients or supposed beneficiaries to work on social problems .

Quadrant $C$ designates all activity in which the social worker directly engages others (nonsufferers) out of concern with all John G.'s (a category of sufferers). Examples include research, social policy development and analys is, social planning, fund raising, lobbying, and organizing scattered pregrammatic efforts to manage or alleviate a particular social problem into coordinated units for comprehensive social service delivery. (1974, p. 21)

4) Quadrant $D$ includes all activity of the worker on behalf of a specific client in which be engages others (non clients) in an effort to help an individual client. 
Quadrant $D$ designates all activity in whcih the social worker directiy engages others (nonsufferers) out of concern with the plight of John G. (a specific sufferer). (1974, p. 22)

(Type D activities) include supervision, consultation, staff training and development, and administration, (1974, p. 23)

The authors remark that social workers have tended to provide either direct services in the form of A-type activities, or social planning in the form of C-type activities. Often direct service practitioners have failed to combine their A-type activities with B- and Dtype activities; and social planners have failed to combine their $C$ type activities with B- and D-type activities. This form of specialization has resulted in fragmented services, poor outreach and a generally ineffective modality for aiding clients. They point out that to be effective social workers need to engage in all four types of practice activities as clients' situations warrant.

The authors provide four practice principles to guide the activities of the social worker. These are the following:

1. The worker should be accountable to the client(s).

2. The worker should follow the demands of the client task.

3. The worker should maximize the potential supports in the client's environment.

4. The worker should proceed from assumption of least contest. (1974, p. 32)

The principle of accountability to the client requires that the social worker negotiate a service contract in an open manner without having any hidden agendas (i.e., any hidden goals and objectives). The client defines the pressures and problems he is experiencing, and these shape the tasks to be performed in that these tasks must be designed to alleviate those pressures or solve those problems. 
The client, with the help of the worker, describes the pressures on him (job discrimination, peer housing), and those pressures, in turn, define the task to be accomplished, what must be done to alleviate the pressures which the client describes. (1974, p. 33)

In sum, the principle of accountability to the client translates the basic assumption of 'adequate man' into action through the structural mechanism, the service contract, comprised by the task which is defined by the pressures on the client and the part the worker will plan in helping to accomplish that task. (1974, p. 35)

The principle of following the demands of the client task requires that the worker in keeping with his professional ethics and resources perform practice tasks that will most effectively meet the needs of his client. Furthermore, it requires that the worker continually look beyond the needs of his particular client(s) to determine whether or not there are others, i.e., potential clients, in a similar plight. If there are, it requires the worker to consider providing or facilitating the provision of services on their behalf as well.

Often this principle requires the worker to engage in all four types of activities, moving from quadrant to quadrant. For example, if a worker is trying to help a client, e.g., a family, obtain housing (Type A activity), he might contact a low income housing authority and inquire as to the possibility of his client's obtaining housing (D-type activity). If the housing authority informed him that there were many other families in need of housing who could not be served due to lack of funding, he might then contact a social planner and/or lobbyist in order to influence the state legislature to more fully fund the housing program (C-type activity). Finally, if the legislature was responsive, he might organize families needing housing into a consumers' interest 
group capable of pressuring the legislature into providing the necessary funds (B-type activity).

The principle of maximizing potential supports in the client's environment requires that as much as possible the worker should create or modify social structures in his environment which will help the client solve his/her problems and meet his/her needs. According to the authors,

This principle embodies the essential thrust of the structural approach to social work practice... The principle of maximizing potential supports in the client's environment tells the worker not to occupy the central position in the helping process. Rather, the worker is directed to change and create structures to reduce the pressures on his clients - to meet social need through social change. (1974, pp. 42, 43)

Finally, the principle of least contest "directs the worker to exert the least pressure necessary to accomplish the client task" (1974, p. 50). The authors point out that once the worker attempts to force to change target systems, he precludes the use of less forceful methods to achieve his ends. Thus, they claim that the worker will achieve greatest success in changing a target system if he uses as little pressure as necessary to make the required changes.

...since low-pressure interventions tend to evoke minimum resistance on the part of the target system, low-pressure interventions are more likely to result in sucessful task accomplishment. Moreover, when low-pressure interventions are not successful, greater pressure can then be exerted... the initial use of forceful intervention behaviors precludes the use of less forceful behaviors. (1974, pp. 50-51)

This principle has implications for both the type of practice activity a social worker should engage in and the nature of relationships he should develop at any given time. 
Roles. The authors (1974) identify four different roles that characterize the activities of social workers engaging in direct service practice: 1) conferee, 2) broker, 3) mediator, and 4) advocate. According to the principle of least contest the worker should perform those roles which are least threatening to the target system while still being effective enough to accomplish the client and/or social tasks.

The worker should take the role of broker prior to the role of mediator, and the role of mediator prior to the role of advocate, for brokerage is less threatening than mediation, and mediation is less threatening than advocacy... The principle of ieast contest, then, directs the worker to rank his interventions along a power dimension, and to use less powerful interventions prior to using more powerful interventions...

Conclusion. The structural approach to social work practice formulated by Middleman and Goldberg is in basic agreement with the practice models of Pincus and Minahan and $\mathrm{Klenk}$ and Ryan. It differs from the latter, however, by restricting its focus to those problems which are caused by and which require changing the environment. Consequently, this model has been criticized for continuing the age-old dichotomy in social work thinking between person and environment. In contrast, the first two models have been described as providing a more holistic and integrated approach to social work -- an approach that focuses on changing the patterns of interaction between individuals and social systems by working with both the individuals and the systems to create these changes. In other words, whereas Pincus and Minahan and Klenk and Ryan view the social worker as a boundary worker, Middleman and Goldberg view him as a social change agent or social reformer -- a repairer or creator of needed social structures. 
Carol H. Meyer

Carol Meyer $(1973,1976,1979)$ provides a systematic and comprehensive model for generalist social work practice which closely resembles that of Pincus and Minahan (1973). She appears to be one of the major theorists of the generalist school. Her model will not be discribed in detail, since it is identical for all practical purposes with that of Pincus and Minahan. She agrees with those authors that in order to be effective all social workers should adopt a basic generalist practice, utilizing an eco/systemic perspective. From this foundation they can then specialize in various fields. She disagrees with Pincus and Minahan when she states that there is a place for social workers who, though they practice as generalists, at the same time specialize in method areas (e.g., casework with individuals, family counseling, community organization, etc.).

Carol Meyer adds two important areas of consideration to the work of Pincus and Minahan and Klenk and Ryan. First, she proposes that social work services be progressively transferred from the social caseworker to social work teams. These teams would utilize various sources of social work manpower, including paraprofessionals and experts from a variety of disciplines, such as nurses and doctors, teachers, recreation workers, etc. The composition of these teams would depend upon the nature of $\mathrm{client}$ needs. When Meyer discusses social work, she is not considering only what has been until now the predominant form of social work, social casework, nor is she proposing of social casework, work which has been enlightened by generalist principles. She is proposing that social work services be delivered by social work teams which are 
guided by generalist principles. This team concept is a significant advance over either generalist thinking about systems of manpower utilization and service delivery. Although Pincus and Minahan discuss the importance of creating action systems to help $c l i e n t s$, they continue to base their direct service practice model on the social casework approach in which the social worker contacts and develops a service contract with the client on an systems individual basis. Meyer goes a step further in suggesting that in certain cases it may be more effective for a social work team to make initial contact, engage the client in problem assessment and contract negotiation, and finally follow through with intervention activities in cooperation with the client.

Carol Meyer is not only looking at the various roles social workers can play, but the various ways these roles can be combined to form effective social work teams for solving human problems. Thus various specialists who are generalist in orientation may work together in teams to provide aid for clients or client groups. This team concept appears to be progressively more accepted as a basis for developing more effective outreach and total service for clients.

Second, Carol Meyer argues that social workers should be located at points where they would naturally be more accessible to potential clients as well as all other citizens. Thus people can receive casework services in convenient locations without experiencing stigma as they go about their usual business. Such contact points include social security offices, shopping malls, schools, health departments, banks, etc. In this way social workers might be expected to greatly improve the availability of services to the poor or minority populations, or 
other potential groups of people who are experiencing problems of living but not presently receiving any social services.

Alex Gitterman and Carel B. Germain

Gitterman and Germain (1976) in their article, "Social Work Practice: a Life Model," discuss direct social work practice from an ecological perspective. The major components of their model have been included in the prior discussion of the works of Pincus and Minahan and Klenk and Ryan. Therefore, we will not describe their model in detail.

Like the previous authors we have discussed, Germain and Gitterman are concerned about the fragmented and ineffective state of traditional social work practice, which has been primarily based on a medical disease metaphor. The authors comment:

Practice has tried to consider the mutual impact of man and milieu in understanding need, yet mutuality has often been obscured by either environmental or psychic determinism... Most often, however, a treatment emphas is on the person has been uppermost while the situation has been viewed as a fixed setting. (1976, p. 31)

In order to improve the quality of social work, Germain and Gitterman (1976, p. 3) propose a Life Model based on an ecological metaphor which focuses on the need for mutual adjustment between the individual and his environment.

...the worker is concerned both with the coping qualities of the person and the qualities of the impinging dyadic, familial, group, organizational, and physical environments. Professional action is directed to matching coping patterns and environmental qualities in such a way that coping capacities are enhanced and the environment is meliorated. Professional outcomes are measured in terms of what is good for both the person and the environment.

The authors combine this perspective with the concepts of life tasks and problems in living, terms borrowed from the field of ego psychology, 
and which also have been used by Pincus and Minahan and $K l$ enk and Ryan.

The authors define the purpose of social work as follows:

to strengthen coping patterns of people and to improve environments so that a better match can be attained between people's adaptive needs and ptoential and the qualities of their impinging environments. Professional action is directed toward helping people and their environments overcome obstacles that inhibit the development of adaptive capacities. (1976, p. 602)

Proceeding from an ecological perspective, the authors expand on the nature of the problem, which is viewed as consisting of the problems of living facing people. These are grouped in the following categories:

1. problems and needs associated with tasks involved in life transitions (developmental changes, status role changes, and crisis situations);

2. problems and needs associated with tasks in using the influencing elements of the environmental (institutions, organizations, and social network); and

3. problems and needs associated with interpersonal obstacles which impede the work of a family or group as it deals with traditional and/or environmental tasks. (1976, pp. 602, 603)

The authors advise a practice process based on the problem-solving casework techniques of Helen Perlman. This process is similar to that discussed by Pincus and Minahan, and Klenk and Ryan.

Gitterman and Germa in conceive the social worker as a boundary worker. They stress the necessity of improving dysfunctional transactions between clients (people) and their environments in each of these three areas of problems in living. Interventions include 1) working with clients to help them overcome their personal deficiencies, 2) 
working with systems in the environment to make them more responsive to client needs, and 3) working with both clients and other systems members to help alter the patterns of interaction taking place between these people. Each of these types of intervention requires special activities, knowledge, and skill on the part of the practitioner.

The Life Model is an improvemenc over the more traditional medicaldisease practice models; yet it appears to be more oriented toward individual $\mathrm{client}$ treatment and adjustment than the other models examined thus far. By focusing on client adjustment the model appears somewhat more vulnerable to being misused by those practitioners who are more comfortable operating out of the medical-disease treatment approach to practice. Nonetheless, the Life Model makes a valuable contribution to the generalist literature. In particular, it provides a perspective for understanding and categorizing problems of living and provides an integrated basis for assessing the types of interventive and practice activity to be engaged in.

\section{Joel Fischer}

In his book, Effective Casework Practice, An Eclectic Approach, Joel Fischer (1978) makes a major contribution to the field of social work. Fischer's practice model is similar to the generalist approaches discussed thus far. Unlike the others, however, he limits his focus to social casework.

The eclectic caseworker serves either individual clients or client groups such as families. He chooses from a wide variety of 
intervention techniques and procedures, selecting those practice activities which will be most appropriate and effective. He intervenes not only by attempting to change the client's behavior, but also by making changes in some of the surrounding social systems which interact with the client. Fischer's description of casework practice differs from other generalist practice formulations in two crucial respects. First, the client system is limited in size (i.e., the client is either an individual, a family, or a small group being served by a caseworker). Second, the level of intervention is limited to micro and mezzo systems. According to Fischer, social casework is "simply one arm of the social work profession -- the arm that concentrates on the provision of individualized services. In other words, casework is a professional, rather than theoretical or methodological designation" (Fischer, p. 10). Caseworkers differ from other social workers in that they serve individual clients.

The major distinction between the functions of caseworkers and other more broadly based professional functions... is that caseworkers, when they are working as caseworkers, concentrate their resources on either the individual or environmental factors immediately affecting the individual. (Fischer, p. 13)

While not all social workers are caseworkers, all caseworkers are social workers, and every caseworker has social worker responsibilities which extend beyond their roles as caseworker, such as promoting social change on community and societal levels through such activities as resource development, advocacy in behalf of disadvantaged populations, mobilization, lobbying, social planning, etc. 
In the 1960's casework was challenged as a major method of service delivery. Attempts were made to make more pervasive social changes in society in order to benefit the disadvantaged. Fischer comments:

An even more serious threat to the [casework] field was in the programs and policies of the 'Great Society' and the 'War on Poverty,' which, in both the popular press and professional journals, tended to minimize the importance of individualized services as compared with the promise of sweeping changes for all society's disadvantaged. (p. 1)

However, in the 1970's the country turned more conservative, and the attempts of the sixties to promote social change were found wanting. Social casework was reinstated as the predominant method of providing services. As Fischer states:

In recent times, the years of the 1970 's, there has been a reassessment of the potential for such sweeping societal change based, among other things, on such factors as conservative national administrations and the realistic appraisal that the grand premises of the 1960's either may not be possible or may require far different or even more comprehensive strategies for social change. Thus to some observers, the 1970's seemed to usher in, as noted in a lead editorial in the journal Social Work, a strong affirmative commitment to the need for and potential value of direct practice in social work. (p. 2)

Given these trends then, Fischer claims that it is imperative to develop a model for casework practice which will be effective and efficient in helping clients within the realistic constraints imposed by the conservative social service allocation policies at all levels of government. Fischer states:

The major thesis of this book is that caseworkers must constantly strive to improve their services and to enhance the effectiveness of their practice. (1978, p. 5)

Fischer $(1973,1978)$ makes several serious criticisms of traditional casework. First and foremost, research to date indicates that 
traditional casework practice is not helping clients and may even be detrimental. Second, social casework practice has been unable to engage and help lower income groups. Third, specific knowledge about changing the surrounding environment has not been developed. Fourth, casework goals are too often focused on client self-insight instead of behavioral change. Fifth, casework goals and objectives are too often vague and general and consequently make it difficult to accurately evaluate casework practice. Sixth, clients are too often not involved in the change process (i.e., the formulation of change goals).

The rational for an eclectic base for casework is to make casework more effective in helping clients. As Fischer states:

Essentially, eclecticism refers to a commitment to being guided in practice by what is most effective for our clients. This commitment takes precedence over devotion to any theory or theoretical orientation. (p. 68)

Since research to date has failed to provide support for any single body of theory but has indicated that certain interventive procedures and techniques are effective in producing desired outcomes, eclectic casework adopts those procedures and techniques, regardless of their theory of origin, which have been found to be effective. Fischer (1978, p. 67) comments:

An eclectic approach to casework practice, then, would consist of a variety of interventive principles and procedures, derived from different systems of induced change, including even those that may appear to be incompatible on the surface, in large part on the basis of their demonstrated effectiveness, and applied with people and problems where the evidence indicates that such application has a substantial chance to produce successful outcome. Such an outcome-oriented approach would be empirically based, grounded in the development and use of interventive techniques that are developed and/or adapted through a process of rigorous and systematic testing, implementation, and retesting. 
Fischer believes that in order to be effective, caseworkers must possess a broad and flexible knowledge base and a wide range of procedures which are grounded on the findings of empirical research. Fischer (1978) divides the knowledge of caseworkers into two parts: 1) causal/developmental knowledge and 2) intervention knowledge. Causal/ developmental knowledge "serves as an aid in understanding the development of behavior (both adaptive and maladaptive), [while] intervention knowledge, on the other hand, is intended to be used to prescribe principles and procedures for inducing change in behaviors and/or situations" (Fischer, 1978, p. 52).

Fischer points out that contrary to past belief one does not always need to know how a maladaptive state of affairs came about in order to change it. Causal/developmental knowledge is useful only in so far as it contributes to improved interventive knowledge (improved intervention). Thus far, as fischer points out, the contribution made by causal knowledge has been rather meager. For the most part, according to Fischer, neither causal/developmental nor interventive theories have been confirmed in their entirety by the current body of research. The most we can say at this time is that certain procedures and techniques appear to be useful in making desired interventions.

Fischer limits the size of the client system to the individual or small group. Within this limitation his description of the client is in close agreement with that of the other authors discussed in this chapter. Clients are viewed as people experiencing problems in living. They may or may not be the targets for change, but they are intended to be the beneficiaries of any change actions. Fischer is an advocate for 
increased client involvement in problem assessment and goal formulation. Caseworkers should give more weight to clients' perceptions of their problems during the assessment phases of the practice process and during the formulation of client-worker goals and objectives. Like Pincus and Minahan, et al. Fischer is concerned about reaching a large population of "potential clients" who are currently not receiving services to which they are entitled.

Fischer's conceptualization of client problems is basically the same as that of those generalists discussed thus far. That is, matters requiring casework aid are various problems of living faced by people as they attempt to fulfill their life tasks. These problems may require intervention at the individual, group, or organizational level for their solution. They may even require intervention beyond the scope of casewrok -- that is, intervention designed to change the broader community or societal systems. Fischer comments:

The problem of an individual, then, can be perceived in terms ranging from the individual failing, or being unable, to carry out certain behaviors or roles, to problems in the structure or performance of proximal or broader community or social systems. In fact, these problems span the range of situations with which social work, as a profession, is concerned. (1978, p. 16)

Fischer used the term social adjustment to describe the fit between the individual and his environment (the social systems in his environment). He does not use it in the sense of its more traditional meaning, but defines the term social adjustment as follows:

Social adjustment, a term with many popular variants such as 'adaptation' and 'coping,' refers merely to the ability of a person to deal with the serious conflicts and problems of life, the situations that may be conceived as social tasks, life situations, or problems of living. These are experienced primarily as pressures from their social environment. (1978,

p. 77) 
Fischer views client problems and social maladjustment in terms of the client's inability to perform certain important behaviors. This focus on behavior makes it easy for caseworkers to evaluate the effectiveness of their interventions. According to Fischer (1978, p. 79) "the behavioral manifestation of social adjustment is social functioning;" thus it follows that "if problems in social adjustment -- or social functioning -- arise, they are most likely to be problems in the performance of certain behaviors."

The purpose of casework is the same as that of social work as a whole -. "[the] prevention of problems in social functioning; remediation of problems in social functioning that have already occurred or facilitation of adaptive functioning; and the development of resources to enhance social functioning" (1978, p. 76). The effectiveness of casework intervention can be measured in terms of the increased ability of the client to perform certain behaviors associated with adequate social adjustment or social functioning. Thus, the goals and objectives of casework can be operationalized in terms of specific changes in client behaviors and behaviors or actions in surrounding social systems. The eclectic caseworker does not engage in practice haphazardly-rather, a systematic, planned change process is integral to Fischer's model for eclectic casework practice. The eclectic caseworker attempts to make a sensitive and accurate assessment of the individual case/ situation and engages the client's participation in defining the goals of intervention, as well as for selecting those interventive procedures which are most appropriate to the client's needs. As Fischer (1978, p. 28) comments: 
Another major implication of the provision of the variety of services described here is that it calls for social caseworkers to be truly able to apply differential diagnosis and treatment, that is, make a careful detailed assessment of each case/situation as a basis for role and technique selection. (p. 26)

According to Fischer, the eclectic caseworker provides a high degree of accountability to both his clients and his sanctioning agency in the following ways. First, he guides his practice by the client's needs without restricting it to a single theoretical approach. Second, he intervenes wherever necessary either with the client himself, or the surrounding social systems. Third, he specifies and operationalizes the client-worker goals and objectives into specific behavior change components, making it possible for any one to determine whether or not any given intervention on his and/or the client's part is successful. Fourth, he continually evaluates his procedures, engages in research, and is familiar with the body of research about various possible techniques and procedures which might be applicable to his practice. And fifth, he selects techniques and procedures to be used on the bas is of their effectiveness. Fischer sums up the eclectic approach to casework practice as follows:

The essence of eclectic practice involves technical flexibility; selecting interventive procedures on the basis of the specific client/problem/situation configuration and, to the extent possible, on the basis of evidence of effectiveness. This is a highly prescriptive approach to casework practice, individually tailored to client needs with a client-specific prescription for dealing with the problems of each client. But above all, perhaps, eclecticism involves a way of thinking about practice; systematic, data based, cognizant of alternative approaches to dealing with problems and the literature and research on those alternatives, oriented to technical flexibility and to specific and often idiosyncratic client concerns, and all this grounded to humanistic values and the philosophy, traditions, and breadth of vision of social work. (p. 237) 
In addition to using techniques of proven effectiveness, caseworkers must be able to intervene with a variety of social systems. Since the purpose of casework is to help improve client functioning, and since the life problems which hinder client functioning are found in many different areas, including individual, small group, family, and community, it follows that in order to be effective, caseworkers must be able to intervene at different levels of interaction. Fischer identifies three different areas of intervention: 1) microsystems, 2) mezzosystems, and 3) macrosystems.

Microsystems consist of problems where the focus of intervention would most logically deal directly with an individual or small group experiencing a problem or those immediately surrounding them.

Mezzosystem problems are those in which the determining force, and hence the locus of intervention, involves not only small human systems (e.g., individuals, families) but social systems such as single institutions and communities.

Macrosystem problems extend beyond the above entities and occur on the broadest level of social organization including large geographically scattered populations. (p. 16)

Fischer points out that the boundaries between these systems overlap and are often blurred. Systems on one level interact with or have important effects upon systems at other levels. Caseworkers intervene only in the first two of these areas. When they engage in broadly based social action, they are not functioning as caseworkers per se. They are functioning as social workers and have a professional responsibility to do so. Fischer comments:

When caseworkers attempt to change social policy, or a particular social institution, on behalf of a broadly based clientele, they are not functioning as caseworkers. They are social workers, engaging in a social work activity -- an appropriate, crucial activity. (p. 16) 
Fischer does not discuss how the experience of a caseworker could be translated into broader social action since it is beyond the scope of his focus on eclectic casework.

Fischer points out that since problems of living occur in various forms and on various system levels, in order to be effective the caseworker must be able to provide various functions (i.e., the functions listed by Pincus and Minahan) and intervene on various levels. This requires that the caseworker be able to perform more than one role, depending on the needs of the client and his situation. Fischer groups the roles performed by eclectic caseworkers into four major clusters: 1) clinical/behavior change role, 2) consultant/educator role, 3) broker/advocate role, and 4) researcher/evaluator role. Fischer describes these role clusters as follows:

Clinical/behavior change role: The first major role of caseworkers is the $\mathrm{clinical/behavior} \mathrm{change} \mathrm{role.} \mathrm{In} \mathrm{it} \mathrm{the} \mathrm{worker}$ attends directly to problems in functioning of families and individuals, attempting to apply any number of individually oriented change strategies. The worker's strategy may involve behavior change, provision of advice, crisis intervention counseling, or therapy. (p. 17)

Consultant/educator role: In this role the caseworker may function to provide information, interpret rules or regulations, teach and transmit knowledge, and so on. The services included in this role may be provided to other professionals (e.g., caseworkers), non-professional workers, or people identified as clients. Thus the caseworker may teach parents principles of childrearing, help colleagues with problems in their own practice, provide training to indigenous non-professionals, interpret certain laws or policy regulations to clients. (p. 19)

Broker/advocate role: The broker/advocate role, then, encompasses a wide range of functions and services, all of which are centered around the notion that it is a primary responsibility of the caseworker to try to enhance the coordination of persons with institutions to see that there is a constructive articulation between society and society's members... The functions performed by the caseworker as broker/advocate are both 
comprehensive and diverse; providing concrete and/or material aid; providing referrals (and following up to see that they are made available and utilized); locating resources; mediating or negotiating between a client and a specific system; detection and problem identification; identification of the need for services or changes in policy in specific agencies or institutions; aggressive representation of client rights, fighting to help clients obtain specific services or resources where they otherwise might be rejected. (p. 22)

Researcher/evaluator role: This focus on research and evaluation as integral to practice suggests the addition of a fourth role to the role clusters basic to functioning as a social caseworker...this is the role of researcher/evaluator, a role which the caseworker can and should perform in relation to his or her activities in any of the other three roles. (p. 47)

The first three role clusters include roles performed by caseworkers when they intervene in behalf of their clients. The last role cluster includes those roles performed by caseworkers when they are in the process of developing, discovering, researching and evaluating new procedures and techniques that might be used to further aid clients through the casework process. The first three role clusters can be ordered in terms of the size of their respective areas of intervention. This order is as follows: 1) clinical/behavior change role (used in intervention in microsystems), 2) consultant/educator (micro and proximal systems in mezzo systems), 3) broker/advocate (micro systems and mezzo systems including not only proximal systems but broader community based systems as well). For a schema which depicts social work roles and casework roles, including the three role clusters and their relationship to levels of intervention, see Figure 3 .

The model proposed by Joel Fischer closely resembles the generalist practice models proposed by Pincus and Minahan, Klenk and Ryan, et a1. More than the other authors, Fischer provides a comprehensive 


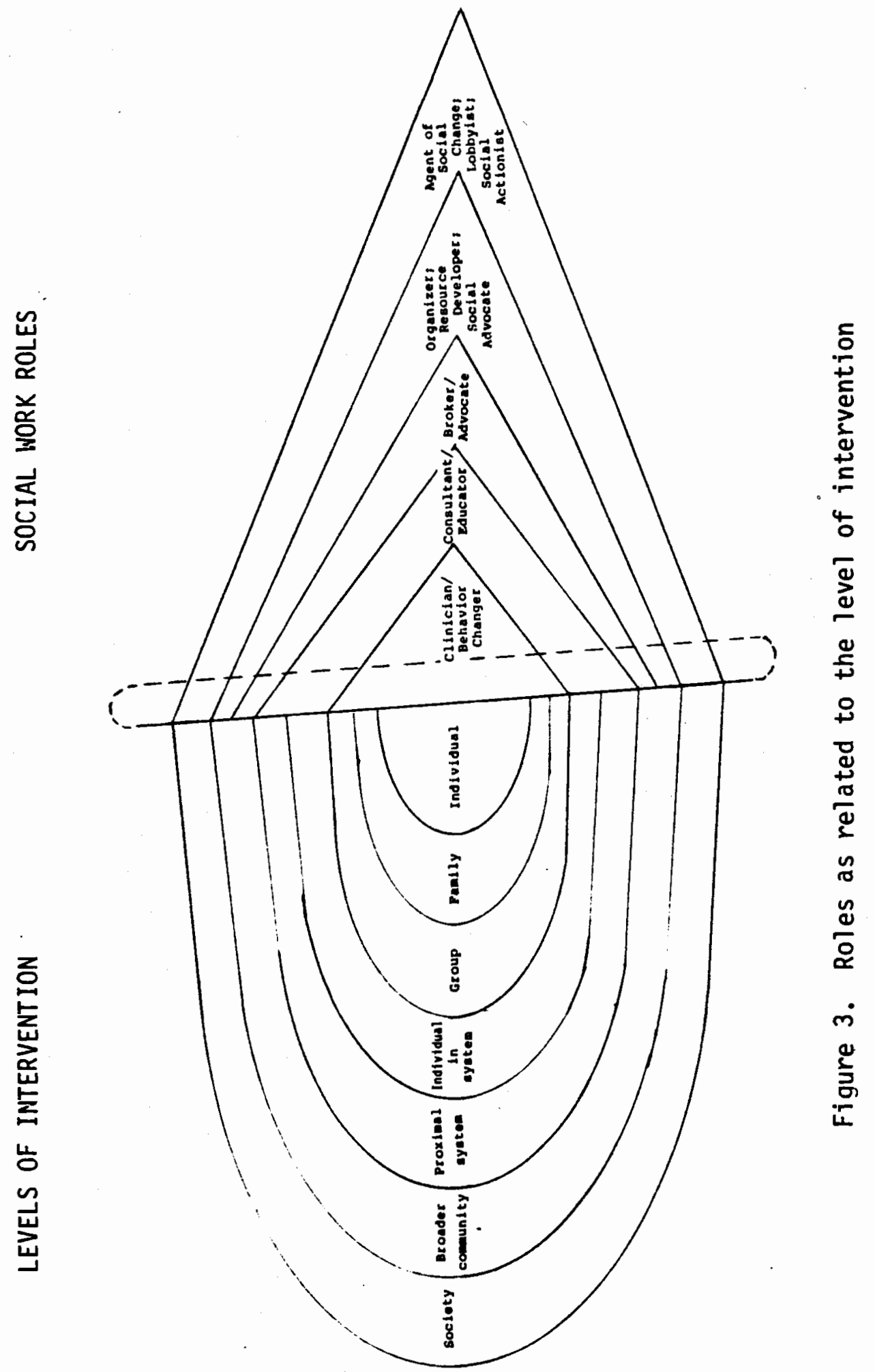


listing of empirically sound procedures and techniques which can be used to effectively help clients in terms of 1) the planned change process and 2) the various practice interventions. Furthermore, Fischer cites the studies which support these techniques and procedures.

Fischer has also provided a more systematic organization of interventive roles, relating them to the various areas of intervention: micro, mezzo, and macro systems. It may appear at first that he has overly restricted the types of intervention available to people in casework positions by excluding from their repertoire interventions directed toward social change. However, he makes it clear that caseworkers who see a need for such social action have a responsibility to engage in it, not in their role per se as caseworkers but as social workers. In sum, it appears that the eclectic social casework approach advocated by Fischer is quite similar to the generalist approaches discussed thus far. Fischer appears to require more rigorous examination of the effectiveness of social work principles and methods of intervention than the other authors. And he offers an interesting way of viewing the various casework roles available that can and, as the occasion warrants, should be practiced by social workers providing direct services.

Conclusion

As this review of generalist literature indicates, there is substantial agreement among the authors cited. At the same time they differ from one another in certain respects, with each making a valuable contribution to generalist thought. All are dissatisfied with traditional social work practice models which they view as 1) contributing to 
the fragmention of the field of social work, 2) blaming the victim, 3) providing inadequate means of helping $c l i e n t s$ and potential clients change their social environment, and 4) providing basically ineffective services to clients.

Their practice models are similar in the following respects. All of them incorporate the value premises found in social work today. They share a common conception of the mission of social work: to enhance social functioning. The concept of client is expanded to include, not only individuals, but families, groups, and organizations as well. $\mathrm{Clients}$ are intended to be the beneficiaries of the social worker's actions. Problems facing clients are viewed as the results of faulty patterns of interaction between the client system and surrounding resource systems. Thus, problems are not viewed as residing in the client alone. Intervention on behalf of client systems is designed to change these faulty interaction patterns in order to provide the client system with necessary resources to achieve its goals and fulfill its life tasks. Depending on the situation, it may be necessary for the social worker to help the client system change either itself or the surrounding social systems. Consequently, the generalist worker must be able to perform a broad range of interventive roles, capable of influencing a variety of social systems of different sizes. The selection, organization, and performance of these roles demand that the worker have a broad knowledge base supported by the findings of empirical research.

The practice process is characterized as a problem solving, planned change process, in which both worker and client democratically 
negotiate client-worker goals and objectives. These are made as explicit and specific as possible. Workers continually evaluate their work as a means of discovering more effective and efficient principles, procedures, and techniques of practice. Furthermore, they continually familiarize themselves with research findings in the field and participate in research studies in order to make social workers more effective in their practice.

In our opinion each of the authors discussed has made a unique contribution to the development of a generalist practice model. Pincus and Minahan and $\mathrm{Klenk}$ and Ryan provide the most comprehensive and integrated overall approach to social work practice. However, thus far, their models lack detailed prescriptive guidelines for social work practice. Middleman and Goldberg focus on making social workers more effective in changing the social environment of their clients, and they provide valuable prescriptive principles and procedures for social workers engaged in social change, e.g., the principle of least contest. Joel Fischer limits his focus to that part of social work which consists of casework practice. However, given this limitation, he provides what is perhaps the most comprehensive and prescriptively detailed model of all the generalist practice frameworks examined. In addition, he describes a useful way of organizing interventive roles, as well as stressing the importance of a solid research base for practice.

In sum, the generalist social work practice is based on a resource-focused, ecosystemic, holistic, and interactional perspective. It utilizes a broad range of theories, propisitions, procedures, and techniques, which are selected in accordance with eclectic principles 
and the scientific method. It includes a goal-oriented, problem-solving, planned change process with goals and objectives clearly specified. Finally, it includes: 1) a variety of professional roles to be used when intervening with different levels of social organization, 2) a broad repertoire of practice skills, and 3) the performance of a variety of social work practice functions. 
CHAPTER IV

PRESENTATION OF THE MODEL

MODELS AND MODEL BUILDING IN SOCIAL WORK

Seemingly, throughout its history, social work has been a profession in search of itself; continuous as well as considerable effort has been expended -- and invariably with great difficulty, confusion, and controversy -- to define the nature of social work. Nonetheless, as Hearn $(1969$, p. 67) has so succinctly stated, "The social work profession has no greater need than a comprehensive conception of its essential nature." Since the 1950's a significant part of the literature has, in fact, been devoted to attempts to formulate a model of practice "...that (would) serve as a frame of reference and a unifying force in defining what it is that professional social workers do" (Kettner, 1975, p. 629). Without question these efforts at model building have been beneficial, even useful, for the profession; yet there have been significant problems associated with these model building efforts.

Problems Associated with Models of Social Work

Although Hearn, as early as 1959, observed that social work seemed to have reached the point of diminishing returns as far as its efforts at building practice theories, (sic) practice models, since then, nevertheless, there has been a proliferation of conceptual and 
theoretical frameworks and practice models. As the diversity, not to speak of the controversy, surrounding these practice models has grown, increased attention has been devoted to many of the persistent and fundamental problems that have plagued these model building efforts (Bartlett, 1970; Lang, 1972; Meyer, 1973; Nelson, 1975; Kettner, 1975). These problems may be summarized as follows:

1) There has been confusion regarding the very definition and use of models themselves. Similarly, the distinctions and relationship between such terms as theory, model, and conceptual framework has been unclear. As Levy (1978, p. 351) notes, "The problem seems to be that there is no universal understanding of the nature and purpose of a conceptual framework... Moreover, such frameworks are being used in various and inconsistent ways."

2) There has been a lack of uniformity with respect to model building, no uniform or consistent criteria have been used to guide model building efforts (Kettner, 1975). This has made it especially difficult to compare -- and make sense out of -- the wide variety of different practice models because they have not been formulated according to similar criteria or in common conceptual terms (Lang, 1972).

3) All too frequently models for social work practice have been overly bound to the settings or contexts in which, and for which, they were developed. Bartlett (1970) has identified these as "method and skill" models. Practice models of this type have grown up under the auspices of methods and fields of service, and exhibit a tendency to emphasize a partial and separate frame of reference. In many instances, as Levy 
(1978) observes, what have been advanced as conceptual frameworks (or practice models), instead, have been conceptualizations of specific aspects, approaches and preferences regarding social work practice. Method and skill models, thus, have not been "... adequate in themselves to provide a complete professional base" (Bartlett, 1970, p. 51).

These trends have not boded well for the conceptual clarity of social work practice models. The result has been a proliferation of competing theoretical approaches to social work practice -- taken as a whole these model building efforts have been haphazard, piecemeal and fragmented.

Now there are so many bandwagons, or at least 50 many choices about ways of giving help, that chaos more than conformity seems a danger... Models of service proliferate. Is the solution a sort of 'to each his own' philosophy? (Nelson, 1975, p. 264)

4) Meyer (1973, p. 87) has identified yet another, but related, major problem area: "...The very investment in the building, and if you will, the selling of models has tended to lead...to the brink of premature closure." And as well, often existing social work practice models have tended to unduly carry the imprint of the prevailing societal or professional concerns of their time (Lang, 1972). Thus, the utility of most practice models has been limited not only to the extent that they have been overly provincial, but also by the fact that they have been one-dimensional, simplistic, and reductionistic. The tendency for social work academicians as well as practitioners to become overly invested in their own models has been observed by Meyer (1973, p. 89) who criptically states "...we marry our models, we don't just court them." 
Definitions of Models and Theories

Models are utilized in the natural sciences as well as in the social sciences, and not surprisingly, there is a variety of definitions. In this review, however, the focus is on those formulations drawn from the social sciences, and particularly, those drawn from social work. Hearn (1959, p. 10), whose writings have been highly influential in this regard, defined a model as "...a symbolic representation...a pattern of symbols, rules and processes regarded as matching, in part or totality, an existing perceptual complex." The definition used by Bartlett (1970, p. 36) was taken from Webster's dictionary: "...A description, a collection of...data, or analogy used to help visualize often in a simplified way something that cannot be directly observed...(and) a theoretical projection in detail of a possible system of human relationships (as in economics, politics...psychology... (or social work)). Meyer (1973, p. 88), drawing from the work of sociologist, David willer, provides what she terms a utilitarian definition: models are by design metaphors or constructs of reality, and are "...conceptualizations of a group of phenomena, constructed by some means of a rationale, whose ultimate purpose is to furnish the terms and realtions, the propositions of a formal system..."

Although models and theories are interrelated, the terms are by no means synonomous -- neither in a definitional nor functional sense. How, then, is the term, theory, defined and what is the relationship between theory and model?

In the most general sense a theory is a "...formalized, explanatory conceptualization of the relationship of variables" (Fischer, 1973, 
p. 441). Stated more pragmatically and concretely, a theory is a hypothetical formulation that can be tested by observation, and consists of a fundamental definition, a set of assumptions, concepts, postulates and laws about the reality of what the theory attempts to describe (Shafer, 1969, p. 26).

What does this mean in terms of the relationship of theory to model? Simply put, a model is not a theory, and vice versa. A model may be built around a theory -- or drawn from a variety of theories -yet, importantly, a model's theoretical underpinnings are but part of its overal1 makeup. Furthermore, as Briar (1977) notes, the profession of social work, or for that matter, models of social work practice, should not be created to support a particular theoretical framework. Rather, models are a necessary -- conceptually and functionally -- intermediate step between theory and practice; models help to organize processes implied by theories (as well as to structure practice problems in relation to theory (Klein, 1970)) in the service of the purposes and functions of social work practice. Kettner (1975, p. 630) sums this up we11:

The relationship between model and theory as related to social work practice ought, ideally, to run a middle course between extremes. On the one hand, intertwining model and theory into one undifferentiated position or posture can... lead to theory dictating the purpose of practice. On the other hand, a model without theoretical underpinnings reduces practice to mere technical competence.

Functions of Models of Social Work

Not surprisingly, most formulations of models are more than purely descriptive or definitional; models are frequently defined in terms of their functions and purposes for social work practice. Models are put 
to a variety of uses, and as Lathrope (1969, p. 46) observes "...represent a highly general and versatile approach to the extraction verification, accumulation, codification, presentation, transmission and use of knowledge." Within the field of social work models are generally used to explain, integrate or unity what is believed to be known about social work, as well as to serve as guides to practice.

1) Explanation and exposition. Explanation and exposition are basic functions of models. As Levy (1978, p. 357) states a model "...must offer an explanation or a constellation of principles of social work practice in general." Similarly, according to Reid and Epstein (1972), models are basically descriptive and definitional. In this sense models describe what is know about social work practice.

2) Integration and unity. Models have also functioned to integrate and unify social work practice. Models have been part of "...an attempt to acknowledge and deal with problems of complexity and separateness by ordering elements of dissimilar practice... Models have provided ways of looking at practice differences with...wholeness and coherence (Lang, 1972, pp. 260-261). In a similar vein, Merton (1957) analyses what he terms the notational function of models; models provide a compact arrangement of the central concepts and their interrelationships so as to allow their simultaneous inspection and understanding.

Social work is a profession that often has been beset with fragmentation; and, as Bartlett implores, one in which there is an overriding concern for integrative thinking. Models have been invaluable in that they work toward "... (enabling) us to perceive social work practice as a whole" (Bartlett, 1970, p. 81). 
3) Guides to practice. Models also serve as frames of reference or guides for social work practice. In this sense they may be both descriptive and prescriptive: models address the issue of how to practice. For example, Nelson (1975) claims that models should pertain to the question of how to practice most effectively. Similarly, Levy (1978) views models as theoretical guides to professional practice. Reid and Epstein (1972) define models, in part, as sets of directives which indicate what practicioners do or should do. Models are, thus, aids to practice; they help practicioners to make practice choices and provide a conceptual framework for doing so. In short, models help social workers to "...progressively limit (their) vision of reality, until, literally, (they) see what (they) can (and should) do" (Nelson, 1975, p. 265).

\section{Types of Models of Social Work}

Model types are closely associated with their intended functions. Lathrope (1969) has identified four primary types of models important in social work. These are classified by the uses to which they are put: expository, research, prescriptive and practice (or professional).

1) Expository models are used to represent and codify that which in the profession is already known, and to condense and organize this body of knowledge in such a fashion as to permit rapid scanning in relation to professional concerns (Lathrope, 1969).

2) Research models are designed to yield research questions and hypotheses that empirically can be investigated. 
3) Prescriptive models function as normative guides; they state how to practice, define acceptable standards, and concepts of desirability, preference and effectiveness.

4) Practitioner models are also referred to as professional models. Most of the models proposed and utilized in social work are, in fact, practice on professional models. Practice models may be either "master models" for social work practice in general, or "working models" designed for concrete cases. This is in keeping with the distinction Chin (1961) draws between analytical and concrete models. Analytic models retain only those features regarded as essential for relating similar processes whenever they occur; whereas concrete models, although based on analytic models, are intended to reveal the essential features of a range of concrete cases. Functionally, practitioner models combine elements drawn from the other types of models: they "...are expository in that they represent what is known; they are prescriptive in that they indicate what to do; and they are research-like in that they bridge, with informed but pragmatically testable guesses, our gaps in knowledge" (Hearn, 1969, p. 64).

Often, the very fact that models for social work practice have been designed for, or based on, different methods of practice, target groups, or fields of practice has tended to obscure their more basic nature and fundamental elements. Yet an understanding, gained through analysis, of the nature of models is essential for effective model building. The more important frameworks that have been proposed for building and evaluating models of social work will now be examined. 
The Systems Model

The work of Gordon Hearn (1958), most notably, Theory Building in Social Work, has been highly influential with respect to models and model building in social work. Hearn's work provides an invaluable conceptual framework for analysing models and model building efforts in social work.

Hearn (1958, p. 10) defines a model as a "...symbollic representation of a perceptual phenomenon." According to Hearn (1958) models vary primarily in two fundamental respects: 1) by their level of abstraction and 2) by the metaphor they employ. In terms of their level of abstraction Hearn identifies three basic types: 1) lower range: iconic or pictorial; 2) middle-range: descriptive; and 3) upperrange: abstract or mathematical. In terms of the types of metaphors employed by models, historically two have predominated: the machine and the organism. More recently, interest has increased in using the system concept as a metaphor for models.

1) The theory domain is the phenomena the model focuses on and attempts to represent and symbolize.

2) The value orientation is essentially the philosophical orientation, and attitudes and beliefs, underlying the model. The value orientation affects, and in fact serves to define, the way the theory domain is viewed. As Hearn (1958, p. 12) comments "Anyone who tries to explain some phenomena inevitably does so with reference to his philosophy or value orientation."

3) The central construct serves to integrate and organize the various constructs, concepts and other components of the model. "Ideally...(the) 
central integrating construct... (must be) capable of encompassing the entire focal domain" (Hearn, 1958, p. 13). In addition, the central construct should be consistent with the underlying value orientation of the model. Thus, it is important that the central construct is well suited to the particular theory domain and value orientation of the model.

With respect to model building in social work, Hearn offers several valuable suggestions and guidelines. In addition, he outlines a systematic process or sequence for model building and formulation. Hearn's (1958) findings, recommendations, and guidelines may be summarized as follows:

1) With respect to the level of abstraction of the model: At least for social work, ${ }^{1}$ and the social sciences, "Considering the present state of our knowledge...the middle-range descriptive kind of models are most appropriate..." (Hearn, 1958, p. 42). ${ }^{2}$

2) With respect to the choice of the metaphor and central construct of the model: Hearn (1958, p. 77) reasons that "...it seems possible...to represent every situation in which a (social) worker renders service as work in and with a system... (that is) it ought to be possible to...describe...the total social work process in systemic terms." Thus, for models whose theory domain focuses on social work practice, Hearn (1958) advocates the use of 'system' as the central integrating construct.

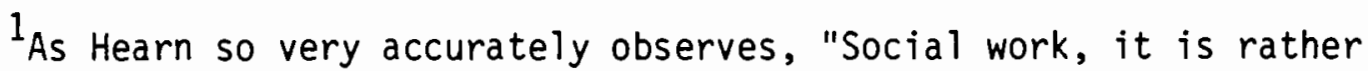
generally agreed, is neither purely an art nor purely an applied science, but rather a science-based art..." (Hearn, 1958, p. 19).

${ }^{2}$ Though this was written twenty years ago, it is still applicable to model building in social work today. 
Models of social work practice, Hearn (1958, p. 43) asserts "...can most appropriately be represented (metaphorically), in genera 1 , as open systems, but more particularly as organismic systems..." Hearn then proceeds to list and analyze the characteristics of open, organismic systems.

First of all, it is important to understand what consitutes a system. Hearn, quoting Allport (1955, p. 469) defines a system as "...any recognizably delimited aggregate of dynamic elements that are in some way interconnected and interdependent and that continue to operate together according to certin laws and in such a way as to produce some characteristic total effect. A system, in other words, is something that is concerned with some kind of activity and preserves a kind of integration and unity..." Although systems may vary in terms of their various manifestations "...there are properties which are common to systems of every order..." (Hearn, 1958, p. 38).

All systems, social work practice included, may be viewed in terms of their structure, process, and function. The arrangement of the components or elements of social work practice is its structure. Social work practice itself is an ongoing, interactional, process. And the connection between social work practice process and its structure is its function. As Hearn notes (1958), these concepts seem to correspond well to the systems model. Consequently, in representing and conceptualizing social work practice as a system, any model should address the structural, process, and functional aspects of social work practice.

Furthermore, all systems may be said to consist of 1) components, or the elements of the system; 2) attributes, or the characteristics of 
these elements; and 3) relationships, or the interaction and interdependence of these elements and their attributes. Thus, a model should also represent and conceptualize the various elements of social work practice, their characteristics and interrelationships.

A11 systems have sub-systems, and are part of a larger suprasystem as well. The factors operating within the system are its subsystems or variables. The external factors operating in its environment define its parameters and are the variables of its supra-system. Thus, in summing up Hearn's recommendations for model building, models of social work practice should 1) employ a metaphor and central construct which are consistent with their theory domain and underlying value orientation; 2) represent the structural, process, and functional aspects of social work practice; 3 ) identify, describe, and analyze the various components of social work practice, their attributes, and the interrelationships between them; and finally, 4) the model building process itself should be planful and systematic:

Having... (first) define(d) the theory domain on which one intends to focus...having assessed the present state of theory within the identified domain, having identified its inadequacies, and having made his value orientation explicit, the theorist will next select or develop appropriate constructs... Ideally, he will select a central... integrating construct capable of encompassing the entire focal domain... In addition, he will select the other constructs required for an adequate description of the domain. The entire set of constructs, in addition to being consistent with the value orientation and superior in theory developing potential to those in existing theory, must constitute an integrated whole--that is, they must be fully integrated with one another and with the central integrating construct... (The)... model... (should) define the relationships within and between the various constructs... Construct and model selection...actually take place concurrently, and each...contribute toward the other (Hearn, 1958, p. 12-13). 
Admittedly, these guidelines and recommendations for model building are highly abstract and general. Nevertheless, they are of considerable import and practicality for our model building efforts. ${ }^{3}$ Hearn's framework will, in fact, for the large part, provide the general foundation to guide out own model building efforts. Yet, Meyer (1973) and Kettner (1975) have also developed highly useful frameworks for analyzing and evaluating models of social work practice. Their approaches are less highly abstract and address the issues and considerations of model building in social work with greater specificity than does Hearn. Their frameworks supplement and complement Hearn's framework very well.

\section{Issues and Guidel ines for Model Building in Social Work}

What are the issues that models of social work practice should address themselves to? Recalling Meyer's (1973) utilitarian definition of a model -- as a conceptualization of 1) a group of phenomena bound together by some 2) rational that formulates propositions and furnishes the terms and relations of these pehnomena -- certain intrinsic questions should be considered in appraising or formulating the makeup of any given model (of social work practice).

1) What phenomena are to be grouped and addressed by the model? This corresponds to Hearn's concept of the theory domain. What are the appropriate concerns for social work practice? What are the proposed boundaries of (social work) practice, the fields of service, the target groups, how is the concept of client defined, the methodologies, and

3It seems most fitting here to recall Kurt Lewin's oft quoted phrase that "there is nothing so practical as a good theory." 
scope and level of interventions?

2) What rationale binds together the purpose, as well as the practice propositions, of the model? This is similar to Hearn's concept of the value orientation. Explicit or implicit, what are the value premises of the model? What view of human nature does the model reflect? Does the model have a strong theory base? To what extent does theory guide, or dictate, practice? What are the purposes of social work practice, and the nature of the desired outcomes? How does the model address the issue of change? Change of what, of whom, and how? Does the model focus on changing individual clients, families or groups, service delivery systems, communities or society itself?

Kettner (1975) after conducting a review of the literature on models and model building (in social work), has developed a comprehensive, and what appears to the authors to be a highly useful listing of criteria for analyzing and comparing models of social work. According to Kettner (1975), models of social work should address the following issues and considerations:

1) A statement of the author's view of social work practice: hwo is social work practice conceptualized?

2) A statement of the theoretical basis of the model: is the model tied to a specific theoretical orientation, or does the model draw from a variety of theoretical perspectives, or permit eclecticism?

3) The appropriate interventive level for social work practice: is the model intended primarily for individuals, families, groups, communities, or for a variety of levels and systems? 
4) The appropriate target group: is the model intended for a specific target group, e.g., in terms of social problems, types of clients, or fields of service?

5) A statement of worker and client roles and responsibilities: how specified, fixed, or detailed are the respective worker and client roles? What kind of knowledge and skill base is required? How detailed are worker responsibilities in various practice areas? How active (directive) or passive a role is expected of the worker? of the client? What is the relative importance of the worker-client relationship? 6) What is the nature, and relative importance, of worker, client, and other input into the decision making process?

7) What is the relative importance placed on goal setting? Are objectives and outcome expectations specific and explicitly stated, or purposely left vague and undefined as a matter of professional discretion?

8) A conceptual statement of the process of social work practice: does the model indicate a flow of events, some direction for the activity of worker and client? Does the model contain statements as to the nature of the initial phase, the methods of assessment, the interventive strategies and techniques, a means of evaluating effectiveness and termination?

9) The value premises of the model: what are the philosophical assumptions of the model, e.g., the view of human nature? What are the underlying beliefs, preferences, and assumptions about what is desirable or good for humankind? 
Selection of Criteria for Building the Model

From the review of the literature, in Chapter III it is apparent that model building efforts in social work have been plagued with confusion, controversy, and considerable difficulty. Model building in social work has been haphazard, and not surprisingly, models of social work have been developed and used in varying and inconsistent ways. Consequently, most models of social work practice have been overly bound to particular methods, theoretical perspectives, or practice settings.

It is our intention to attempt to transcend these 1 imitations. Therefore, our model building efforts will be governed by the following considerations and requirements:

1) In formulating a model for generalist practice it is essential that the model be comprehensive. The model must avoid fragmenting or dichotomizing social work practice; the model should be applicable to all of the fields of practice, settings, types of clientele, theoretical perspectives and methodologies encountered in social work practice. 2) In formulating a model for generalistic practice it is essential to develop and utilize a comprehensive, adequate, consistent, and explicitly stated set of criteria.

Based on our review of the literature on models and model building in social work, we have developed the following criteria to guide our formulation, as well as presentation, of a comprehensive model for generalist social work practice.

General Considerations.

1) The model should provide an explanation or overview of its general characteristics (of the model), as well as of the author's view or 
conceptualization of social work practice.

Structure, Function and Process Considerations. The model should contain statements as to the following:

2) The behavioral science, theoretical base of the model;

3) The value premises of the model;

4) The client unit of concern;

5) The level(s) of intervention;

6) The types of appropriate problems;

7) The target groups;

8) The purposes and expected outcomes of social work practice;

9) The process and phases of social work practice, including statements about engagement, assessment, intervention, evaluation and termination;

10) The interventive strategies and tasks utilized in practice;

11) The nature of change;

12) The nature of the roles and responsibilities of worker and $\mathrm{client}$;

13) The desired ways of relating to clients;

14) The degree of client input into the decision making process.

The criteria we have outlined above will serve not only as the basis for developing and formulating our model, but also for the format of the presentation of the model. Thus, in keeping with the two-fold nature of our model building criteria -- the presentation of our model is made in two parts. Part Two -- Overview of the Model -- is intended to provide a glimpse of the larger picture; that is, to highlight the general characteristics of the model. Part Three -- Constructs of the Model -- is intended to provide an explanation and analysis of the specific components and elements of the model. 
OVERVIEW OF THE MODEL

Often it is necessary to view the whole before proceeding to understand or analyze its parts -- thus, our purpose in Part Two is to present an overall view of the moder, in terms of its purposes, scope and content, organization, and conceptual components. We will also provide a graphic representation of the model, so that the reader may view the specific constructs and elements of the model in their entirety. And finally, we will provide an overview of the generalist approach to social work practice, a summary of the essence of generalist practice. Hearn (1958) commented that model building actually begins by identifying the inadequacies of existing models -- and as Klenk and Ryan (1974, p. 1) state "...the knowledge and skills required by this (generalist) approach have not yet been organizable in such a way that one can simultaneously understand the parts and the whole." And this is despite the fact that, semmingly numerous authors have put forward formulations of models for generalist practice. ${ }^{4}$ The problem, briefly stated, is that however articulate these authors may have been in their espousal of the generalist approach to social work practice, invariably in their writings there appears to be a tendency to over-

${ }^{4}$ See Hearn, 1958 and 1969; Pincus and Minahan, 1973 and 1977; Bartlett, 1970; Klenk and Ryan, 1974; Middleman and Goldberg, 1974; Goldstein, 1973, Siporin, 1975; Meyer, 1976; Germain and Gitterman, 1976; Couch et a1, 1976; Germain, 1979, and Fischer, 1978. 
emphasize certain aspects of the generalist approach to social work practice. $^{5}$

These differences of emphasis and focus, albeit slight at times, need to be transcended and integrated into a more comprehensive and representative formulation of the generalist approach to social work practice. In developing our model (of generalist practice) our purpose is not so much to present new material or theory, but to draw together, reorganize, and conceptualize the most useful and essential elements of these various models of generalist practice. Our basic intent, then, is to present a synthesis -- a mode 1 -- that is truly comprehensive and representative of the generalist approach to social work practice.

In the previous section ${ }^{6}$ we identified four basic types of models that have been used in the field of social work. The model we have developed is a practitioner model, designed to serve as a bas is for social work practice in general. In terms of its level of abstraction, consistent with Hearn's (1958) recommendations, it is a middle range, descriptive model. And in keeping with the fact that it is a practitioner model, the functions of the model are expository, prescriptive,

${ }^{5}$ For instance, Middleman and Goldberg (1974) emphasize macro, social structure oriented concerns: the need to adjust the environment to the needs of people. Whereas, Germain and Gitterman (1976) are more psychodynamically, or treatment, oriented. Klenk and Ryan (1974), who have written what is perhaps the single most concise description of the generalist approach, emphasize the social work practice process as well as social work roles and objectives. And Pincus and Minahan (1973 and 1977), who have developed the single most comprehensive formulation of generalist social work practice, place heavy emphasis on resource development and utilization (clearly, four out of five of their objectives for social work relate to this).

${ }^{6}$ See Part One, Types of Models of Social Work, pages 89-90. 
and research oriented. The model is expository in that it reorganizes, conceptualizes, and describes that which is known about generalist practice. The model is prescriptive in that it is intended to serve as a guide -- descriptively and prescriptively -- for generalist practitioners. The model is research oriented in that it was designed to have applications. 7

\section{Theory Domain}

The model is intended to serve as a basis for conceptualizing and representing -- in terms of the generalist approach -- direct service social work practice and theory. ${ }^{8}$ The theory domain of the model addresses such considerations as the scope and boundaries for social work practice, the fields of service, the target groups, the nature of problems, and the types of practice interventions and methodologies. One of the most significant characteristics of the model is that it does not restrict or limit (social work) generalist practice to any particular,

${ }^{7}$ The model was designed to be operationalized into a written questionnaire and to be used as a basis for a descriptive survey and research project. See Chapter V, Research Applications of the Model, for a discussion of the research applications of the model and of the questionnaire that was developed from the model.

8 Reluctantly, the authors decided to limit the scope of the model to direct service social work practice for pragmatic and operational considerations. Given our limited time and resources it did not seem feasible to develop a questionnaire measuring both direct and indirect service generalist practice approaches. This decision, then, was made from practical necessity; theoretically, and ideally, generalist social work practice is not dichotomized -- indeed, one of its strengths lies in the diversity of the practice approaches it utilizes. 
specific field of service, practice setting, type of clientele or target problem, theoretical, methodological, or interventive approach or perspective. As a representation and conceptualization of generalist social work practice, the model is intended to be applicable to all of the various fields of service, practice settings, types of clientele and social problems typically encountered in direct service practice and meant to utilize a variety of interventive strategies and practice approaches.

The underlying rationale of the model corresponds to what we term as the generalist practice perspective. ${ }^{9}$ The value orientation of the model, the generalist practice perspective, affects all the other facets of the generalist approach to social work practice -- it, in effect, provides the 'whys' of the model and of generalist practice. Thus, in relation to this underlying value orientation or practice perspective, the model represents all the other various facets of generalist practice as necessarily interrelated. Both what generalists do, that is, generalist practice activity, as well as how generalists do what they do, the generalist practice process, are influenced and defined by the generalist practice perspective. ${ }^{10}$

As Hearn (1958, p. 38) suggests "...after the theory domain has been defined....and...the value orientation made explicit..selecting

${ }^{9}$ See Part III, The Generalist Practice Perspective, pages 113-127.

${ }^{10}$ The constructs of the model represent generalist practice in terms of its practice perspective, practice process, and practice activity. See Part III, Presentation of the Model: Constructs of the Mode 1, pages 112-150. 
(identifying and explaining) the central construct follows as the next logical step." Our model (of the generalist approach to social work practice) is a systems model .. it is a means for representing and conceptualizing social work practice systematically. System as the central integrating construct of the model is ideally suited to both the theory domain and value orientation of the model.

1) With respect to the theory domain of the model: Through use of a systems construct it is possible to formulate a common, or uniform, framework for concept utilizing all of the various aspects of social work practice, e.g., types of clientele and social problems, fields of service and practice settings, and methodologies and functions. As Hearn (1958, pp. 42-43) observes "Considering the present (1 imited) state of our knowledge...organismic (systems) models are probably the most appropriate for (model) building in social work... and seems to offer the best overall integrating basis for such a conception (of generalist social work practice)."1l And as Meyer (1975, p. 93) notes:

A systems perspective seems to me the only way to provide for (a) realistic assessment of the true unit of attention (i.e., social work practice)... (For it is)...a framework that accounts for the transactional processes, (but) lays no claim to certainty or cure.

2) With respect to the value orientation of the model: A systems perspective was chosen because "...it seemed directly related in so many

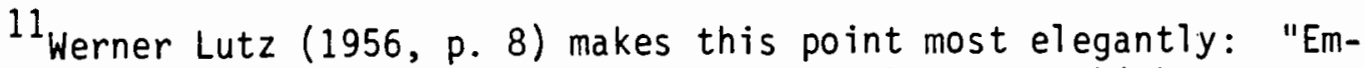
pirical experience is richer than any theoretical system which attempts to describe it... No single...description is the 'right' one to the exclusion of the others... To take the position that any single frame of reference describes a phenomena fully and adequately is to impose on empirical experience a closure that is rightly a property only of abstract theoretical systems (e.g., mathematics)." 
ways to the values and beliefs underlying this formulation" (Hearn, p. 52). The generalist practice perspective, as well as much of the generalist terminology throughout the literature, is expressed in systemic terms. For example, in Pincus and Minahan's (1973) framework clients, workers, and their employing agencies, target populations and service delivery organizations are all referred to as systems. In their model social work practice Pincus and Minahan (1973) identify four basic systems: the client system, the change agent system, the target system, and the action system. 12

The model views and represents generalist social work practice in terms of two primary conceptual distinctions. ${ }^{13}$

1) The cognitive aspects of generalist social work practice -- what we term "ways of thinking" about social work practice. By use of this concept we refer to an overall sense of orientation, frame of reference, or practice perspective. This includes values, beliefs, philosophy, assumptions, attitudes, knowledge, sense of purpose, and view of the practice process; and

2) The behavioral aspects of general ist social work practice -- what we term "ways of doing," or performing social work practice. By use of this concept we refer to all social work practice activities: the use of the planned change practice process, application of interventive

${ }^{12}$ For a detailed description and analysis of these concepts, see Pincus and Minahan, Social Work Practice: Model and Method (Itasca, I11.: F.E. Peacock PubTishers, 1973).

${ }^{13}$ This means of conceptualization provided the basis for developing the questionnaire. The questionnaire was designed to measure the extent that practitioners utilize generalist ways of thinking or doing. See Chapter Five, Research Applications of the Model, pp. 151-161. 
techniques and skills, and the performance of social work practice tasks, roles, and functions.

Central to the essence of the generalist approach to social work practice is the dynamic interrelationship and integration that exists between generalist ways of thinking and doing.

1) Generalist ways of thinking inform and enhance generalist ways of doing: the generalist practice perspective provides the rationale and direction for generalist practice activities; whereas

2) Generalist ways of doing operationalize and actualize generalist ways of thinking: generalist practice activities provide the means for the implementation and realization of the goals and purposes of general ist practice. Judith Nelson (1975, p. 265) makes this point well, observing that

To be a responsible social worker, one must certainly act as well as think. Ideally...a worker should first determine whom to serve and toward what ends, and then make choices of how to give service... Social workers should make these choices consciously...

Conceptual Organization and Components of the Model

As a system generalist social work practice consists of interrelated and interdependent sub-systems. Conceptually, the model identifies three primary sub-systems, or fundamental elements of the generalist approach to social work practice -- the model represents generalist practice in terms of the generalist practice perspective, practice process, and practice activity. And in turn, the specific elements and aspects of these sub-systems are represented in the model as constructs. The generalist practice perspective is represented in terms of the 
following five constructs: value premises, knowledge base, mission/ purpose, nature of problems, and notion of clients. The generalist practice process is represented by two constructs: nature of the helping relationship and the planned change process. Generalist practice activity is represented by two constructs: social work functions and roles.

Graphic Representation of the Model

Systems are most accurately represented not as 1 inear processes but as circular processes (Hearn, 1958). Since we are using a system's framework, the model may be best represented graphically, that is pictorially, in the form of a circle. ${ }^{14}$ This seems most fitting and indicative of the nature of the generalist approach to social work practice -- as a social work practice framework the generalist approach is holistic, interactional, and systemic in its orientation, and similarly, a circle by its very nature implies wholeness and flow (in that it is non-linear and without abrupt edges).

The circular figure (see Figure 1, page 108) is a visual representation of the model -- inside the circle we identify and place the three primary subsystems as well as the various constructional elements

${ }^{14}$ Within the social work literature there is support for using a circular figure as a means to visually represent the model (Chin, 1961, p. 203):

It is heipful to visualize a system (i.e., a model of social work practice) by drawing a large circle. We place elements, parts, variables inside the circle as components (constructs of the model). The lines may be thought of as rubber bands which stretch or constrict as the forces increase or decrease. 


\section{A) Generalist Practice Perspective}

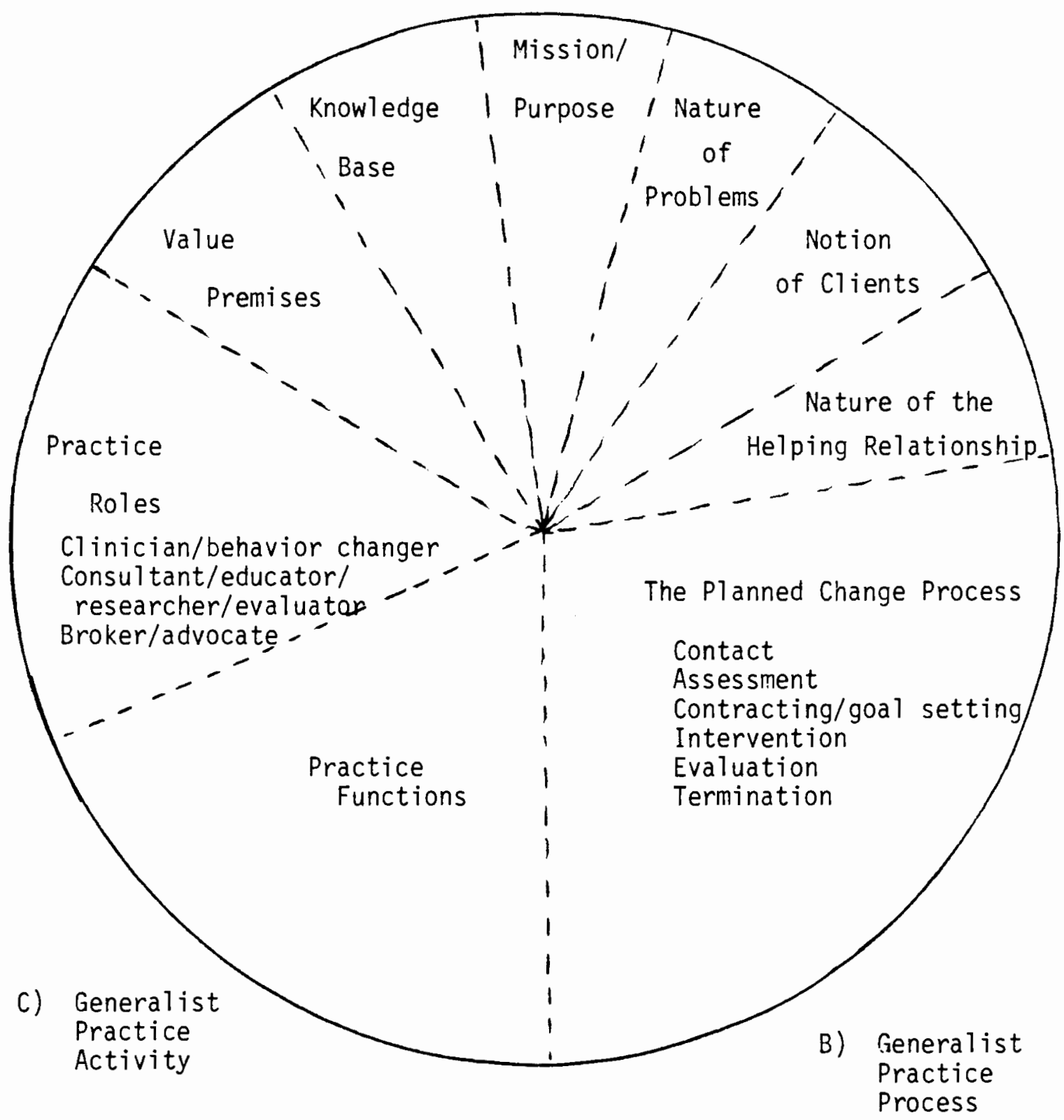

Figure 4. Graphic representation of the model. 
of the model. The circle is divided into three major parts -- these divisions correspond to the three most fundamental aspects, i.e., subsystems, of the generalist approach to social work practice. Separated by dotted lines, the wedges or slices within each section of the circle are labelled with the constructs which represent the various elements of generalist practice.

Through the use of a systems framework and circular figure to represent the model, our intent is to metaphorically and visually convey this essential point -- taken as a whole, the combination and interaction of its practice perspective, practice process, and practice activity, the generalist approach to social work practice is qualitatively different than the mere sum total of its parts. Since generalist practice activity is informed and directed by the generalist practice perspective and structured by the generalist practice process, the model represents generalist practice not only in terms of what generalists do, but also in relation to how and why generalists engage in their various practice activities.

\section{Overview of the Generalist Approach to Social Work Practice}

The generalist approach to social work practice is a goal oriented, problem-solving, planned change process (Pincus and Minahan, 1977). As its basic purpose generalist social work practice seeks to enhance the social functioning of clients -- whether perceived as individuals, groups, organizations, or communities. And so, generalist social work practice focuses on "...the linkages and interactions between people and resource systems and the problems to be faced in the functioning of both individuals and systems" (Pincus and Minahan, 1977, p. 78). 
Generalist social work practice is based on an eco-systemic, holistic, and interactional perspective. The generalist practice perspective utilizes concepts drawn from general systems theory, and pays particular attention to the interactions and interdependence between people, their resource systems, and environments, Individuals and groups, as well as organizations and resource systems, are viewed as units within interrelated systems. In short, the generalist "...worker must have a frame of reference that allows for the simultaneous understanding of many interacting (variables and) ...relationships" (Klenk and Ryan, $1974, p .2)$. The generalist practice perspective views people and environments as necessarily interrelated and understandable only in terms of their influence on each other.

Generalist social work practice is informed by theories and concepts drawn from a variety of sources. As a practice framework, the generalist approach embraces eclecticism; in no way are its purposes dictated, nor its practice propositions or methodologies bound to any one, particular theoretical orientation.

Also central to the essence of the generalist approach is the viewpoint that problems are not attributes of people, but aspects of their life situations (Pincus and Minahan, 1973). Clients are not regarded as the problem; rather, they experience problems in living (Klenk and Ryan, 1974). Clients are, in fact, referred to as the client system -thus the client system may be an individual, group, organization, or community (Pincus and Minahan, 1973). Essential to the generalist practice perspective is the critical need to differentiate between the expected beneficiaries of service, i.e., the client system, and the 
targets for change, that is, the expected targets of the interventive effort. The generalist practice perspective and planned change process is problem-solving rather than person centered; consequently, the generalist practitioner must be able to work not only with the client system, but also with a variety of persons and systems of various types and sizes.

Given its value premises and purposes, as a practice framework the generalist approach places great emphasis on viewing, responding, and attempting to meet the needs of the total client, or person(s) in situation. Use of a goal orientation and objectives framework allows the generalist worker to link purpose to practice activities and tasks. Integral to the generalist approach is the insistence that methodological choices follow from, and are in fact based upon, a goal and objectives framework. As Meyer (1979, p. 269) observes "...methods (should) become the servants rather than the masters of practice activities." Thus, as the client situation warrants, the generalist worker is willing and able to 1) draw from a broad repetoire of practice skills, techniques, and methodologies, 2) assume a wide variety of professional roles, and 3) perform a variety of social work practice functions. Methodologically, the generalist approach is planful, goal oriented, flexible, and eclectic. For above all, the generalist worker strives to work and be facilitative of the best interests of the client, and consequently, is willing to be able to assume "... whatever roles and do whatever activities are necessary" (Klenk and Ryan, 1974, p. 4). As a model of social work practice, one of the most distinguishing characteristics of the generalist approach to social work practice is that it 
is "...based on the premise that often the recipients of social services can best be helped by a practitioner who can relate to a variety of needs, rather than by a specialist" (Klenk and Ryan, 1974, p. 26).

\section{CONSTRUCTS OF THE MODEL}

The constructs of the model were developed and formulated to be consistent with the guidelines established for model building. ${ }^{15}$ The constructs are conceptualizations of all the major aspects and elements of the generalist approach to social work practice. And since the model represents generalist social work practice in terms of its practice perspective, practice process and practice activity, likewise the constructs are organized and presented in terms of these three fundamental aspects of the generalist approach to social work practice.

It is realized that to a certain extent the substantive content of the constructs of the model has much in common with other approaches to social work practice. ${ }^{16}$ However, this analysis shall focus or highlight on those aspects of the constructs of the model -- those elements, characteristics and interrelationships -- that are most distinctly generalist in nature.

The model is comprised of the following constructs:

${ }^{15}$ See Part One, Selection of Model Building Criteria, pages 98-99.

${ }^{16}$ And this is, indeed, understandable -- the generalist approach to social work practice is as much a synthesis of all the various social work practice approaches as it is a response to the limitations and problems within the profession of social work. 
Practice Perspective:

1) Value premises;

2) Knowledge base;

3) Purpose/mission;

4) Nature of problems;

5) Notion of clients;

Practice Process:

6) Nature of the helping relationship;

7) The planned change process;

Practice Activity:

8) Functions; and

9) Roles.

The Generalist Practice Perspective

Perhaps, the most significant contribution the generalist approach has made to the profession of social work has been its practice perspective. More so than anything else, the generalist approach to social work practice is a perspective -- a way of looking at the world, of viewing people and their environments, and of thinking about social work practice. The generalist practice perspective underlies all of generalist practice, influencing not only what generalists do (i.e., practice activity), but also how generalists do what they do (i.e., the practice process). Thus, it seems most appropriate to begin by examining the nature of the generalist practice perspective and the constructs of the model which represent it. 
Value Premises

As Pincus and Minahan (1977, p. 92) state "Value issues permeate all (of) social work practice." Value premises are integral to social work practice in that they help to define 1) the mission or purposes of social work practice, 2) the knowledge required for social work practics, 3) the situations or conditions that are regarded as appropriate problems for social work practice, 4) the people and/or entities that are regarded as appropriate clients, 5) the nature and kinds of relationships involved in social work practice as well as, 6) the means and methodologies used in social work practice.

As Bartlett (1970, p. 38) observes, "Values are beliefs, preferences, or assumptions about what is desirable or good for man." In the social work literature two basic types of values have been identified (Levy, 1973; Pincus and Minahan, 1973; Perlman, 1976). Core values are abstract, general, ethical, or philosophical assumptions or cherished beliefs that are generally assumed to have inherent value or worth. ${ }^{17}$ Instrumental values, al though reflecting eithical concerns, are of a decidedly more pragmatic nature -- essentially, they serve as guides to action or practice. $^{18}$ In short, values define, and provide a sense of

${ }^{17}$ In the social work literature core values are also referred to as primary or ultimate values.

${ }^{18}$ Instrumental values are sometimes referred to as practice principles. Perlman (1976, p. 382) defines an instrumental value as an operationalization or instrumentation of a core value -- "If values are to serve as action guides, they must be drawn down to earth. They must be operationalized, changed into instruments that fashion and direct our doing." 
direction, as to that which should be in social work. It is with respect to these definitions and functions that we shall examine the value premises of the model.

On the most fundamental level generalist social work practice is based on the following philosophical assumptions:

1) Man should not passively accept his condition (if unsatisfactory);

2) Man has the capacity, and therefore, should make rational use of knowledge (a belief in the possibility of planned change); and 3) Man should, thus, intervene to change unsatisfactory conditions (Pincus and Minahan, 1973).

In addition, generalist practice is based on specific value premises. What follows is a listing of the core values underlying generalist practice and the instrumental values that derive from them.

1) The generalist approach to social work practice is based on the belief in the inherent dignity, worth, intregrity, and individuality of all people. The instrumental value given in practice to the confidentiality, acceptance, and individualization of clients reflects the concern for these core values. Similarly, in terms of the generalist practice process, instrumental value is placed on openness, honesty and collaboration, particularly with respect to the working relationship established between the worker and clients.

2) The generalist approach to social work practice is based on the belief in the rights of all people to self-determination and opportunity for self-fulfillment and realization. As Dean (1977, p. 370) observes, clients have the "...right...to determine (their) own needs and how (their needs) are to be met." Major instrumental value is placed on 
enhancing the social functioning of individuals, groups, organizations, or communities. Instrumental value is placed on ensuring that "People... have access to the resources they need to accomplish iife tasks, alleviate distress and realize their own aspirations and values" (Pincus and Minahan, 1977, p. 347).

3) The generalist approach to social work practice is based on the belief in the rights of all people to equality, equal opportunity, and equitable social and economic provision. Underlying generalist practice is the belief and commitment that society, as well as the profession of social work, has the responsibility to remove obstacles, and to otherwise foster conditions, which enhance the quality of social functioning. In light of these considerations instrumental value is placed on ensuring client access and utilization of the resources, services, and opportunities necessary for enhanced social functioning. In addition, instrumental value is placed on fostering mutuality and democratic decision making in the practice process.

In summary, the value premises underlying generalist practice help to set the boundaries and scope as well as the directions and purposes of general ist practice. The combination of values, which indicate what should be, and knowledge, which indicates that which is or can be, thus form the cornerstones of the generalist practice perspective.

\section{Knowledge Base}

Although interrelated and interdependent, knowledge and values differ, as we have seen above, in certain essential respects -- and for this reason should not be confused or equated. Knowledge refers to verified 
experience or observation; knowledge should be as objective as possible and subject to empirical verification.

What kind of knowledge base is required for generalist social work practice? Since the focus of generalist practice concerns itself with the various aspects of the social functioning of individuals, groups, organizations, and communities, it is appropriate that the generalist knowledge base is primarily drawn from the social and behavioral sciences. Fischer (1977) identifies two primary types of knowledge: 1) causal, addressed to understanding human behavior, questions of why, or etiology, and 2) interventive, addressed to principles and processes for changing behavior, social situations, or conditions. As Pincus and Minahan (1977, p. 91) note, both of these primary types of knowledge are integral to generalist social work practice:

The social worker draws on two main sources in linking purposes to tasks. The first is his general knowledge of practice skills ...A second source... is his knowledge of theories of behavior and dynamics of the interactions of individuals, families, groups, organizations, and communities.

More specifically, what kinds of knowledge, then, are required for generalist social work practice? We concur with the listing presented by Pincus and Minahan (1977) which includes knowledge about:

1) The developmental life tasks encountered by all people;

2) The special obstacles and tasks that confront people experiencing problems of living;

3) The resources needed by people to alleviate distress, accomplish life tasks, and realize their aspirations;

4) The functioning and policies of societal resource systems, and the factors affecting linkages between and within resource systems; 
5) The development of frameworks that help one view a social situation in its entirety and comprehend the relationships between life tasks, resource systems, and linkages.

To meet these requirements theoretical understanding as well as practice skills are necessary in the following areas:

1) Interpersonal relationships, communication skills, interviewing, and group process;

2) Means of formal communication: writing skills, grantsmanship, testimony;

3) Teaching and consultation; and

4) Data collection, evaluation, and assessment.

Cooper (1977) suggests the need for knowledge of developmental, affective, cognitive, and interpersonal processes as well as of social policy, institutional organization and functioning, and systems theory. Reid (1977) stresses the importance of both causal and interventive knowledge of social problems; this he explains as the need to define and describe social problems, and identify causes and means for change. Dean (1977) suggests the need, and usefulness, for a smattering of general practical information as wel1, such as of public health, medicine, welfare regulations and procedures, legal rights and entitlements, etc.

The knowledge base for generalist practice is not entirely different, and does in fact borrow, from other approaches to social work practice. However, the following characteristics of the knowledge base are unique and most distinctly generalist: 
1) The generalist approach is eco-systemic. Although more so in spirit, that is, metaphorically and as a conceptual aid, than formally or explicitly, a systems perspective is employed. ${ }^{19}$ As a frame of reference the generalist perspective pays particular attention to the interaction and interdependence between people, resource systems, and other aspects of their social and physical environments. As Dean (1977, p. 372) states the social work practitioner "...must know how the different aspects of society are interrelated."

2) The generalist approach is holistic. As "...a frame of reference (it) allows for the simultaneous understanding of many interacting relationships" (Klenk and Ryan, 1974, p. 12). Thus, individuals and groups, as well as organizations and communities, are viewed as units within interrelated systems. ${ }^{20}$ In addition, importance is placed on viewing the whole person, that is, the total needs of people within their environmental or situational contexts. As a result, generalist social work practice focuses on "...the 1 inkages and interactions between people and resource systems and the problems to be faced in the functioning of both individuals and systems" (Pincus and Minahan, 1973, p. 9).

3) The generalist approach is eclectic. By use of the term, eclectic, we mean that generalist practice does not bear allegiance to any

${ }^{19}$ The generalist approach to social work practice does not rotely or strictly adhere to general systems theory.

${ }^{20}$ This is one of the general characteristics of all systems: every system has sub-systems, and in turn, is part of a larger supra-system. See Part One, "The Systems Model," pp. 93, 94. 
particular theoretical orientation or practice approach, but rather is guided foremost by considerations of what works, of what is most effective. That is, as the practice situation and purposes warrant, the generalist practitioner utilizes theoretical and practical approaches that are the most appropriate, and proven effective. We agree with Pincus and Minahan (1977, p. 103) who state:

The (generalist) model is not based on any one substantive theoretical orientation, such as ego-psychology, or conflict resolution, but allows for the selective incorporation of such orientations in working with specific situations.

Generalist social work practice utilizes a variety of theoretical frameworks and interventive approaches -- and this seems especially appropriate...

Since human behavior and the functioning of social systems are complex topics, any one theory cannot be adequate for all situations. Further, while some theories offer competing explanations, many are complementary, offering different perspectives on the same situation. Ideally, the worker will be familiar with several approaches and pick the most suitable for his purposes (Pincus and Minahan, 1977, p. 91).

It is in this sense of the word then, that the model, and its knowledge base, is eclectic -- for generalist social work practice adheres to the commitment to be guided in practice by what is most effective and relevant for the needs of clients. Or as Turner (1879, p. 129) states, "Knowledge is useful if it helps clients, regardless of its source."

As previously stated, the constructs of the model, such as its value premises, knowledge base, and purposes, are all interrelated and interdependent. For instance, the knowledge base and value premises provide a sense of orientation for generalist practice, and it is out of this constellation that the mission and purposes of generalist practice are derived. 


\section{Purpose Mission}

As Bartlett observes, "A profession's purposes are in general directed toward fulfilling the outcomes implied in its values" (1970, p. 59). Furthermore, a profession's purposes are tempered in part by its knowledge base. For example, at any particular time the available knowledge makes certain goals or purposes more practical or attainable than others. The purposes of social work practice ideally should follow from the combination of its knowledge base and value premises. One of the distinguishing characteristics of the generalist approach to social work practice is that its purposes or sense of mission are in fact derived from an effective integration of knowledge and values.

Briefly stated, the purpose of generalist social work practice is to enhance, by means of a planned change process, either directly or indirectly, and whether individually or collectively perceived, the social functioning of current or potential clients (Klenk and Ryan, 1974). Or stated more concretely, the purpose of generalist social work practice is

to strengthen (the) coping patterns of people and to improve environments so that a better match (emphas is added) can be attained between people's adaptive needs and potential and the qualities of their impinging environments (Gordon, 1969, p. 5-11).

The focus of generalist social work practice, thus, is on the interactions between people and the (resource) systems in their social and physical environments (Pincus and Minahan, 1973). Enhancing social functioning is viewed in terms of 1) the 1 ife tasks confronting people and 2) the resources, whether personal attributes of clients or of 
the community or society, such as social welfare services, necessary to facilitate coping, alleviate distress or realize aspirations and 3 ) maximizing the extent to which distress is alleviated, life tasks are coped with, and aspirations are realized. The purposes of generalist social work practice are well summarized by Pincus and Minahan (1977, pp. 7879): $:^{21}$

1) enhance the problem-solving and coping capacities of people, 2) link people with systems that provide them with resources, services and opportunities, 3) promote the effective and humane operation of these systems and 4) contribute to the development and improvement of social policy.

From the standpoint of the generalist practice perspective the profession of social work has the responsibility for preventing social dysfunction as well as for promoting social well-being. Thus, as its mission, social work has the responsibility not only to enhance the social functioning of people, but also the capability of resource systems to adequately respond to the needs of people. As the situation warrants, the targets of the planned change process, and its goals and specific objectives, may vary: the purposes of generalist social work practice may require change of individuals and/or social structural or environmental changes.

The Nature of Problems

The value premises, knowledge base, and sense of purpose underlying the generalist approach to social work practice influence and to help

21 pincus and Minahan (1973 and 1977) have made other formulations of the purposes of social work practice which they conceptionalize in terms of the objectives and functions of social work practice. 
define that which is viewed as the nature of problems. And in turn, what is understood to constitute the nature of (social) problems determines the boundaries, scope, and targets of generalist practice. Fundamental to the generalist practice perspective is the view that human behavior, as well as social problems, can be best understood in terms of multiple causal factors, involving interacting and interdepent sys tems .

The generalist view of the nature of problems has been profoundly influenced by what the literature refers to as the Life Model of social work practice. $^{22}$ The generalist practice perspective utilizes the concept of problems of living. ${ }^{23}$ As such, generalist practice is problem-focused, or problem solving in its nature, rather than personas-problem centered. Thus, problems of living are viewed "not as reflections of pathological states, but as consequences of interactions among elements of the eco-system, including other people, things, places, organizations, ideas, information, and values" (Germaine and Gitterman, 1976, p. 602). This is a distinguishing characteristic of the generalist view of the nature of problems and certainly contrasts sharply withother practice perspectives, such as those derived from the medical model.

${ }^{22}$ See, in particular, the work of Carel B. Germaine, "Social Study: Past and Future," Social Casework, 49 (July, 1968) pp. 403-409; "An Ecological Perspective in Casework Practice," Social Casework, 54 (June, 1973) pp. 323-330; and Alex Gitterman and Carel B. Germaine, "Social Work Practice: A Life Model," Social Service Review, 50 (Apri1, 1976) pp. 601610. For a review of the life model see K. Jean Peterson, "Assessment on the Life Model: A Historical Perspective," Social Casework, 60 (December, 1979) pp. 586-596.

${ }^{23}$ The term, problems of living, is a major concept of the Life Model of social work practice. 
Klenk and Ryan (1974) have developed a most useful framework for conceptualizing the nature and various aspects of social problems. They identify three primary concepts: domains of living, obstacles to functioning, and level of functioning. Using this framework a problem in living may be viewed in terms of its 1) substantive aspects or content -- domains of living, e.g., health, education, financial, employment, family, and community integrity; 2) dysfunctional aspects -- obstacles to functioning, which range from individual client deficiency to social structural deficiency; and 3) functional or status aspects -level of functioning, which ranges from states of well-being to those of stress, problem, or crisis (Klenk and Ryan, 1974).

The process or means of defining and assessing the nature of problems in generalist practice is undertaken in a spirit of collaboration with clients. As Pincus and Minahan (1977) observe the purpose of the assessment task is to establish the goals for change and the necessary targets for the change effort. The people, organizations, or conditions that need to be changed or influenced in order to attain the established goals are termed the "target system" (Pincus and Minahan, 1973). Often, the target system co-responds to what has been identified as the obstacles to functioning and well-being. As Pincus and Minahan (1977, p. 79) so clearly state:

This means that we do not view problems as an attribute of people; rather, we see people's problems as an attribute of their social situation. The question is not who has the problem, but how the elements in the situation (including the characteristics of the people involved) are interacting to frustrate the people in coping with life tasks. 
Thus, from the generalist practice perspective, no social situation or condition is inherently viewed as a problem. Rather, a problem is considered to be a social situation or condition which has been identified by someone, e.g., client, worker, agency, or society, as an undesirable state of affairs (Pincus and Minahan, 1973).

\section{Notion of $\mathrm{Cl}$ ients}

The generalist notion, or view, of clients is systemic. Clients are, in fact, referred to as the "client system" (Pincus and Minahan, 1973). In terms of the generalist practice perspective, the client is that system -- whether individual, family, group, organization, neighborhood, or community -- for and with whom the social worker engages in the planned change effort (KTenk and Ryan, 1974; Pincus and Minahan, 1973 and 1977). And as such, generalist and social work practice, and the model as its representation, is applicable to a wide range of possible client systems experiencing a wide range of problems of living.

The client system is viewed in an individualized and holistic fashion. Although the client may be experiencing problems in living, the client is not presumed to be the problem. Rather, there is a systemic effort to view and assess, as well as work toward meeting, the total needs of the client system. However, since the needs of client systems are highly individualized and situation specific, the needs of client systems are viewed in particular with respect to the transactions between $c l$ ient system and its social and physical 
environment. 24

The important fact that the generalist perspective does not presume that the client is the problem distinguishes it from more traditional models of casework. The generalist concept of client as a system transcends many of the limitations of the medical model, particularly the notion of the identified patient and the corresponding presumptions of client, or patient, pathology or deficiency. And consequently, from the generalist practice perspective, the $c l$ ient system is not necessarily the focus or target for change. In point of fact, it may be more appropriate to attempt to change deficiencies in the client system's environment. Thus, the generalist notion of client does not focus on, nor is it preoccupied with, pathology or deficiency. Rather, the client system is viewed in terms of its strengths. Value, as well as purpose, is placed on building on the assets or strengths of the client system and its supporting environment.

Similarly, as we shall discover in the following section, the nature of the helping relationship between the social worker and the client system is collaborative and facilitative. In viewing clients and the problems of living clients may be experiencing, $c l$ ients are assumed to know the general nature of their problems as well as their own needs. In fact, certain authors, Pincus and Minahan (1973) in particular, define the notion of clients not only as the specific system that is being

${ }^{24}$ Similar to the concept, notion of clients, is the concept, unit of attention. As Peterson (1979) notes, the unit of attention is the object of social work practice, "...the 'what' to which social work pays attention ( $p$. 589). Specifically, the unit of attention for generalist practice is the person(s)-in-situation, the... whole...person in transaction with the environment" (Peterson, 1979, p. 589). 
helped, but also in terms of the fact that clients willfully and voluntarily request help and engage the services of social workers. In this view, people only become clients by means of their expressed consent and sanction. It is then, only after a working agreement or contract has been established that a potential client actually becomes a client.

\section{The Generalist Practice Process}

This section will examine the two constructs of the model -- the nature of the helping relationship and the planned change process -- which represent the nature and elements of the generalist practice process. Process considerations are extremely important -- often what is done in social work practice is no more crucial than how it is done.

First, the nature of the helping relationship will be examined, and by the use of this term, we refer to the quality and type of relationship established in the course of social work practice between worker and client (system). ${ }^{25}$ Then, the nature of the generalist planned

${ }^{25}$ The nature of the helping relationship, however, should not be construed to be synonymous, or representative, of all the various professional relationships that the generalist worker establishes. The generalist worker enters into professional relationships not only with clients, but with other people, organizations, and particularly with resource systems, as wel1. It is important, then, to emphasize the fact that not all of the professional relationships of the generalist worker are collaborative. As Pincus and Minahan note, "...there are important differences in social work relationships to achieve different purposes with different systems. A relationship can be thought of an an affective bond between the worker and the other systems operating within a major posture or atmosphere of collaboration, bargaining, or conflict. There has been a tendency in social work to view professional relationships as being synonymous with collaborative relationships. This is largely because of our preoccupation with focusing on relationships with client systems. But... the social worker must be concerned with his relationships with all systems. While in practice, every relationship contains elements of collaboration, bargaining, or conflict, at any point in time a worker may be relating to another system essentialiy in one of these stances" (1977, p. 84). Later, in the section, Generalist Practice Activity, see pp. 134-150, these issues shall be addressed more fully. 
change process will be examined, and by use of this term we refer to the purposeful and sequential aspects of the generalist practice process itself.

Nature of the Helping Relationship

The generalist approach to social work practice is a joint or mutual process, both the worker and the client system are viewed and valued as bringing something essential to the practice process (Klenk and Ryan, 1974). Significantly, this is not coincidental -- that the nature of the generalist halping relationship is collaborative, democratic, and mutual is related, and certainly consistent with, the generalist view of the nature of problems, notion of clients, knowledge base, and value premises.

A distinguishing characteristic of the generalist practice process is that client input into the practice process is not only highty valued, but actively encouraged. The worker attempts to elicit the client's participation throughout the entire practice process. Thus, both worker and client bear a joint responsibility for the exploration and definition of the problem(s), decision making, goal formulation, taking action, and, ultimately, for resolution of the problem and goal atta inment.

Above al1, the generalist worker strives to be facilitative -- of client self-determination, greater realization of client potential, and enhanced social functioning -- not prescriptive. The nature of the helping relationship that the worker strives to establish with the client system is characterized by openness, honesty, trust, collaboration, mutuality, democratic decision making, and joint responsibility 
and participation in the problem-solving effort. Although the nature of the helping relationship and practice process is relatively structured -- that is, systematic, planful, and purposeful -- nevertheless the helping relationship between the worker and client system is not highly directive, and certainly not prescriptive. Since the client is not presumed to be the underlying cause of the problem, likewise, neither is the worker presumed to have all the knowledge, or to assume total responsibility, for resolution of the problem, i.e., curing the client. The generalist social worker avoids being unilateral or authoritarian in his actions or communications. Thus, the worker consciously downplays acting in the role as expert; rather the worker offers and shares his expertise with the client system.

The worker, and the nature of the working relationship, however, is directive in the sense that the worker is imposing a problem solving, planned change approach -- exerting influence of this kind is part of the professional role. As Pincus and Minahan (1977, p. 84) state, the relationship the generalist worker establishes with the client is a professional relationship.

There are common elements in all professional relationships which differentiate them from personal relationships. These elements are: 1) purposefulness: relationships are formed for purposes related to the worker's planned change effort; 2) client focused: devoted to the client's interests, needs, and aspirations rather than those of the worker; and 3) objectivity: self-awareness which allows the worker to step outside his own personal troubles and emotional needs and to be sensitive to the needs of others.

The Planned Change Process

It is important to examine the generalist planned change process itself, and the ways in which practice methods, roles, and functions are 
selected and applied in the course of practice. Use of the term, planned change process, reflects the fact that generalist social work practice is essentially a problem-solving, goal oriented process by means of a planned sequence of practice tasks and activities. This terminology, the planned change process, has been developed by Pincus and Minahan (1973) who go on to elaborate that...

The word 'plan' conveys the idea of a purposeful and well thought out scheme, method, or design for the attainment of some objective or goal. The word 'change' implies movement, a difference in, or alternative of a situation or condition from one point of time to another... (And) the word 'process' can be defined as a systematic series of actions directed toward some purpose... (Pincus and Minahan, 1977, pp. 8687).

The sequence of the generalist planned change process may be outlined as follows:

1) The experience of problems of living: the perception, whether by an individual, group, organization, or community, of a condition of stress or crisis;

2) Contact: the intial engagement of the worker and an actual or potential client. This may be initiated by the client or involve the outreach and detection efforts of the worker.

3) Assessment: a joint exploration by worker and client of the nature of the problematic life situation(s). This involves the identification and statement of the problem(s), data gathering and collection, ${ }^{26}$ analysis of the dynamics of the social situation, and of the feasibility and priorities for intervention;

${ }^{26}$ Data gathering and collection includes, for instance, but is not entirely limited to verbal and written questioning, interviewing, observation, use of existing written materials, public and case records. 
4) Contracting and goal setting: a) contracting -- a mutual decision or working agreement as to what needs to be done and how to do it; b) goal setting -- formulated in terms of explicitly stated, general goals and measurable objectives; the goal statement should specify the overall purposes of both worker and client; the objectives should more specifically identify the practice tasks to be performed and the responsibilities of both worker and client;

5) Intervention: based on the problem assessment, contracting, and goal setting an interventive plan is formulated. In a nutshell, intervention is the translation of purpose into specific practice tasks and activities. Intervention consists of the designing and carrying out of the tasks that must be accomplished for goal attainment (Pincus and Minahan, 1973). Intervention, thus, involves all of the practice activities engaged in by worker and client in order to accomplish the goals of the planned change effort. In doing so, the generalist worker is not only wiliing, but able as appropriate to assume a variety of interventive roles, select, and utilize various practice skills and techniques, and serve a variety of social work practice functions; 6) Evaluation: intervention is accompanied by ongoing and final evaluation of effectiveness. Evaluation involves both 1) an ongiong process of reassessment -- which should be a continuing activity throughout the planned change process, and 2) final or terminal evaluation with respect to the degree to which the goals and objectives of the planned change effort have been achieved; and finally,

7) Termination: is reached with 1) mutual agreement between worker and client, 2) evaluation to demonstrate that the goals and objectives have 
been achieved, and 3) follow-up to insure continuity of service provision.

As stated above, the generalist planned change process is planful, sequential, and purposeful, and in certain respects borrows from the scientific method of investigation and problem solving. Yet, these scientific, sequential aspects of the generalist planned change process should not be misconstrued -- the generalist planned change process is not entirely predetermined, linear, or fixed. One phase does not necessarily have to wait for the completion of the preceeding one. As Pincus and Minahan observe (1977, p. 87), to assume that there exists "...any logical linear sequencing of tasks is an oversimplification of the actual process. The worker may be operating in more than one phase at any one point, and with different types of systems...At various times...certain phases...may be repeated."

How does this sequence of events occur? The generalist worker begins with what may be termed as a needs perspective. The first concern is with problem solving and resolution -- that is, with the life tasks, problems, and obstacles confronting people and the resources which would facilitate coping and the realization of client potential and aspirations. The generalist worker places primary emphas is on what needs to be done, and in so doing, seeks the participation, advice, and consent of the client system. And in turn, this forms the basis for the setting of goals and objectives, after which "...the techniques and tasks required to satisfy those needs and achieve those goals are selected" (Klenk and Ryan, 1974). As Pincus and Minahan state (1973, p. 96), "After the purposes toward which the process of social work is 
directed have been determined, the next step is the translation of these purposes into specific tasks that must be accomplished in order to achieve them. The designing and carrying out of these tasks is the heart of practice."

The generalist planned change process is the means for effectively combining purpose and practice activity. As Pincus and Minahan (1977, p. 88) note, "The process of social work practice...calls for the worker to have a purpose for each (practice) activity as well as for the whole planned change effort." The insistence that methodological choices must be based on and follow from assessment and goal formulation is a distinguishing characteristic of the generalist planned change process -- for as Hartman (1974, p. 206) notes, "Specialized practitioners tend to prescribe the interventions they do well, so that it is not uncommon in the complex situations faced by social workers that an inapporpriate intervention is performed skillfully."

Whereas the specialist begins by judging the client's needs in terms of their suitability to his particular, predetermined method, the generalist begins with client defined needs, the goals and objectives relating to these needs, and then, as the situation warrants, selects the techniques and methodologies most appropriate to work on them. The generalist worker assumes, "...whatever roles and does whatever activities are necessary... His concern is the person in need -- not specific tasks or techniques, (agency) or professional perogatives" (Klenk and Ryan, 1974, p. 4). Thus, the worker will often have to work with and through many different sizes and types of systems, e.g., one-to-one 
relationships, families, community groups, and organizations, in working with a client system. The methodological approaches to general ist practice suggested by the model thus are not limited to any one size or type of client systems, social problems, or social work practice setting. The appropriate and potential size and types of systems to work with and through depends upon the nature and assessment of the task at hand.

In certain important respects the generalist social worker acts as kind of a general contractor -- and in this sense is similar to a general medical practitioner, who is not only willing but able to assume a variety of professional social work roles: as casefinder, service broker, coordinator, advocate, therapist, counselor, organizer, consultant, and others as required. The generalist worker, however, is cognizant of the rimits of his competence, and "... when the demands of a situation exceed these limits, he would be expected to call on experts for consultation (or) service delivery...(Still) he would tend to retain primary responsibility for services to that $\mathrm{Client"} \mathrm{(Klenk}$ and Ryan, 1974, p. 7). This is an important and distinguishing facet of generalist approach to social work practice. The generalist practitioner remains involved with the client system, act as a source of support, as a go-between, mediator, or whatever as necessary, and takes responsibility to insure the appropriateness and continuity of service.

\section{Generalist Practice Activity}

The previous section provided an overview of the generalist practice process. This section examines the nature of practice activity -- 
to consider what generalists actually do in their practice of social work.

The model conceptualizes and represents generalist practice activity in terms of the variety of roles and functions performed by generalist practitioners. In this section, then, we will provide an overview and analysis of practice roles and functions. Initially, we shall examine the nature and interrelationships between practice roles and functions, and their relation to the whole of generalist practice. Then, we shall identify and describe generalist practice roles and functions and their distinguishing characteristics.

Al though the concepts of social work roles and functions are interrelated in theory as well as in practice, they are by no means synonymous. Consequently, it is important to differentiate between them.

According to Webster (1959) function is defined as the proper or characteristic action of anything; or more specifically, as a special purpose or duty. With respect to social work practice, the concept, functions of social work, refers to that which has been identified as the special purposes, goals, and duties of social work practice. Role is defined as a part, or character, performed by an actor; or hence, a part taken or assumed by anyone (Webster, 1959). With respect to social work practice the concept, social work practice roles, refers to the assumption and performance, on the part of the social worker, of a combination or set of practice tasks and activities which carry with them certain responsibilities and expectations. 
The concept of social work practice roles is descriptive of what social workers do -- in terms of their practice tasks, activities, and responsibilities. Whereas, the concept of social work practice functions are descriptive of why, or toward what ends, goals, or purposes social workers engage in these various roles. In short, the social worker performs a role in order to fulfill a function or purpose.

Generalist social work practice roles and functions are highly interdependent and complementary -- that is one of the distinguishing characteristics and strengths of the generalist approach to practice. Generalist social workers select and perform various practice roles on the basis of the pruposes or functions that have been established for the planned change effort. The planned change process provides the means by which purpose is linked to task, and how generalist roles and functions are integrated into the course of practice. 27

Functions of General ist Social Work Practice

The functions of generalist social work practice stem from the sense of the mission for the profession of social work ${ }^{28}$-- to enhance the social functioning of people as well as the more effective and humane functioning of societal resource systems. Not surprisingly, the generalist approach emphasizes the need for social workers to "...be able to function at a variety of levels of intervention, to be comfort-

${ }^{27}$ See Pincus and Minahan (1973, pp. 96-98) for a more detailed description of how purpose is translated into task in generalist social work practice.

${ }^{28}$ See pages 125-126 for a description of this component of generalist practice. 
able and knowledgeable about interventions with systems and in communities as well as in direct work with individuals, because (problems in living)...may be at any one of these points" (Fischer, 1978, p. 28). The functions of generalist practice, thus, are varied and broad in scope.

As Pincus and Minahan (1973, p. 15) observe, generalist social work practice focuses "...on the interactions between people and resource systems and between resource systems." Based on this framework, the functions of practice have been well summarized by Minahan and Pincus (1977). Six major functions of generalist social work practice can be differentiated: ${ }^{29}$

1) Dispense material resources.

2) Help people enhance and more effectively utilize their own problem solving and coping capabilities.

3) Establish initial linkages between people and resource systems and among various systems to make them accessible to one another.

4) Facilitate interaction between individuals within resource systems to promote the effective and humane operation of these systems to enable them to work together effectively.

6) Help develop new resource systems to meet the needs of people. Although interrelated, there is no one-to-one relationship between any one given practice function and role. Any one of the practice

${ }^{29}$ This list is drawn from the work of Pincus and Minahan (1973, 1977 ) and Minahan (1977). We are utilizing their terminology and have only combined and reordered their listings of the functions of generalist practices. 
functions may be fulfilled by performing any number of practice roles. For example, in order to help clients develop and more effectively utilize their own internal problem solving and coping resources (the function), the worker could perform any of the following roles: counselor, therapist, enabler and/or instructor, model, or trainer. Or, in order to develop new community resources (the function), the worker could perform any of the following roles: consultant, educator, data collector, researcher, evaluator, advocate, organizer, or mobilizer.

\section{Generalist Social Work Practice Roles}

The most pressing task of social work, as Fischer (1978, p. 11) suggests, is to develop "...those services that offer the greatest promise of being translated into demonstratable positive gains for (its)...clients." Social work practice roles offer the means by which generalist practitioners are able to translate their sense of purpose -- what functions need to be fulfilled -- into appropriate and effective practice activities.

Both the number and types of social work practice roles performed by generalist are profoundly influenced by the other major aspects of this approach to social work practice:

1) The generalist practice perspective is holistic, eco-systemic, and eclectic. The knowledge base required for generalist practice is broad -- a wide range of theories, interventive approaches, and practice skills are utilized. The generalist view of the nature of problems is broad in scope, taking into account the need for social and environmental change as well as for individual client change. As 
Fischer observes, "...experience points to the fact that the diversity of problems and situations encountered in practice dictates the necessity of a response in kind: diversity of...roles to more adequately deal with such situations as they arise" (1978, p. 26).

2) The generalist practice process is systematic and purposeful. Generalist practice activity is guided by assessment of what needs to be done and by what appears to be most appropriate to the needs of clients. "The services...used are selected on the basis of the worker's assessment of what needs to be done...Actual practice... often involves the (social worker)...functioning in more than one role depending on the needs of the client situation" (Fischer, 1978, pp. 16-17). Or as Meyer comments "...methods become the servants rather than the masters of practice activities" (1979, p. 269).

Generalist practice roles have the following distinctive characteristics:

1) Diversity. Practice is characterized by a multiplicity of roles. These roles are diverse both in terms of their number and quality. They cover a broad (micro, mezzo, and macro) range of possible interventive approaches: intrapersonal, interpersonal, person-environment, and social/environmentally based.

2) Eclectic. Practice does not utilize or foeus on any one social work role or modality to the exclusion of others. As Fischer (1978, pp. 68-69) comments, "Essentially, eclecticism refers to a commitment to being guided in practice by what is most effective... This means that we look wherever we can for methods that work." Generalist practice is characterized by utilization of a balanced mixture of roles. 
3) Flexibility. (Generalist) practice roles are not highly specialized: the worker needs to be capable of performing a variety of roles -- depending on the needs and situations of $\mathrm{clients.} \mathrm{Thus,}$ neither the number or types of practice roles generalists perform are predetermined, fixed, or limited, by practice setting, agency, or specialty. The 'specialty' of generalist social workers is that they are able to respond to a variety of client situations often requiring a wide variety of services.

Given the large variety of practice roles within social work, several authors have developed frameworks for conceptualizing social work practice roles (Teere and McPheeters, 1970; Federico, 1973; Klenk and Ryan, 1974; Pincus and Minahan, 1973 and 1977; Fischer, 1978). Fischer groups social work practice roles into four major role clusters which he labels as follows: 1) the clinical/behavior changer, 2) the consultant/educator, 3) the broker/advocate, and 4) the researcher/ evaluator.

We have drawn substantially from Fischer. Since our model describes direct service generalist social work practice, we have consolidated Fischer's consultant/educator and researcher/evaluator into one category. Three primary role clusters can be differentiated.

1) Clinician/behavior changer;

2) Consultant, educator/researcher, evaluator;

3) Broker/advocate. 


\section{Clinician/Behavior Changer}

The social work practice roles belonging to this role cluster include the following: assessor, diagnostician, therapist, behavior changer, counselor, casemanager, casemonitor, caretaker, caregiver, and group facilitator.

The primary purposes of the roles within this cluster are 1) to provide psycho-social treatment and 2) to provide clients with necessary supportive services or maintenance, including both the provisions of emotional support as well as of necessary material resources.

Similarly, Klenk and Ryan (1974, p. 9) identify two primary objectives 30 associated with this role cluster:

Behavior Change: (The) primary objective is to bring about change in the behavioral patterns, habits, and perceptions of individuals or groups. The key assumption is that problems may be alleviated or crises prevented by modifying, adding, or extinguishing discrete bits of behavior, by increasing insights, or by changing the values and perceptions of individuals, groups, and organiztions.

Continuing Care: The primary objective is to provide for persons who need on-going support or care on an extended basis. The key assumption is that some persons will require constant...monitoring or continuous support and services (for example: financial assistance, 24-hour care), perhaps in an institutional setting or on a community basis.

According to Pincus and Minahan (1973, p. 9) the roles in this cluster share one basic function: to "...enhance the problem solving and coping capacities of people..." In order to work toward fulfilling this function there is virtually an infinite variety of possible social work

${ }^{30} \mathrm{Klenk}$ and Ryan (1974) conceptualize generalist practice in terms of an "objectives framework." Within their framework the term, objective, implies 1) a purpose for worker activitiy as well as 2) a method, or role. This is similar to Pincus and Minahan's concept of method goals. 
practice tasks and activities. For instance, the worker could attempt to provide support and encouragement, the opportunity for people to talk about their difficulties, help clients to organize their thoughts and feelings, provide understanding and help clients to view their life situations in new, constructive ways, facilitate problem solving and decision making, and where appropriate confront people with the reality of their life situations and attempt to motivate them to change (Pincus and Minahan, 1973). As Pincus and Minahan (1977, p. 93) observe, "the worker's activities might include eliciting information and opinions, facilitating expression of feelings, interpreting behavior, discussing alternative courses of action, clarifying situations..." In doing so the worker may act as an advisor, counselor, therapist, behavior changer, or crisis intervenor (Fischer, 1978).

In sum, there are numerous social work practice tasks and activities as well as several basic social work functions associated with the roles in this cluster. First, are those clinical tasks and activities related to psychosocial treatment. These include enhancing client problem solving and coping skills, providing therapeutic intervention to facilitate behavior change, conflict resolution, or growth, and developing treatment contracts with specific, time limited goals. Second, are those practice tasks and activities related to the support and maintenance of clients. These include providing understanding, support and encouragement, arranging for the provision of supportive and caretaker services, e.g., such as day care, shelter or foster care, homemaker services, and insuring for the provision of material resources 
to clients, e.g., such as employment, housing, financial, or medical assistance.

In actual social work practice there is a great deal of overlap between the various practice tasks and activities involved in each of the major role clusters. For example, a large part of what constitutes therapy, or part of the clinical role, is actually instruction, or part of the educator role (Klenk and Ryan, 1974). Often it is therapeutic to teach by modeling or to educate by providing information. Similarly, acting in the role of educator or consultant, the social worker might need to be supportive and encouraging and have knowledge of group process.

Consultant, Educator/Researcher, Evaluator

The social work practice roles belonging to this role cluster include the following: consultant, educator (instructor, teacher, trainer), supervisor, data collector, researcher, and evaluator.

The primary functions of the roles within this cluster are twofold:

1) person centered: to help people to develop and more effectively utilize their own internal capabilities, and

2) system centered: to help community or societal resource systems become more effective and humane in their operation and in meeting the needs of people.

Klenk and Ryan (1974, pp. 10-11) identify several objectives which are associated with the roles in this cluster: 
Instruction: The primary objectives are to convey information and knowledge and to develop various kinds of skills.

Consultation: The primary objective is to help other workers or agencies increase their skills and to help them to assist their clients to solve their social welfare problems.

Information Processing: The objective is to collect, classify, and analyze data generated within the social welfare environment; included would be data about the individual case, the community, and the institution.

Evaluation: Involves gathering information, assessing personal or community problems, weighing alternatives and priorities, and making decisions for action.

Detection: The primary objective is to identify persons or groups who are experiencing difficulty, or are in danger of doing so (at risk). A further objective is to detect and identify conditions in the environment that are contributing to the problems or are raising the level of risk.

Similarly, Pincus and Minahan (1973, p. 113) identify a cluster of social work practice roles which they term the educative approach.

The educative approach covers a cluster of roles such as those of teacher, expert, and consultant. The objective is to help people and systems acquire information, knowledge, and skilis.

And as Fischer (1978, p. 19) notes, within this role cluster the social worker "...may function to provide information, interpret rules or regulations, teach or transmit knowledge, and so on." The services in this role cluster may be provided to other human service workers, agencies and programs, or to people identified as clients (Fischer, 1978).

Thus, using this role cluster generalist social workers can assume both direct and indirect service roles. The worker performs personcentered practice roles directly with and in behalf of clients. As Pincus and Minahan (1977) suggest typical activities the worker might 
engage in are giving information and advice, providing feedback, teaching skills, role playing and modeling, and demonstrating behavior. In addition, the worker performs system centered practice roles with community organizations, human service agencies and their staffs. Typical activities the worker might engage in are providing consultation services to community resource systems, such as sharing expertise, research or evaluative data, providing inservice training or supervision to program staff, providing information to encourage or influence programs or agencies to examine and change aspects of their policies or operating procedures which hinder service delivery, and working to estabiish the need for the development of new resource systems.

As noted above, the distinctions between these three role clusters, although conceptually valid, often become blurred in practice. This is largely because these role clusters, although different in overa) 1 focus, are well integrated and complementary. For instance, in acting as a consultant, educator, researcher, or evaluator in order to improve the functioning of resource systems or to develop new resource systems, the worker is also acting within the realm of the broker/ advocate role cluster.

\section{Broker/Advocate}

The social work practice roles belonging to this role cluster include the following: outreach worker and problem identifier; resource broker, locator, and referral maker; coordinator; mediator; developer; advocate; organizer; mobilizer; community activist; and planner. 
As Fischer emphasizes the broker/advocate role cluster is "...not onty... (one of) social work's most traditional and...important roles... (but) a moral imperative as well" (1978, p. 22).

In addition, Fischer (1978, p. 22) observes that:

The broker/advocate role...encompasses a wide range of functions and services, all of which are centered around the notion that it is a primary responsibility of the (social worker)... to try to enhance the coordination of persons with institutions, to see that there is a constructive articulation between society and society's members.

Pincus and Minahan (1977, p. 348) have identified five primary functions of social work practice -- four of which clearly pertain to this role cluster:

1) Help develop new resource systems to meet the needs of people.

2) Establish initial linkages between people and resource systems to make them accessible to one another.

3) Facilitate interaction between individuals within resource systems to promote the effective and humane operation of these systems to make them responsive to people's needs; and

4) Facilitate ongoing interactions between resource systems to enable them to work together effectively. 6

As with the consultant, educator/researcher, evaluator role cluster, the primary objectives of the broker/advocate role cluster

${ }^{5}$ Throughout the generalist social work 1 iterature, marked consensus exists as to the importance of the functions of this role cluster -that of facilitating effective and humane societal resource provision (Pincus and Minahan, 1973; 1977; Klenk and Ryan, 1974; Middleman and Goldberg, 1974; Meyer, 1976; Siporin, 1975; Fischer, 1978).

${ }^{6}$ These functions also relate to the consultant, educator/researcher, evaluator role cluster. Fulfilling these functions often requires that the worker be capable of performing various roles from both role clusters. Both of the role clusters have similarities and are, in fact, complementary. For instance, many of the concepts they employ are alike: person/system centered; case, group, and community consultation; case, broker/group, class advocacy. 
similarly have a two-fold nature: "The performance of roles within this cluster...calls for a balance of person and system oriented interventions, differentially performed depending on the needs and priorities of each situation" (Fischer, 1978, p. 23). Fischer (1978) lists what he considers to be the major objectives of broker/advocate roles: locating resources, providing referrals, facilitating the provision of concrete and/or material aid; mediating or negotiating between clients and specific resource systems, detection and problem identification, and aggressive representation of clients' rights to help clients obtain specific resources or services.

Klenk and Ryan (1974, p. 10-11) specify in greater detail several of the objectives associated with performance of the roles within this ciuster:

Linkage: The...objective is to steer persons toward the existing services that can benefit them. Its focus is on enabling or helping them to use the system and to negotiate its pathways.

Advocacy: The objective... is to gain the rights and dignity of persons in need of help. The key assumption is that sometimes practices, regulations, and general conditions will prevent a person from receiving services... Advocacy aims at removing the obstacles or barriers to the exercise of a person's right to the receipt of the benefits and use of the resources they need.

Mobilization: The...objective is to assemble and energize existing groups, resources, or organizations... and to bring them to bear on current or incipient problems. Its principle focus is on available or existing institutions, organizations, and resources within the community.

Community Planning: The objective is to assure that the service needs of the community are represented and met as well as possible by groups and agencies at all levels... This involves participating in and assisting neighborhood planning groups, (and) agencies... in the development of their programs. 
There are a variety of practice approaches and skills, tasks and activities involved in performing any of the roles within the broker/ acvocacy role cluster:

1) Locating resources: canvassing the community, contacting various resource systems, and learning about the services, policies and procedures, and staff of community resource systems;

2) Information sharing: informing clients about available resources and how to work with resource systems;

3) Making referrals: learning referral procedures and protocol, referring clients to resource systems, and otherwise helping clients gain access to resource systems;

4) Coordinating service delivery: establishing and maintaining working relationships with resource systems and service providers, and attempting to insure coordination, continuity, and appropriateness of service delivery;

5) Advocating for clients' resource needs: mediating and negotiating between $\mathrm{clients}$ and resource systems, representing $\mathrm{clients}$ rights and claims to resource provision, helping clients to gain acces to resources, removing obstacles to resource provision, e.g., helping to cut red tape;

6) Providing outreach: seeking out and identifying groups of people who are in need, but who may not be aware of available resource systems or about how to gain access to them; and

7) Developing new resources: identifying and documenting gaps or unmet service needs in the community, organizing and mobilizing client groups 
and community support, and participating in task forces, community advisory boards, etc.

Middleman and Goldberg (1974) provide insight into one of the distinguishing aspects of this role cluster. They note that the objectives and practice tasks associated with performance of broker/advocate roles are directed primarily toward social or environmentally based change. ${ }^{33}$ There are, however, a variety of possible interventions -directed toward changing clients' environments in some way -- to utilize as a means with which to facilitate effective and humane resource provision.

For instance, the worker may begin acting as a broker who shares information with clients about resource systems and refers clients to these resource systems. Or, the worker may act as a mediator, if clients and resource systems experience different or conflicting expectations regarding resource provision. In those instances where community resources are failing to make adequate and appropriate resource provision, the worker may need to assume the role of client advocate or community activist. In such instances the worker may need to aggressively represent $c l i e n t s '$ needs and to confront and challenge resource systems in order to help clients obtain necessary resources.

The foregoing is a hierarchy of possible broker/advocate roles. Within this progression, and in relation to the established goals of the planned change effort, the worker would initially tend to assume

${ }^{33}$ This contrasts with the objectives of the clincian/behavior changer role cluster where the focus is on facilitating internaliy or behaviorally based client change. 
more aggressive, confrontive, or conflictual roles only if performance of collaborative and bargaining roles had proven ineffective. Thus, generalist social workers would use only as much confrontation or conflict as would appear necessary to meet the needs of clients. This concept has been termed by Middleman and Goldberg (1974) as the principle of least contest. As a practice principle it is fully consistent with the value premises underlying generalist practice. In addition, this practice principle provides a pragmatic guide for the selection of appropriate interventive strategies and the assumption of the various possible practice roles within the broker/advocate cluster. 


\section{CHAPTER $V$}

\section{RESEARCH APPLICATIONS OF THE MODEL}

The original goals of this research project were to: (1) develop a comprehensive model/analysis of the generalist approach to social work practice, (2) construct a questionnaire, derived from the model, capable of operationally defining generalist practice in empirical terms, and (3) conduct a survey of generalist social work practice in Oregon. These goals proved to be too ambitious, since it has not been feasible to conduct the survey, the scope of this project has become more limited. We did, however, expend considerable time and effort in designing a questionnaire and developing a research design for the proposed research project. The purposes of this chapter are: (1) to examine the research applications of the model, (2) to present a proposal and research design for a descriptive survey of generalist social work practice in Oregon, and (3) to discuss the derivation, design, and utilization of the questionnaire.

\section{The Research Problem}

As represented in the 1 iterature, the generalist approach has been in the vanguard of social work practice theory for most of the past decade. Ideally, social work practice theory has value largely in so far as it informs and pertains to issues of social work practice; yet, to date, there have been no empirical studies of generalist practice in the field, nor have there been any research instruments, developed to 
study generalist practice. Although much has been written to describe and define generalist practice, there has not been any research to determine if there are any generalist practitioners. If generalist practitioners do exist, then what are the factors -- such as characteristics of the practitioner or practice context -- that tend to be coorelated with their practice? Research findings of this nature would be of value to social work educators and theorists as well as of interest and relevance to social work practitioners.

The purpose of the research project is to conduct a descriptive survey of generalist social work practice in Oregon. The primary research problem is to determine the extent to which social workers in Oregon practice in accordance with the generalist approach. Empirically, the research project is intended to generate data regarding the extent to which social work practitioners report a set of concepts, or ways of thinking about social work practice, and a range of practice activities, or ways of doing social work practice, that are consistent with the generalist approach to social work practice as represented by the model.

The secondary research problem, assuming that there are generalist practitioners in Oregon, is to determine what factors are correlated with generalist practice. Empirically, the research project is intended to generate data that can be used to establish correlations between generalist practice, practitioner characteristics, and practice contexts. A questionnaire, derived from the model, was developed as the research instrument to generate the data necessary for the research project. 1 
Although the authors firmly believe in the appropriateness and efficacy of the general ist approach for social work practice, our purpose is not to prove its effectiveness or supremacy. Nor is our purpose to establish any statistically valid causal relationships, especially since the nature of the research problem does not lend itself to precise quantification; rather the purpose is mainly descriptive.

Research Hypotheses, Questions, and Variables

(I) The primary research question pertains to the occurence of non-occurence of generalist social work practice:

To what extent will social work practitioners report a set of practice concepts and a range of practice activities that are consistent with generalist practice as represented by the model?

Two hypotheses follow from this:

(Ia) Social work practitioners utilize ways of thinking about their practice that are consistent with the set of generalist practice concepts as represented in the model; and

(Ib) Social work practitioners perform a range of activities that are consistent with the set of generalist practice activities as represented in the model.

(II) The secondary research questions pertain to identifying those factors -- characteristics of the practitioner and/or practice setting -- that are correlated with the occurrence of generalist practice.

(A) Practitioner Characteristics: Is the occurrence of generalist practice correlated to: 
(1) The age of the practitioner?

(2) The sex of the practitioner?

(3) The educational background of the practitioner?

(4) The number of years social service work experience?

(B) Practice Context: Is the occurrence of generalist practice correlated to:

1) The funding source ${ }^{2}$ of the agency setting?

2) The size of the agency setting?

3) The field of service or target problem of the agency setting?

4) The size of the community in which the agency/practice setting is located.

The dependent variable is defined as the occurrence or non-occurrence of generalist social work practice as represented by the model. Parts Two and Three of the questionnaire were designed as a measure of the dependent variable -- that is, to measure the extent of generalist social work practice. The occurrence of generalist practice as measured by the questionnaire is operationally defined as a total score greater than or equal to 176 (mean greater than or equal to 4 ) for all 44 items in Parts Two and Three of the questionnaire. ${ }^{3}$

The independent variables are defined as various demographic factors regarding the characteristics of practitioners and their practice contexts. The practitioner characterics to be studied include: age,

2 Funding source refers to the type of agency: public, private-nonprofit, and private-profit.

${ }^{3}$ See below pp. 159-161 for a more detailed explanation of the scoring procedure and data analysis. 
sex, educational background, and years of social work experience. The practice context factors to be studied include: agency size, funding source, field of service or target problem, and location and population of the community setting. ${ }^{4}$ Part One of the questionnaire was designed to generate this data.

These independent variables pertain to the secondary research questions and hypotheses -- the data generated regarding these variables will be used to establish possible correlations with the dependent variable. For example, we are interested in knowing if generalist practice is more prevalent in rural than in urban areas. Several social work writers (Couch et al, 1977, and Sundet and Mermelstein, 1976) have claimed that the generalist approach is particularly appropriate for social work in rural areas. In addition, we wonder if generalists tend to be younger than non-generalist practitioners. Since the teaching of the generalist approach is a relatively new development in social work education, it would be expected that generalist practitioners would tend to be relatively young, new to the social service field, and recent graduates of MSW programs.

Population and Sampling

The population to be sampled would include all direct service social work practitioners in Oregon who are members of the National Association of Social Workers (NASW) at the bachelors, masters, or doctorate levels.

${ }^{4}$ We are interested to examine if any factors of the community setting -- such as population, geography, rural/urban -- have an influence on the occurrence of generalist practice. 
To obtain a representative sample of this population, it should: (1) "Be representative of the population from which it is selected, (that is) all members of the population (should) have an equal chance of being selected in the sample" (Babbie, 1971, p. 78), and (2) Select a large sample in order to insure that diverse factors (such as age, years of experience, agency size, etc.) are proportionately represented.

The proposed random sample would include 20 percent (or approximately 150 social workers) of the NASW membership in Oregon. Sample selection would be accomplished by utilizing a random number total.

In order to increase the response rate, cover letters would accompany the initial mailing of the questionnaires and follow-up letters would be utilized as needed.

The Research Instrument

Derivation of the Questionnaire. The questionnaire was designed to operationalize the model so that it could be empirically tested.

The model is a conceptual representation of both the cognitive and behavioral aspects of generalist social work practice. Similarly the questionnaire contains items which measure the extent of generalist ways of thinking as well as of generalist practice activities. The model utilizes ten primary constructs. Each model construct, e.g., knowledge base, is operationalized by specifying several logically related conceptual elements. For example, eco-systemic, holistic, and eclectic are conceptual elements associated with the construct, knowledge base. In turn, each conceptual element is further defined and described in terms of its specific characterics and attributes. 
The questionnaire is constructed of items that contain statements which represent and describe these conceptual elements and their characteristics as identified in the model. As much as possible, questionnaire items were written to employ the same phrasing and terminology as used in the model. In addition, certain questionnaire items, particularly those items in Part Three, which measure general ist practice activity, were derived from a thorough review of the literature on generalist practice.

Appendix $3^{5}$ lists all 44 (non-demographic) items in the questionnaire and shows their relationship and derivation from the model. Each questionnaire item is 1 isted with its related model construct, conceptual element and characteristics.

The items in the questionnaire cover every construct of the model. Thus the questionnaire may be used to measure the extent that generalist ways of thinking and practicing -- as represented by the model -- are present in the respondents' social work practice.

Questionnaire Design

The questionnaire is organized into three parts.

Part One, of the questionnaire, was designed to generate demographic data useful for discussing and analysing the influence of the independent variables. In the first section of Part One, under the heading of Practitioner Characteristics, respondents are asked questions regarding their age, sex, educational background, and length of employ-

${ }^{5}$ See pp. 178. 
ment in the social services. In the second section under the heading of Practice Context, questions are asked regarding the agency size, funding source, field of service or target problem, and the population and type of community setting.

Part Two of the questionnaire was designed to generate data regarding the extent that respondents express agreement with general ist ways of thinking about social work practice. Part Two contains 22 items that represent various social work theoretical orientations and practice perspectives (see hypothesis Ib). Half of the items in Part Two contain statements that are representative of generalist ways of thinking about social work practice; the other half of the items contain statements that are representative of non-general ist practice perspectives. Appendix $B$ identifies both generalist and non-generalist items. Items were selected for inclusion in Part Two based on their ability to clearly represent a generalist or non-generalist practice perspective as well as their consistency with the model and its terminology.

Part Three of the questionnaire was designed to generate data regarding the extent that respondents engage in generalist practice activities. Part Three contains 22 items which describe essential generalist practice tasks and activities (see hypothes is 1b, p. 153).

In the literature review we discovered two general approaches were utilized to describe social work practice activities. One approach identifies activities in terms of their social work practice functions; the other approach describes social work practice roles or role 
clusters. In an effort to be systematic and comprehensive we utilized both approaches as a basis for selecting questionnaire items for inclusion in Part Three.

A comprehensive range of generalist practice activities was defined as a list that would be consistent with the model's representation of generalist practice activities, as well as cover the full range of generalist practice roles and functions as outlined in the literature. Our first list contained 265 items. It was reduced by eliminating duplicate items or those items that did not clearly identify a distinctly generalist practice activity.

The items selected for inciusion in Parts Two and Three of the questionnaire were then randomly ordered -- we wanted to minimize whatever possible influence the sequence of the questions might exert on the respondents.

The questionnaire utilizes a Likert-type scale. The Likert scale format was chosen for the following reasons:

(1) it is easier to devise than other scales, such as multiple choice;

(2) fewer items are needed with a Likert scale for reliability than with other types of scales; and

(3) it was well suited to the research problems under study in that it lends itself well to having respondents rate their agreement with items as well as the frequency of their behavior with respect to each item.

In sum, our questionnaire asks respondents to rate the extent of their agreement or disagreement with a series of items representing various social work practice concepts and principles, and to rate the 
frequency of their engagement in certain activities. In this way each item is used as a partial measure of generalist practice. Individual respondents will be rated as generalists when their scored responses indicate sufficient agreement with a generalist practice perspective and sufficient engagement in generalist practice activity. Individual respondents whose responses do not meet our criteria for sufficiency will be rated as non-generalists.

A respondent's practice rating depends on his scores for those items in Parts Two and Three of the questionnaire.

In Part Two of the questionnaire respondents are asked to rate the extent to which they agree or disagree with a series of items representing various social work practice concepts and perspectives. The instructions define a response of " 1 " as "strongly disagree", a response of "3" as "uncertain", and a response of "5" as "strongly agree". Although a response of "2" is not defined, such a response may be taken to mean a measure of disagreement that is greater than "uncertain" but less than "strongly disagree". Similarly a response of "4" may be taken to mean a measure of agreement that is greater than "uncertain" but less than "strongly agree".

One half of the items in Part Two represent generalist practice concepts and principles, while the other half represent non-generalist practice concepts and principles. The generalist items are scored by using the number written down by the respondent. The non-general ist items are scored inversely to the respondent's rating. That is, a rating of "1" by the respondent would be scored as "5", a "2" would be scored as a "4", a "3" as a "3", a "4" as a "2", and a "5" as a "1". 
In Part Three of the questionnaire respondents are asked to rate each item in terms of the frequency with which they engage in a practice activity. Each item states an activity identified as consistent with and essential to generalist practice. All the items in Part Three are generalist items, and therefore the scoring procedure is the same throughout.

Data Analys is

Data obtained from Parts Two and Three of the quesionnaire can be analyzed in at least two different ways: (1) by calculating the respondent's total score in order to determine whether or not his or her practice can be called generalist, and (2) by examining the profile of construct scores to determine in what areas the respondent's practice resembles or differs from generalist practice. In accordance with our operational definition of generalist practice, a respondent will be said to be a generalist practitioner if his total score for the 44 items is greater than or equal to 176 (a mean score greater than or equal to 4). In addition to determining each respondent's overall generalist practice score, additional information concerning his/her practice may be obtained by examining the scores for each practice construct. The score for each construct may be found by summing the scores for all those items which are partial measures of that construct and dividing by the number of items. This procedure produces a mean score which represents the respondent's rating for a particular construct. A mean score of greater than or equal to 4 is considered to indicate generalist practice. A score of less than 4 would indicate non-generalist practice. 
CHAPTER VI

\section{CONCLUSION}

In this research practicum we have presented a generalist model for direct service practice, which we believe is more comprehensive and adequate than most traditional social work practice models. In addition, we have constructed a questionnaire based on this model which can be used to identify the relative presence and/or absence of this form of generalist practice and which can then serve as a first step in researching the relative effectiveness and feasibility of this generalist approach to social work practice. We believe that such research will bear out our contention that generalist practice is indeed an improvement over traditional forms of service delivery, and we urge other social workers to engage in research designed to test this hypothesis.

Current social work is primarily based on traditional models of practice. Many of these traditional casework practice perspectives viewed clients as personally deficient and responsible for their problems -- even if their problems were environmentally caused -- which has resulted in a "blaming of the victim." At times these perspectives have contributed to coercive and punitive treatment of clients. Consequently, often social workers have provided one-dimensional, inappropriate services which have been largely ineffective in meeting the needs of clients. 
The influence of the agency setting has also greatly limited the effectiveness of social workers. Often the organizational needs of the agency have predominated over the interests of clients. The profession's preoccupation with specialization throughout its history has brought certain advantages but the costs have been severe, including fragmentation, polarization, professional turf building, interagency competition and distrust. The net result of this specialization has been a lack of coordination and cooperation between various agencies and social service personnel and a consequent lack of effectiveness in meeting the needs of clients.

Social work can no longer afford the luxury and liabilities of increased specialization without integration. Given the increasingly conservative fiscal and political climate in the United States, particularly with respect to social service funding, the bottom line is that the profession must develop practice approaches that will enable it to do more with less. Social workers face the challenge of providing a larger variety of appropriate and effective social services with less funding and manpower resources. Without question, need exists for social service practitioners who have the training, capability, and willingness to effectively respond to a variety of human service needs and clientele. The relevance of a generalist approach to social work practice is ever increasing, the profession must develop and utilize a more integrated, flexible, and multi-facited approach to social work.

Given these considerations, in our opinion the generalist approach offers the greatest potential for developing a more humane and effective social work practice. Generalist social work practice, 
however, is still in its formative stage of development. While the literature reflects an ever-increasing number of propositions and ideas about generalist practice -- that is a body of generalist practice theory -- there is a definite need to incorporate and implement theory into practice. Therefore, we want to stimulate social workers to take an increased interest in the generalist approach and to discover ways by which they can incorporate generalist perspectives and practice principles into their day to day practice. And finally, there is a great need for empirical research to study generalist practice with respect to its effectiveness, feasibility, and to identify those practice contexts for which it is most appropriate. 


\section{A SELECTED BIBLIOGRAPHY}

Adams, Jane. Twenty Years at Hull House, MacMillan Co., New York, 1910.

Alexander, Chauncy. "Social Work Practice: A Unitary Conception," Social Work, 22:5 (September 1977).

Allport, Floyd H. Theories of Perception and the Concept of Structure, John Wiley and Sons, New York, 1955.

Altmeyer, Arthur. "Dynamics of Social Work," Social Work, 1:2, (April 1936).

Auerswald, Edgar. "Interdisciplinary Versus Ecological Approach," in The Practice of Social Work, Robert Klenk and Robert Ryan, (editors), 2nd edition, 1974, Wadsworth Publishing Co., Belmont, California.

Babbie, Earl. Survey Research Methods, Wadsworth Publishing Co., Belmont, California, 1971.

Bartlett, Harriet. The Common Base of Social Work Practice, National Association of Social Workers, New York, 1970.

Bisno, Herbert. The Philosophy of Social Work, Public Affairs Press, Washington, D.C., 1952.

Bisno, Herbert. "How Will Social Work Be?" Journal of Social Work, Vol. 2 (April 1956).

Boehm, Werner $W$. "The Nature of Social Work," Social Work, 3:2 (Apri1 1958).

Bolter, Agnes. Toward a Generic Conceptualization of Human Systems, School of Social Welfare, University of California, Berkeley, California, 1962.

Borenzweig, Herman. "Social Work and Psychoanalytic Theory: A Historical Analysis," Social Work 16:1 (January 1971).

Briar, Scott. "The Casework Perdicament," Social Work, 13:1, January, 1968.

Briar, Scott, Miller, Henry. Problems and Issues in Social Casework, Columbia University Press, New York, 1971.

Brown, Phil. Radical Psychology, Harper Colophon Books, New York, 1973. 
Chambers, Clark A. Seedtime of Reform, University of Minnesota Press, Minneapolis, 1963.

Chin, Robert. "Utility of the System's Model," in The Planning of Change: Readings in the Applied Behavioral Sciences, Wamer Bennis (editor), Holt, Rinehart, andWinston, New York, 1961 .

Cooper, Shirley. "Social Work: A Dissenting Profession," Social Work, 22:5 (September 1977).

Couch, Beverly. "A Specialist/Generalist Model of Social Work Practice for Contemporary Rural America," in Social Work in Rural Areas: Preparation and Practice, Ronald Green and Stephen Webster (editors), University of Tennessee School of Social Work, 1977.

Cross, James. "Can Casework Be Rationale?" Social Work, 24:5 (May 1979).

Dean, Walter R. Jr. "Back to Activism," Social Work, 22:5 (September 1977).

Encyclopedia of Social Work, National Association of Social Work, New York, 1977.

Eysenck, Hans. "The Effects of Psychotherapy," International Journal of Psychiatry, Vol. 1 (January 1965).

Federico, Ronald C. The Social Welfare Institution, D.C. Health and Co., Lexington, Massachusetts, 1976.

Ferguson, El izabeth A. Social Work, An Introduction, J. B. Lippincott Co., Philadelphia, 1969.

Fischer, Joel. "A Framework for the Analysis and Comparison of Clinical Theories of Induced Change," Social Service Review, Vol. 45 (December 1971).

Fischer, Joel. "Is Casework Effective?" Social Work, 18:1 (January 1973).

Fischer, Joel. Effective Casework: An Eclectic Approach, McGraw Hill Book Co., 1978 .

Germain, Carel B. "Social Study: Past and Future," in Social Casework, 49 (JuTy 1968).

Germain, Carel B. "Casework and Science: A Historical Encounter" in Theories of Social Casework, Roberts, Robert W. and Nee, Robert H., (eds.), University of Chicago Press, Chicago, Illinois, 1970.

Germain, Carel B. "An Ecological Perspective in Casework Practice," Social Casework, 54 (June 1973). 
Gitterman, Alex and Germain, Carel B. "Social Work Practice: A Life Model, Social Service Review, 50:4 (April 1976).

Goldstein, Howard. Social Work Practice: A Unitary Approach, University of South Carolina Press, Columbia, South Carolina, 1973.

Gilbert, Neil and Specht, Harry. Dimensions of Social Welfare Policy, Prentice-Ha11, Inc., Englewood Cliffs, New Jersey, 1974.

Gordon, William E. "Knowledge and Value: Their Distinction and Relationship in Clarifying Social Work Practice," Social Work, 10:3 (July 1965).

Gordon, William E. "Basic Constructs for an Integrated and Generative Condeption of Social Work," in The General Systems Approach: Contribution Toward a Hol istic Conception of Social Work, Council on Social Work. Education, New York, 1969.

Hamilton, Gordon. Theory and Practice of Social Casework, Columbia University Press, New York, 1940.

Harrington, Michael. The Other America: Poverty in the United States, MacMillan Company, New York, 1962.

Hartman, Ann. "The Generic Stance and the Family Agency," Social Casework, Vol. 55 (April 1974).

Hearn, Gordon. Theory Building in Social Work, University of Toronto Press, Toronto, Canada, 1958.

Hearn, Gordon (editor). The General Systems Approach: Contributions Toward an Hol istic Conception of Social Work, Council on Social Work Education, 1969.

Hearn, Gordon. "General Systems Theory and Social Work," in Social Work Treatment, Francis Turner (editor), Free Press, New York, 1974.

Holl is, Florence. Casework: A Psychosocial Therapy, Random House, New York, 1972.

Hyman, Herbert. Survey Design and Analysis, Free Press, New York, 1955.

Kaufman, Jack. "Jane Addams and Mary Richmond: The Constrasting Roots of a Hybrid Profession," in Journal of Social Wel fare, University of Kansas.

Kettner, Peter M. "A Framework for Comparing Practice Models," Social Service Review, 49:4 (December 1975).

Klein, Alan F. Social Work Through Group Process, University of New York, School of Social Welfare, Albany, New York, 1970. 
Klenk, Robert and Ryan, Robert. The Practice of Social Work, 2nd edition, Wadsworth Publishing Company, Belmont, California, 1974.

Kluckhohn, Clyde and Murray, Henry A. Personality in Nature, Society, and Culture, 2nd edition, Alfred Knopf Publisher, New York, 1953.

Knopka, Gisela. Social Group Work: A Helping Process, Prentice Hall, Engl ewood Cliffs, New Jersey, 1963.

Lang, Norma. "A Broad Range Model of Practice in the Social Work Group," in Klenk and Ryan (editors), The Practice of Social Work, op. cit.

Lathrope, Donald. "The General Systems Approach in Social Work Practice," in Gordon Hearn The General Systems Approach: Contributions Toward an Hol istic Conception of Social Work, op. cit.

Lee, Porter. Social Work as Cause and Function, New York School of Social Work, Columbia University Press, New York, 1937.

Levy, Charles S. "The Value Base of Social Work," Journal of Education for Social Work, 9:1 (Winter 1973).

Levy, Charles. "On Concepts, Conceptualizations and Conceptual Frameworks," Social Work, 23:5 (September 1978).

Lutz, Werner. Concepts and Principles Underlying Social Work Practice, National Association of Social Work, New York, 1956.

McPheeters, Harold, and Teare, Robert. Manpower Utilization in Social Welfare, Southern Regional Education Board, At7anta, Georgia, 1970.

Mermelstein, Joanne, and Sundet, Paul. "Social Work Education for Rural Program Development," in Social Work in Rural Conmunities, Leon $H$. Ginsberg (ed.), New York: Council on Social Work Education, Inc., 1976.

Merton, Robert. Social Theory and Social Structure, Free Press, Glencoe, Illinois, 1957.

Meyer, Carol H. "Direct Services in New and 0ld Contexts," in Shaping the New Social Work, Alfred J. Kahn (editor), Columbia Press, New York, 1971.

Meyer, Carol H. "Practice Models: The New Ideology," in Smith College Studies in Social Work, 43:2 (February 1973).

Meyer, Carol H. Social Work Practice: A Response to the Urban Crisis, 2nd edition, Free Press, New York, 1976.

Meyer, Carol H. "What Directions for Direct Practice?" Social Work, 24:4 (JuTy 1979). 
Middleman, Ruth. "Generalists and Specialists," Social Work, 22:2 (March 1977).

Middleman, R., and Goldberg, G. Social Service Delivery: A Structural Approach to Social Work Practice, Columbia University Press, New York, 1974.

Miller, James G. "Toward a General Theory for the Behavioral Sciences," American Psychologist, Vol. 10, 1955.

Minahan, Anne. "Generalists and Specialists in Social Work: Implications for Education and Practice," Arete, 4:2 (Fal1 1976).

Minahan, Anne, and Pincus, Allen. "Conceptual Framework for Social Work Practice," Social Work, 22:7 (September 1977).

National Association of Social Workers. Standards of Social Services' Manpower, Washington, D.C., 1974.

Nelson, Judith C. "Social Work Fields of Practice, Methods and Models: The Choice to Act," Social Service Review, 49:2 (June 1975).

Perlman, Helen H. Social Casework, A Problem Solving Process, University of Chicago Press, Chicago, I7linois, 1957.

Perlman, Helen $H$. "Believing and Doing: Values in Social Work Education, Social Casework, 57:6, 1976.

Peterson, K. Jean. "Assessment on the Life Model: A Historical Perspective," Social Casework, 60 (December, 1979).

Pincus, Allen, and Minahan, Anne. Social Work Practice: Model and Method, Peacock Publishers, Inc., Itasca, I1linois, 1973.

Pincus, Allen, and Minahan, Anne. "A Model for Social Work Practice," in Integrating Social Work Methods, Harry Specht and Anne Vickey (eds.), George Allen Ltd., London, 1977.

Pinker, Robert. Social Theory and Social Policy, Heinemann Educational Books Ltd., London, 1971.

Piven,Francis F., and Cloward, Richard A. Regulating the Poor: The Functions of Public Welfare, Tavistock Publishing Co., London, 1972.

Piven, Francis F., and Cloward, Richard A. "Notes Toward a Radical Social Work," in Radical Social Work, Roy Bailey and Mike Brake (eds.), Pantheon Books, New York, 1975.

Piven, Francis F., and Cloward, Richard A. Poor Peoples Movements, How They Succeed and Why They Fail, Pantheon Books, New York, 1977. 
Rank, Otto. Will Therapy, and Truth, and Reality, Knopf Publishing, New York, 1947.

Reid, William, and Epstein, Laura. Task Centered Casework, Columbia University Press, New York, $19 \overline{72 .}$

Reynolds, Bertha. "Rethinking Social Casework," Social Work Today, 5:5 (Apri1 1938).

Richmond, Mary E. Friendly Visiting Among the Poor: A Handbook for Charity Workers, MacMillan Company, New York, 1899.

Richmond, Mary E. Social Diagnosis, Russell Sage Foundation, New York, 1917.

Roberts, Robert W., and Nee, Robert H. (editors). Theories of Social Casework, University of Chicago Press, Chicago, Illinois, 1970.

Robinson, Virginia. A Changing Psychology of Social Casework, Chapel Hili University Press, New York, 1930.

Ross, Murray. Community Organization: Theory and Principles, Harper and Row, New York, 1955.

Rubin, Gerald K. General Systems Theory and Selected Modalities of Social Work Intervention: A Conceptual Analysis, University of Denver, School of Social Work, 1970.

Ryan, William. Blaming the Victim, Vintage Books, New York, 1970.

Schneiderman, Leonard. "Social Welfare, Social Function, and Social Hork: An Effort at Integration," in Klenk and Ryan, The Practice of Social Work, op. cit.

Schwartz, William. "Private Troubles and Public Issues: One Social Work Job or Two?" The Social Wel fare Forum, 1969.

Seltiz, Claire, Wrightsman, Lawrence, and Cook, Stuart. Research Methods in Social Relations, Holt, Rinehart, and Winston, New York, 1976.

Siporin, Max. Introduction to Social Work Practice, MacMillian, New York, 1975.

Siporin, Max. "Vested Interests and General Systems Approach," Social Service Review, $52: 3$ (September 1978).

Shafer, Carl M. "Teaching Social Work Practice in an Integrated Course: A General Systems Approach," in The General Systems Approach: Contributions Toward an Hol istic Conception of Social Work, Gordon Hearn (ed.), op. cit. 
Smalley, Ruth E. "Social Casework: The Functional Approach," Encyclopedia of Social Work, National Association of Social Workers, New York, 1971.

Specht, Harry, and Vickey, Anne V. (editors). Integrating Social Work Methods, George Allen Ltd., London, 1977.

Spitzer, K., and Welch, B. "A Problem Focused Model of Practice," in Social Work Processes, (revised edition), Dorsey Publishing, Homewood, Illinois, 1979.

Taft, Jessie (editor). Family Casework and Counseling: A Functional Approach, University of Pennsylvania Press, Philadelphia, Pa., 1948.

Towle, Charlotte. "Social Work Cause and Function," Social Casework, Vol. 42 (October 1961).

Turner, Francis J. (editor). Social Work Treatment, Free Press, New York, 1974.

Turner, Francis J. Book Review of Joel Fischer's Effective Casework Practice Social Service, 1979 Social Service Review, 53:1 (March 1979).

Vetz, Barbara. "The Problem Solving Approach and Therapeutic Effectiveness," American Journal of Psychotherapy, Vol. 20, 1966.

Webster, Stephen A., and Campbe11, Paul M. "The 1970's and Changing Dimensions in Rural Life-Is a New Practice Model?" in Social Work in Rural Areas: Preparation and Practice, Ronald Green and Stephen Webster (editors), University of Tennessee School of Social Work, Knoxville, Tennessee, 1977.

Yates, Aubrey J. Principles and Practice of Behavior Therapy, Wiley Publ ishing Company, New York, 1970.

Yelaja, Shankar A. "Functional Theory for Social Work Practice," in Social Work Treatment, Francis Turner (editor), op. cit. 
PART ONE

\section{Practitioner Characteristics:}

For each of the following items please check the appropriate entry.

1. Age_ 25 or under 2. Sex_Female 3. Education $26-39$
$40-50$ Male $A A$
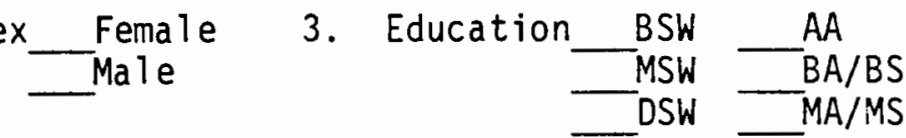
51 and over

4. If other than Social Work, list your field of study.

5. Indicate by checking the appropriate entry the total number of years you have been employed in the social service field. under 1 year at least 1 but under 3 years at least 3 but under 6 years at least 6 but under 20 years at least 10 but under 20 years more than 20 years

\section{Practice Context:}

6. With respect to your present employment, are you involved in the direct provision of social services to clients? YES NO

8. What is the name and address of your agency?

10. Indicate the approximate total 11. size of your employing agency or organization. less than 15 $15-40$ more than 40
7. Check the entry which best desscribes your type of practice setting.

Public Private non-profit Private profit/private practice

9. The county where you are employed 11. Indicate the number of persons employed in your office/department.

less than 15
$-15-40$
- more than 40

12. Indicate the population of the city or town where you are employed. under 5,000 $5,000-11,000$ $20,000-49,000$ $12,000-19,999$ 
13. a) Circle all entries which describe your employing agency's field of service, problem area or setting. b) Rank order your selection by placing a ' 1 ' next to the most descriptive item, a ' 2 ' next to the second most descriptive, etc.

Aging

Alcohol and Drug

Child Welfare/Family Services

Corrections
Health

Mental Health

Schools/Education

Other ( $p$ lease specify)

PART TWO

\section{INSTRUCTIONS}

This part of the questionnaire consists of 22 statements which have to do with various ways of thinking about social work practice.

The following scale is to be used in rating all 22 statements.

1

strongly

disagree
2
3

uncertain
4

5

strongly

agree

Please indicate your rating for each statement by circling the number which most closely approximates your opinion. Rate each statement in terms of the extent to which you agree or disagree.

$\left(\begin{array}{lllll}1 & 2 & 3 & 4 & 5\end{array}\right)$ 1. As a social worker I have the professional responsibility to work with my $\mathrm{clients}$ in a collaborative effort in decision making and problem solving.

$\left(\begin{array}{lllll}1 & 2 & 3 & 4 & 5\end{array}\right)$ 2. In order to resolve my client's problem it is necessary to help my client adjust to the reality of his situation.

$\left(\begin{array}{lllll}1 & 2 & 3 & 4 & 5\end{array}\right)$ 3. Organizations, groups, neighborhoods and communities are all potential clients for direct service practice.

$\left(\begin{array}{lllll}1 & 2 & 3 & 4 & 5\end{array}\right)$ 4. Specific, time limited contracting with my clients is not usefur since it is too time consuming and may hinder the helping process.

$\left(\begin{array}{lllll}1 & 2 & 3 & 4 & 5\end{array}\right)$ 5. The services I provide should be limited to those clients who are best suited to my style of practice and agency or program setting.

( $\left.\begin{array}{lllll}1 & 2 & 3 & 4 & 5\end{array}\right)$ 6. Effective termination with clients should include all of the following: 1) evaluation by the worker and client of progress and need for further service 2) mutual agreement for termination and 3) follow-up. 
$\left(\begin{array}{lllll}1 & 2 & 3 & 4 & 5\end{array}\right)$ 7. As a social worker I believe it is most appropriate for direct service practice to work with individual clients.

$\left(\begin{array}{lllll}1 & 2 & 3 & 4 & 5\end{array}\right)$ 8. The problems experienced by my clients can best be viewed as resulting from the interplay between my clients and their social and physical environments.

( $\left.\begin{array}{lllll}1 & 2 & 3 & 4 & 5\end{array}\right)$ 9. Human behavior can best be described and explained through understanding the psychodynamics of an individual's functioning.

$\left(\begin{array}{lllll}1 & 2 & 3 & 4 & 5\end{array}\right)$ 10. To be most effective direct service practice should be based on an eclectic approach utilizing concepts drawn from multiple theoretical frameworks.

$\left(\begin{array}{lllll}1 & 2 & 3 & 4 & 5\end{array}\right)$ 11. As a social worker I have the professional responsibility and authority to provide solutions and make decisions for my clients.

$\left(\begin{array}{lllll}1 & 2 & 3 & 4 & 5\end{array}\right)$ 12. Social workers should become specialists and offer services in their areas of specialization.

( $\left.\begin{array}{lllll}1 & 2 & 3 & 4 & 5\end{array}\right)$ 13. The problems experienced by my client can best be viewed as resulting from their own personal attributes--(e.g., personality traits, pathological behaviors).

$\left(\begin{array}{lllll}1 & 2 & 3 & 4 & 5\end{array}\right)$ 14. In order to resolve the problems my client is experiencing it is necessary to change those factors, (e.g. social, economic, personal), in my client's environment that are impinging on his/her functioning.

$\left(\begin{array}{lllll}1 & 2 & 3 & 4 & 5\end{array}\right)$ 15. Contracting and goal setting should be a joint process involving the client's consent, input and participation.

$\left(\begin{array}{lllll}1 & 2 & 3 & 4 & 5\end{array}\right)$ 16. As a social worker I have the professional responsibility to jointly explore and define the nature of the problem with the client.

$\left(\begin{array}{lllll}1 & 2 & 3 & 4 & 5\end{array}\right)$ 17. As the client's situation and need warrant, social workers must be able to assume a variety of roles and interventions, e.g., advocate, counselor, group leader, trainer, therapist.

$\left(\begin{array}{lllll}1 & 2 & 3 & 4 & 5\end{array}\right)$ 18. As a social worker it may be necessary for me to strategically withhold information which I determine would not be in the client's best interests. 
$\left(\begin{array}{lllll}1 & 2 & 3 & 4 & 5\end{array}\right)$ 19. As a social worker, because of my professional expertise, I assume major responsibility for determining and defining my client's problem.

$\left(\begin{array}{lllll}1 & 2 & 3 & 4 & 5\end{array}\right)$ 20. To be most effective direct service practice should be based on a single theoretical framework.

( $\left.\begin{array}{lllll}1 & 2 & 3 & 4 & 5\end{array}\right)$ 21. In my practice I find it essential to adapt my methods and techniques to fit the needs of my clients.

$\left(\begin{array}{lllll}1 & 2 & 3 & 4 & 5\end{array}\right)$ 22. When unable to provide necessary services for my clients--whether due to limitations in my expertise, authority, agency, or practice setting--I believe it is my professional responsibility as a social worker to insure that the needs of my clients are met--(e.g., through appropriate referral or other means).

\section{PART THREE}

\section{INSTRUCTIONS}

This part of the questionnaire consists of 22 statements which have to do with various roles, tasks and functions performed in the practice of social work.

The following scale is to be used in rating all 22 statements.

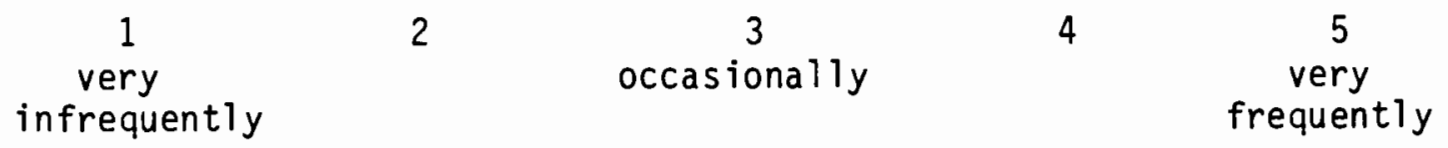

Please indicate your rating for each statement by circling the number which most closely approximates your response. Rate each statement in terms of how frequently you are engaged in performing the following practice activities.

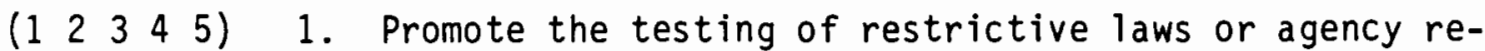
gulations through specific involvement in court or administrative action.

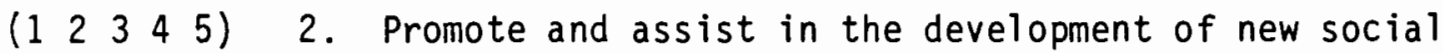
service programs by participating in community groups and task forces.

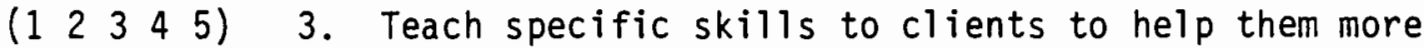
fully realize their aspirations and cope with the problems of living (e.g., interpersonal communication, parenting, problem solving or budgeting skills). 


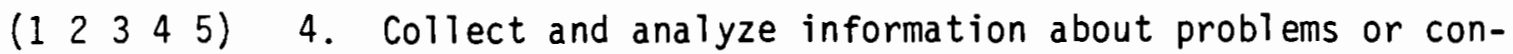
ditions which indicate the need for change in social policy and/or service provision.

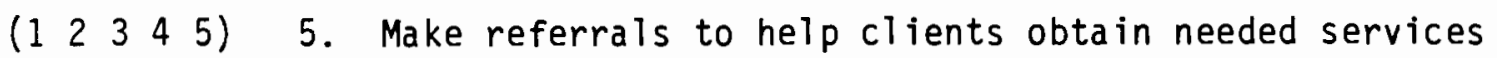
and benefits.

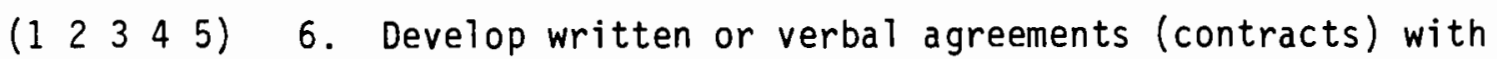
clients regarding specific goals, objectives, tasks, and time limits.

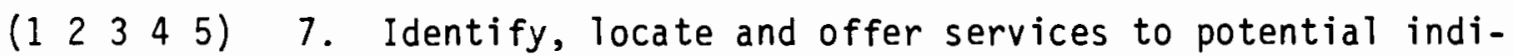
vidual clients and client populations.

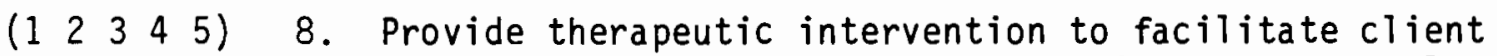
behavioral change, conflict resolution, or personal growth.

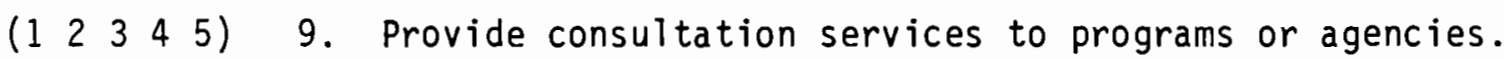

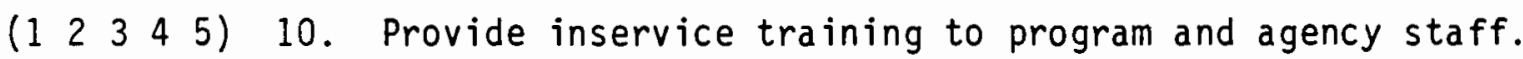

$\left(\begin{array}{lllll}1 & 2 & 3 & 4 & 5\end{array}\right)$ 11. Arrange for caretaking and supportive services to clients (e.g., daycare, foster care, homemaker services).

(l $\left.\begin{array}{lllll}1 & 2 & 3 & 4 & 5\end{array}\right)$ 12. Testify, write letters, make telephone calls, or otherwise attempt to inform or influence legislators, administrators, and policy makers.

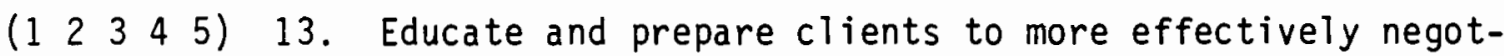
iate and utilize existing human service resource systems.

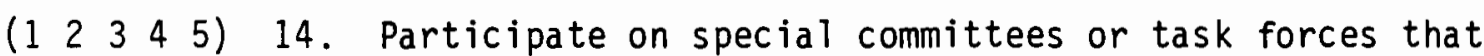
conduct research and make recommendations for social change.

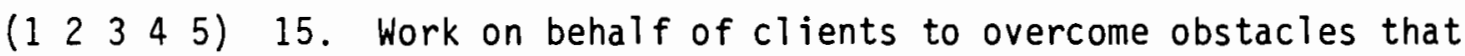
prevent the client from obtaining services and benefits; for example, help to cut red tape, provide transportation, or overcome other practical problems.

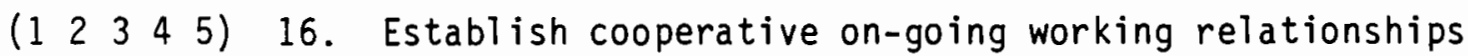
with staff from other agencies to insure continuity and coordination of service delivery.

$\left(\begin{array}{lllll}1 & 2 & 3 & 4 & 5\end{array}\right)$ 17. Promote effective service delivery through community outreach and field work activities (e.g., visiting clients where they live, or schools, businesses, neighborhood clubs, and organizations). 


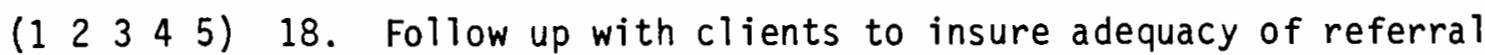
and service provision.

$\left(\begin{array}{lllll}1 & 2 & 3 & 4 & 5\end{array}\right)$ 19. Provide or arrange for material resources to clients (e.g., employment, shelter, or financial assistance).

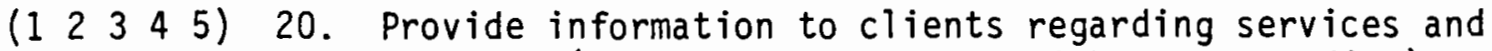
benefits (e.g., procedures and rights to benefits).

$\left(\begin{array}{lllll}1 & 2 & 3 & 4 & 5\end{array}\right)$ 21. Provide information to encourage or influence programs or agencies to examine and change aspects of their policies and operating procedures which unnecessarily hinder effective service delivery.

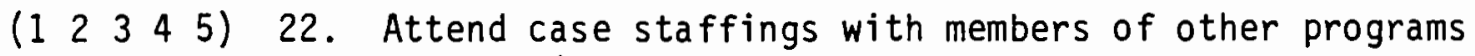
or agencies.

This is the end of the questionnaire. Thank you for your participation.

Comments about the questionnaire: 
Items that are followed by (NG) are non-generalist items. All other items are generalist items.

1. Knowledge Base:

In Part 2 of the Questionnaire:

\# 9

Human behavior can best be described and explained by understanding the psychodynamics of an individual's functioning. NG

$\# 10$

To be most effective, direct service practice should be based on an eclectic approach utilizing concepts drawn from multiple theoretical frameworks.

\#20

To be most effective, direct service practice should be based on a single theoretical framework. NG

2. Purpose:

In Part 2:

\#2

In order to resolve a client's problem it is necessary to help the client adjust to the reality of his situation. NG

\#21

In my practice I find it essential to adapt methods and techniques to fit the needs of clients.

\section{Nature of the Problem:}

In Part 2:

$\# 13$

The problems experienced by my client can best be viewed as resulting from their own personal attributes, e.g., personality traits, pathological behaviors. NG

\#14

In order to resolve the problems a client is experiencing it is necessary to change those factors, e.g., social, economic, personal, in a client's environment that are impinging on the client's functioning. 
4. Notion of the Client:

In Part 2:

\#3

Organizations groups, neighborhoods, and communities are all potential clients for direct service practice.

$\# 7$

As a social worker I bel ieve it is most appropriate for direct service practice to focus on individuals as clients. NG

\#8

The problems experienced by $\mathrm{clients}$ can best be understood as resulting from interaction between the clients and their social and physical environments.

$\# 13$

The problems experienced by $c$ lients can best be understood as resulting from their own individual psychological characteristics, e.g., personality traits, pathological behavior. NG

5. Nature of the Helping Relationship:

In Part 2:

$\# 1$

As a social worker, I have the professional responsibility to work with my clients in a collaborative effort in decision making and problem solving.

\#11

As a social worker I have the professional responsibility and authority to provide solutions and make decisions for clients. NG

6. Planned Change Process:

(a) Engagement:

In Part 2:

\#1

As a social worker I have the professional responsibility to work with clients in a collaborative effort in decision making and problem solving.

\#18

As a social worker it may be necessary for me to strategically withhold information which I determine would not be in a client's best interests. NG 
(b) Assessment:

In Part 2:

\#16

As a social worker I have the professional responsibility to jointly explore and define the nature of the problem with a client.

\#19

As a social worker, because of my professional expertise, I assume major responsibility for determining and defining the client's problem. NG

(c) Goal Formulation and Contracting:

In Part 2:

\#4

Specific, time limited contracting with clients is not useful since it is too time consuming and may hinder the helping process. NG

\#15

Contracting and goal setting should be a joint process involving the client's consent, input, and participation.

In Part 3:

\#6

Develop written or verbal service agreements (contracts) with clients regarding specific goals, objectives, tasks, and time limits.

(d) Intervention:

In Part 3:

\#3

Teach specific skills to clients to help them more fully realize their aspirations and cope with the problems of living, e.g., interpersonal communication, parenting, problem solving, budgeting skills.

\#8

Provide therapeutic intervention to facilitate client behavioral change, conflict resolution or personal growth.

\#11

Arrange for caretaking and supportive services for clients, e.g., food, employment, shelter, financial assistance.

(e) Evaluation and Termination:

In Part 2: 
\#6

Effective termination with clients should include all of the following: 1) evaluation by the worker and cleint of progress and need for further service, 2) mutual agreement for termination, and 3 ) follow-up.

In Part 3:

$\# 18$

Follow-up with clients and agency personnel to insure adequacy of referral and service provisions.

7. Function:

(a) Access to resources:

In Part 3:

$\# 1$

Promote the testing of restrictive laws or agency regulations through specific involvement in court or administractive action.

\#5

Make referrals to help clients obtain needed services and/or benefits.

$\# 7$

Identify, locate, and offer services to potential individual clients or client populations through outreach efforts

$\# 13$

Educate and prepare clients to more effectively negotiate and utilize existing human services agencies.

$\# 15$

Work on behalf of $c l i e n t s$ to overcome bureaucratic or practical obstacles that prevent the client from obtaining services and benefits, e.g., help to cut red tape, arrange transportation.

\#20

Provide information to $\mathrm{clients}$ regarding which services or other benefits are available and how to obtain them.

(b) Enhanced Functioning of Resource Systems:

In Part 3:

\#9

Provide consultation services to individuals, programs, or agencies.

\#10

Provide inservice training to agency staff. 
$\# 17$

Promote effective service delivery through community outreach;

e.g., make home visits, and/or visit schools, businesses, clubs, other organizations.

$\# 21$

Actively encourage or influence programs or agencies to examine and change aspects of their policies and operating procedures which unnecessarily hinder effective service delivery.

(c) Coordinate Existing Resource Systems:

In Part 3:

$\# 16$

Establish cooperative on-going working relationships with staff from other agencies to insure continuity and coordination of service delivery.

\#22

Attend case staffings with personnel from other programs or agencies.

(d) Develop Needed Resource Systems.

In Part 3:

\#2

Promote and assist in the development of new social service programs by participating in community groups and task forces.

$\# 4$

Collect and analyze information about problems or conditions which indicate the need for change in social policy and/or service provision.

$\# 12$

Testify, write letters, make telephone calls or otherwise attempt to inform or influence legislators, administrators, or policy makers.

\#14

Participate on special committees or task forces that evaluate and make recommendations regarding community needs and services.

8. Roles:

In Part 2:

\#5

The services I provide should be limited to those clients who are best suited to my style of practice. NG 
\#12

Social workers should become specialists and offer services in their areas of specialization. NG

$\# 17$

As the client's situation and need warrant, social workers must be able to assume a variety of roles and methods of intervention, e.g., advocate, counselor, group leader, trainer, therapist.

$\# 22$

When unable to provide necessary services for clients, whether due to limitations in my expertise, authority, or practice setting, I bel ieve it is my professional responsibility as a social worker to insure that a client's needs are met, e.g., through appropriate referral or other means. 


\section{APPENDIX B}

\section{QUESTIONNAIRE DERIVATION}

Items that are followed by (NG) are non-generalist items. All other items are generalist items.

1. Knowledge Base:

In Part 2 of the Questionnaire:

\#9

Human behavior can best be described and explained by understanding the psychodynamics of an individual's functioning. NG

$\# 10$

To be most effective, direct service practice should be based on an eclectic approach utilizing concepts drawn from multiple theoretical frameworks.

$\# 20$

To be most effective, direct service practice should be based on a single theoretical framework. NG

2. Purpose:

In Part 2:

\#2

In order to resolve a client's problem it is necessary to help the client adjust to the reality of his situation. NG

\#21

In my practice I find it essential to adapt methods and techniques to fit the needs of clients.

3. Nature of the Problem:

In Part 2:

$\# 13$

The problems experienced by my client can best be viewed as resulting from their own personal attributes, e.g., personality traits, pathological behaviors. NG

\#14

In order to resolve the problems a client is experiencing it is necessary to change those factors, e.g., social, economic, personal, in a client's environment that are impinging on the client's functioning. 
4. Notion of the Client:

In Part 2:

\#3

Organizations groups, neighborhoods, and communities are all potential clients for direct service practice.

\#7

As a social worker I believe it is most appropriate for direct service practice to focus on individuals as clients. NG

\#8

The problems experienced by $\mathrm{clients}$ can best be understood as resulting from interaction between the clients and their social and physical environments.

\section{$\# 13$}

The problems experienced by clients can best be understood as resulting from their own individual psychological characteristics, e.g., personality traits, pathological behavior. NG

5. Nature of the Helping Relationship:

In Part 2:

\#1

As a social worker, I have the professional responsibility to work with my clients in a collaborative effort in decision making and problem solving.

\#11

As a social worker I have the professional responsibility and authority to provide solutions and make decisions for clients. NG

6. Planned Change Process:

(a) Engagement:

In Part 2:

\#1

As a social worker I have the professional responsibility to work with clients in a collaborative effort in decision making and probiem solving.

$\# 18$

As a social worker it may be necessary for me to strategically withhold information which I determine would not be in a client's best interests. NG 


\section{(b) Assessment:}

In Part 2:

$\# 16$

As a social worker I have the professional responsibility to jointly explore and define the nature of the problem with a client.

$\# 19$

As a social worker, because of my professional expertise, I assume major responsibility for determining and defining the client's problem. NG

(c) Goal Formulation and Contracting:

In Part 2:

\#4

Specific, time limited contracting with clients is not useful since it is too time consuming and may hinder the helping process. NG

\section{$\# 15$}

Contracting and goal setting should be a joint process involving the client's consent, input, and participation.

In Part 3:

\#6

Develop written or verbal service agreements (contracts) with clients regarding specific goals, objectives, tasks, and time limits.

(d) Intervention:

In Part 3:

\#3

Teach specific skills to clients to help them more fully realize their aspirations and cope with the problems of living, e.g., interpersonal communication, parenting, problem solving, budgeting skills.

\#8

Provide therapeutic intervention to facilitate client behavioral change, confict resolution or personal growth.

$\# 11$

Arrange for caretaking and supportive services for clients, e.g., food, employment, shelter, financial assistance.

(e) Evaluation and Termination:

In Part 2: 
\#6

Effective termination with clients should include all of the following: 1) evaluation by the worker and cleint of progress and need for further service, 2) mutual agreement for termination, and 3) follow-up.

In Part 3:

\#18

Follow-up with clients and agency personnel to insure adequacy of referral and service provisions.

7. Function:

(a) Access to resources:

In Part 3:

$\# 1$

Promote the testing of restrictive laws or agency regulations through specific involvement in court or administractive action.

$\# 5$

Make referrals to help clients obtain needed services and/or benefits.

\#7

Identify, locate, and offer services to potential individual clients or client populations through outreach efforts

\section{\#13}

Educate and prepare clients to more effectively negotiate and utilize existing human services agencies.

\#15

Work on behalf of $c$ lients to overcome bureaucratic or practical obstacles that prevent the client from obtaining services and benefits, e.g., help to cut red tape, arrange transportation.

\#20

Provide information to $\mathrm{clients}$ regarding which services or other benefits are available and how to obtain them.

(b) Enhanced Functioning of Resource Systems:

In Part 3:

$\# 9$

Provide consultation services to individuals, programs, or agencies. $\# 10$

Provide inservice training to agency staff. 
\#17

Promote effective service delivery through community outreach; e.g., make home visits, and/or visit schools, businesses, clubs, other organizations.

$\# 21$

Actively encourage or influence programs or agencies to examine and change aspects of their policies and operating procedures which unnecessarily hinder effective service delivery.

(c) Coordinate Existing Resource Systems:

In Part 3:

$\# 16$

Establish cooperative on-going working relationships with staff from other agencies to insure continuity and coordination of service delivery.

$\# 22$

Attend case staffings with personnel from other programs or agencies.

(d) Develop Needed Resource Systems.

In Part 3:

\#2

Promote and assist in the development of new social service programs by participating in community groups and task forces.

\#4

Collect and analyze information about problems or conditions which indicate the need for change in social policy and/or service provision.

$\# 12$

Testify, write letters, make telephone calls or otherwise attempt to inform or influence legislators, administrators, or policy makers.

$\# 14$

Participate on special committees or task forces that evaluate and make recommendations regarding community needs and services.

8. Roles:

In Part 2:

\#5

The services I provide should be 7 imited to those clients who are best suited to my style of practice. NG 
\#12

Social workers should become specialists and offer services in their areas of specialization. NG

\#17

As the client's situation and need warrant, social workers must be able to assume a variety of roles and methods of intervention, e.g., advocate, counselor, group leader, trainer, therapist.

$\# 22$

When unable to provide necessary services for $\mathrm{clients,} \mathrm{whether} \mathrm{due}$ to 1 imitations in my expertise, authority, or practice setting, I believe it is my professional responsibility as a social worker to insure that a client's needs are met, e.g., through appropriate referral or other means. 